UNESP - Universidade Estadual Paulista

Faculdade de Medicina de Botucatu

Programa de Pós-Graduação de Fisiopatologia em Clínica Médica

Elisiane Tonon

\title{
AVALIAÇÃO DOS EFEITOS DE DIFERENTES MANOBRAS DE FISIOTERAPIA RESPIRATÓRIA NO DESFECHO DE PACIENTES VENTILADOS MECANICAMENTE
}




\title{
Elisiane Tonon
}

\section{AVALIAÇÃO DOS EFEITOS DE DIFERENTES MANOBRAS DE FISIOTERAPIA RESPIRATÓRIA NO DESFECHO DE PACIENTES VENTILADOS MECANICAMENTE}

\author{
Dissertação apresentada ao Programa de Pós-Graduação \\ Fisiopatologia em Clínica Médica, da Faculdade de \\ Medicina de Botucatu - UNESP, para obtenção do título \\ de Mestre
}

Orientadora: Profa. Adjunta Ana Lúcia dos Anjos Ferreira

Bolsa Mestrado FAPESP \# 08/52596-6

BOTUCATU-SP 
FICHA CATALOGRÁFICA ELABORADA PELA SEÇÃO TÉCNICA DE AQUISIÇÃO E TRATAMENTO DA INFORMAÇÃO

DIVISÃO TÉCNICA DE BIBLIOTECA E DOCUMENTAÇ̃̃O - CAMPUS DE BOTUCATU - UNESP BIBLIOTECÁRIA RESPONSÁVEL: Selma Maria de Jesus

Tonon, Elisiane.

Avaliação dos efeitos de diferentes manobras de fisioterapia respiratória no desfecho de pacientes ventilados mecanicamente / Elisiane Tonon. - Botucatu : [s.n.], 2010.

Dissertação (mestrado) - Faculdade de Medicina de Botucatu, Universidade Estadual Paulista, 2010.

Orientadora: Ana Lúcia dos Anjos Ferreira Assunto CAPES: 40102009

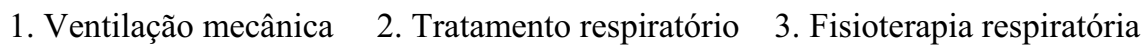
CDD 615.836

Palavras-chave: Compressão torácica; Fisioterapia respiratória; Hiperinsuflação ma-nual; Período de internação; Unidade de terapia intensiva (UTI); Ventilação mecânica 
Dedieatória 


\begin{abstract}
Aos meus pais
José e Emília

pelo imenso amor e compreensão e pelo

apoio irrestrito em todos os momentos de minha vida.

Minha eterna gratidâo e amor por vocês!
\end{abstract}

\author{
Aos meus irmãos \\ Erenete, Edvaldo, Enide e Érika
}

que sempre permaneceram ao meu lado compartilhando

momentos de angústias, incertezas e alegrias, e me impulsionaram a lutar a cada dia por esse objetivo.

Vocês sấo muito especiais!

Ao meu esposo

Thiago

pelo amor e incentivo e por compreender os meus momentos de ausência.

Te amo!

A professora

Ana Lúcia dos Anjos Ferreira

pela amizade e por transmitir suas experiências

e conhecimentos com muita dedicaçâo e respeito.

Obrigada por todos esses anos preciosos de ensinamentos!!!

Obrigada por fazerem parte de minha vida!!! 
Agradecimentos 
Meus sinceros agradecimentos a todos aqueles que de alguma forma doaram um pouco de si para que a conclusão deste trabalho se tornasse possível:

A Deus, presença constante em minha vida.

Em especial, aos amigos Fernando, Raíssa, Silvio e Tatiana, que muito colaboraram para o desenvolvimento deste trabalho. Serei eternamente grata!

À Professora Adjunta Ana Lúcia dos Anjos Ferreira pela amizade, presença e orientação de todo o trabalho.

Aos pacientes da UTI-PS e seus familiares pela participação e por tornarem possível este trabalho.

Ao Corpo Clínico da UTI-PS do Hospital das Clínicas da Faculdade de Medicina de Botucatu, UNESP, pela atenção e colaboração neste estudo.

Ao Corpo de Enfermagem da UTI-PS do Hospital das Clínicas da Faculdade de Medicina de Botucatu, UNESP, pelo constante apoio durante a realização desta pesquisa.

Ao Programa de Pós-Graduação em Fisiopatologia em Clínica Médica pela oportunidade de realização desta dissertação.

Aos Professores Doutores Luis Cuadrado Martim, Laercio Martins De Stefano e Ana Lúcia Gut, do Departamento de Clínica Médica da Faculdade de Medicina de Botucatu, UNESP, pela amizade e pelas preciosas sugestões que enriqueceram este trabalho.

Ao Professor Titular Carlos Roberto Padovani, do Departamento de Bioestatística do Instituto de Biociências de Botucatu, UNESP, pela colaboração na análise estatística.

Aos Funcionários da Biblioteca do Campus da UNESP de Botucatu, em especial à Rosemary Cristina da Silva e Selma Maria de Jesus, pela amizade, revisão das referências bibliográficas e elaboração da ficha catalográfica. 
Aos Funcionários do Departamento de Clínica Médica pela disponibilidade e por todos os auxílios prestados.

Aos Funcionários da Secretaria da Pós-Graduação pela atenção, disponibilidade e eficiência nas soluções de problemas.

À Fundação de Amparo à Pesquisa do Estado de São Paulo pela concessão da bolsa de Mestrado e por viabilizar a realização deste estudo.

Aos Amigos que fiz durante esta caminhada, em especial à Adriana, Carolina, Priscila, Renata $\boldsymbol{e}$ Viviane, pela amizade sincera e por dividirem comigo momentos de angústias e alegrias e pela participação na concretização deste sonho. Obrigada por darem sentido especial a minha vida! 
Epígrafe 
"Quem nâo tem fé, nâo tem amor.

Quem nấo tem amor, nấo tem consciência de si mesmo.

E quem nâo tem consciência de si mesmo, nẫo está preparado para cuidar dagueles gue sofrem"

(Madre Teresa de Calcutá) 
Resumo 
Apesar da fisioterapia respiratória aparentemente beneficiar pacientes sob ventilação mecânica, não há evidências suficientes para sua recomendação. Usando associação das manobras compressão torácica (CT) e hiperinsuflação manual (HM), prévio estudo de nosso grupo identificou significante redução no período de ventilação mecânica (VM), no período de internação e melhora da extensão de lesão pulmonar (Murray) em pacientes sob VM. Contudo, é desconhecido o papel isolado de cada manobra nos benefícios encontrados. Portanto, o objetivo deste estudo foi comparar prospectivamente o efeito isolado e associado das manobras CT e HM no período de internação e de VM em pacientes sob VM. O estudo foi conduzido por 13 meses na UTI (Pronto-Socorro do Hospital das Clínicas, UNESP, Botucatu, SP, Brasil) de um hospital universitário terciário. Foi também avaliada a interferência das manobras nos seguintes parâmetros: índice prognóstico (APACHE-II), Murray, oxigenação $\left(\mathrm{PaO}_{2} / \mathrm{FiO}_{2}\right)$, mecânica respiratória, repercussões hemodinâmicas e saturação periférica de oxigênio $\left(\mathrm{SpO}_{2}\right)$. A análise estatística utilizou o teste de Goodman para contrastes entre e dentro de populações multinomiais, qui-quadrado, análise de variância e análise de variância para o modelo de medidas repetidas em grupos independentes. Dos 204 pacientes que preencheram os critérios de inclusão e exclusão e foram admitidos no estudo, 20 pacientes foram alocados no grupo CT, 20 no grupo HM e 20 no grupo CT+HM de acordo com o processo de sistematização. Diversas causas levaram à exclusão de alguns pacientes durante o estudo e cada grupo passou a ser constituído por 15 pacientes. O grupo CT recebeu compressão torácica, o grupo HM recebeu hiperinsuflação manual e o grupo $\mathrm{CT}+\mathrm{HM}$ recebeu a associação de ambas as manobras duas vezes ao dia durante cinco dias. Os grupos foram semelhantes no momento inicial em relação a todas as variáveis estudadas (idade, gênero, índice de massa corpórea, período de VM pré-estudo, freqüência respiratória, valor da pressão expiratória final, fração inspiratória de oxigênio, índice de co-morbidade Charlson, APACHEII, Murray, $\mathrm{PaO}_{2} / \mathrm{FiO}_{2}$, complacência estática, dose de drogas sedativas). A aplicação da manobra $\mathrm{CT}$ foi associada à diminuição $(\mathrm{p}<0,05)$ da média do índice APACHE-II no momento final (inicial, 17,08 vs. final, 11,62). A aplicação de cada manobra (CT, HM e $\mathrm{CT}+\mathrm{HM}$ ) durante os cinco dias não modificou o período de $\mathrm{VM}$, período de internação, Murray, $\mathrm{PaO}_{2} / \mathrm{FiO}_{2}$ e complacência estática. Embora a análise estatística não tenha mostrado diferenças significantes entre os grupos, destaca-se que em relação aos outros grupos, o CT+HM necessitou de menor período (horas) de VM, (CT,102,2; HM,114,1; CT+HM,90,8) e também representou a maior porcentagem de altas da unidade (CT,7,7; HM,0,0; $\mathrm{CT}+\mathrm{HM}, 15,4)$. Em geral, não foram observados efeitos clínicos adversos importantes das manobras em relação à mecânica respiratória e $\mathrm{SpO}_{2}$ em nenhum dos grupos no decorrer do 
estudo. Contudo, é relevante mencionar que, ao contrário da CT, as manobras $\mathrm{HM}$ e CT+HM foram associadas a comprometimentos hemodinâmicos (frequencia cardíaca e pressão arterial média). Os resultados mostraram que as 3 manobras foram semelhantes em relação ao período de VM, período de internação e extensão de lesão pulmonar de pacientes intubados e ventilados mecanicamente. Desta forma, é possível que a aplicação combinada de CT e HM, e não individual, tenha desempenhado um papel importante nos benefícios encontrados em nosso prévio. Futuros estudos clínicos, controlados utilizando um maior número de pacientes, serão de grande importância para confirmar os resultados identificados no presente estudo.

Palavras-chaves: fisioterapia respiratória; compressão torácica; hiperinsuflação manual; ventilação mecânica; período de internação; unidade de terapia intensiva (UTI). 
Abstract 
There is no evidence to support the recommendation of chest physiotherapy on mechanically ventilated (MV) patients, although this procedure apparently improves those patients. Using association of thoracic compression (TC) and manual hyperinflation (MH), our previous study identified significant reduction in duration of weaning from ventilation, discharge from intensive care unit (ICU) and extent of lung damage index (Murray). However, it is unknown the individual role of each maneuver on those benefits. Therefore, the aim of the study was evaluate the isolated and associated effect of $\mathrm{TC}$ and $\mathrm{MH}$ on the mechanical ventilation period and length of stay in mechanically ventilated patients. Secondarily, outcomes of interest were the effect of physiotherapy on Murray, severity score and on hemodynamics, gas exchange, and respiratory mechanics. It was conducted at ICU of the Emergency Room (ER) at Hospital das Clínicas of São Paulo State University (UNESP-HC) (Botucatu, SP, Brazil) for 13 consecutive months. The significance of differences between groups was accessed by Goodman test, chi-squared analysis, ANOVA and a nonparametric repeated measures ANOVA. The present study was a three-group (TC, $\mathrm{MH}$, and $\mathrm{TC}+\mathrm{MH})$, prospective and systematized clinical study lasting 5 days. Of the 204 patients who fulfilled all the inclusion criteria and were enrolled in the study, 20 patients were allocated into TC group, 20 into $\mathrm{MH}$ group or 20 into $\mathrm{TC}+\mathrm{HM}$ group. The TC group received expiratory chest compression, the $\mathrm{MH}$ group received manual hyperinflation and the $\mathrm{TC}+\mathrm{HM}$ received manual hyperinflation combined with expiratory chest compression twice a day for 5 days. Five patients from TC, 5 from $\mathrm{MH}$ and 5 from $\mathrm{TC}+\mathrm{HM}$ were withdrawn during the study period due to several reasons and therefore, 15 patients remained in each group. The 3 groups had similar baseline characteristics (age, body mass index, gender, mechanical ventilation period prior to the study, respiratory frequency, PEEP, inspired oxygen concentration, Charlson, APACHE-II, Murray, $\mathrm{PaO} 2 / \mathrm{FiO} 2$, static compliance, dose of sedation drugs). The CT intervention was associated to improvement $(\mathrm{p}<0.05)$ of APACHE-II mean at final moment (initial, 17.08 vs. final, 11.62). All groups (TC, $\mathrm{MH}, \mathrm{TC}+\mathrm{MH})$ were similar regarding mechanical ventilation period, length of stay, Murray, $\mathrm{PaO}_{2} / \mathrm{FiO}_{2}$, and static compliance. Although there were no differences among groups, it should be observed the small MV period (hours) needed by patients from $\mathrm{TC}+\mathrm{MH}$ group (TC,102.2; $\mathrm{MH}, 114.1 ; \mathrm{TC}+\mathrm{MH}, 90.8)$. In addition, higher percentage of patients from $\mathrm{TC}+\mathrm{MH}$ group was discharged from ICU within five-days study (TC, 7.7; $\mathrm{MH}, 0.0 ; \mathrm{TC}+\mathrm{MH}, 15.4$ ), in comparison to the other groups. Important adverse clinical effects were not observed during the study. However, the maneuvers $\mathrm{MH}$ and $\mathrm{TC}+\mathrm{MH}$ were associated to hemodynamic impairments (heart rate, mean arterial pressure). Our results showed the 3 maneuvers affected similarly the mechanical ventilation period, 
length of stay and Murray score in intubated and ventilated patients. Therefore, it is possible that the combined application of TC and $\mathrm{MH}$, but not individualized, played an important role on benefits found in our previous study. Futures randomised controlled trials using a larger number of patients will be of great importance to confirm our results.

Key Word: respiratory physiotherapy; thoracic compression; manual hyperinflation; mechanical ventilation; length of stay; Intensive Care Unit (ICU) 
Sumário 


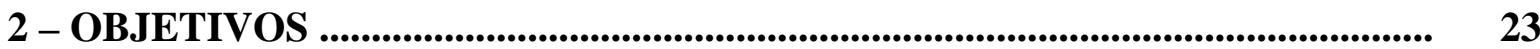

2.1 - Objetivo principal ............................................................................... 24

2.2 - Objetivos secundários ................................................................................ 24

3 - PACIENTES E MÉTODOS ............................................................................. 25

3.1 - Pacientes e desenho .............................................................................. 26

3.2 - Variáveis estudadas ................................................................................ 27

3.3 - Descrição do tratamento ………………………………………………..... 29

3.3.1 - Compressão torácica …………………………………………..... 29

3.3.2 - Hiperinsuflação manual ................................................................... 29

3.3.3 - Compressão torácica + hiperinsuflação manual ................................ 30

3.4 - Análise estatística ................................................................................. 30

4 - RESULTADOS

4.1 - Características da amostra no momento inicial ............................................. $\quad 34$

4.2 - Características evolutivas dos pacientes durante os cinco dias de intervenção...................................................................................... 35

4.3 - Condições após 30 dias de estudo ..................................................................... 40



5.1 - Efeito das intervenções no período de internação e no período de ventilação mecânica ................................................................................................ 43

5.2 - Efeito das intervenções nos índices de gravidade, de extensão da lesão pulmonar e oxigenação ............................................................................. 43

5.3 - Efeito das intervenções na mecânica respiratória, na saturação periférica de $\mathrm{O}_{2}$ e na condição hemodinâmica ..................................................................... 45

5.3.1 - Mecânica respiratória …………………………………………….. 45

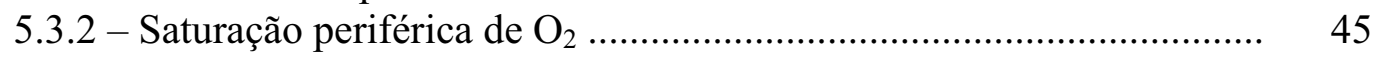

5.3.3 - Condição hemodinâmica ................................................................. 45

5.4 - Efeito das intervenções nas condições do paciente após 30 dias do estudo .... $\quad 46$

5.5 - Características iniciais da população estudada ............................................... 47

6 - CONSIDERAÇÕES FINAIS ........................................................................................ 51

$\mathbf{6 . 1}$ - Limitações do estudo ............................................................................. 52

7 - REFERÊNCIAS BIBLIOGRÁFICAS ............................................................ 53

8 - APÊNDICES .......................................................................................................

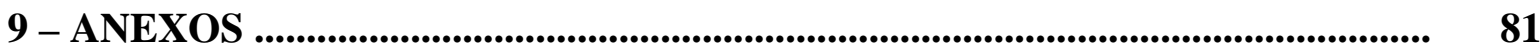


1. Introduęão 
Existem evidências que o acúmulo de secreção e as consequentes complicações que ocorrem em pacientes ventilados mecanicamente podem prolongar o tempo de ventilação mecânica (VM) e assim, aumentar o período de internação. Estratégias que contribuam para a remoção de tal acúmulo de secreção podem indiretamente acelerar o desmame do ventilador. Uma tática amplamente usada é a aplicação de fisioterapia respiratória (FR). Apesar de já consagrada na prática, não há evidências que suportem a afirmação de que a FR possa reduzir o tempo de ventilação mecânica e de internação na unidade de terapia intensiva (UTI).

A retenção de secreções, atelectasias e pneumonia associada ao ventilador são complicações comuns em pacientes intubados e ventilados mecanicamente ${ }^{1}$. Alguns dos fatores de risco associados com o desenvolvimento destas complicações incluem intubação endotraqueal prolongada, uso de sedação contínua, ventilação mecânica superior a 24 horas e uso de pressão positiva no final da expiração ${ }^{1}$. Existem evidências que, pacientes intubados e ventilados mecanicamente desenvolvem disfunção mucociliar ${ }^{1}$ e aumento da produção de secreções brônquicas ${ }^{2}$. Tais alterações estão associadas à alta prevalência e alta mortalidade em pacientes com pneumonia associada à ventilação mecânica ${ }^{3}$. Assim, a fisioterapia respiratória representa uma estratégia importante no tratamento do paciente criticamente doente $^{4-9}$ desde que potencialmente pode contribuir para a redução do período de internação na UTI. Uma aceleração da alta em UTI poderia ser especialmente pertinente em hospitais públicos de países emergentes, onde o suporte financeiro é bastante limitado.

Várias técnicas, como a percussão torácica ${ }^{7,10,11}$, vibração ${ }^{7,8,12}$, compressão torácica $^{7,13,14}$, Bag Squeezing ${ }^{12,15,16}$, drenagem postural ${ }^{8,10,17}$ e hiperinsuflação manual $^{6,17-22}$ são utilizadas na fisioterapia respiratória como conduta de tratamento de pacientes sob ventilação mecânica com o objetivo de remover secreções das vias aéreas e prevenir ou reverter atelectasias $^{6-8,12,15,17}$, além de otimizar a ventilação e consequentemente facilitar o desmame da $\mathrm{VM}^{9}$.

As manobras fisioterápicas convencionais consistem na percussão torácica, vibração, drenagem postural ${ }^{7,17,18}$ e compressão torácica ${ }^{7,13,14}$, as quais são aplicadas isoladamente ou em conjunto. A vibração e a percussão torácica ocupam uma posição pouco significativa. A vibração devido à dificuldade em sua aplicação que exige uma frequência eficaz mínima de $13 \mathrm{~Hz}$ e por um período de tempo adequado, e a percussão torácica manual que atinge apenas de 1 a $8 \mathrm{~Hz}$, o que está muito longe das freqüências ideais para o transporte do muco que é de 25 a $35 \mathrm{~Hz}^{14}$. 
Dentre as técnicas convencionais destaca-se a manobra de compressão torácica, a qual consiste na aplicação de uma força exercida manualmente sobre a parede torácica durante a fase expiratória, com o objetivo de aumentar o fluxo expiratório e, consequentemente auxiliar na remoção de secreções brônquicas. A técnica é realizada colocando-se uma das mãos de forma plana sobre o tórax, enquanto que a outra apóia o abdome no sentido cefálico para a elevação do diafragma ou no sentido descendente para reter a massa abdominal. Após o posicionamento das mãos realiza-se a manobra de compressão torácica durante a expiração, gerando uma modificação da pressão intratorácica ${ }^{14}$, facilitando assim a mobilização e remoção de secreções das vias aéreas. Estudo prévio, utilizando técnicas de drenagem postural, compressão torácica e aspiração, mostrou melhora do quadro em $68 \%$ dos 47 portadores de atelectasia pulmonar com concomitante aumento na remoção de secreções das vias aéreas durante a VM prolongada ${ }^{7}$.

Outro procedimento atualmente bastante utilizado nas UTIs é a hiperinsuflação manual, a qual consiste na insuflação manual dos pulmões com pressões de 20 a $40 \mathrm{cmH}_{2} \mathrm{O}$ e frações inspiradas de oxigênio $\left(\mathrm{FiO}_{2}\right)$ de $100 \%{ }^{6,17,18}$. O dispositivo de ventilação manual é comprimido lentamente com ambas as mãos e uma pausa inspiratória é mantida por aproximadamente 3 segundos. Após, realiza-se uma descompressão abrupta do dispositivo de ventilação manual ${ }^{18}$, otimizando o fluxo expiratório, o que consequentemente auxilia na mobilização e remoção de secreções das vias aéreas. Isto é realizado em séries de 4 a 6 insuflações e entre cada série ocorre a aspiração ${ }^{6,17}$. Ntoumenopoulos et al. (1998) ${ }^{17}$, também aplicaram a hiperinsuflação manual associada à drenagem postural, em pacientes politraumatizados e ventilados mecanicamente. A pressão utilizada foi de $40 \mathrm{cmH}_{2} \mathrm{O}$ mantida por no mínimo 3 segundos, com séries de 6 insuflações repetidas 4 vezes após drenagem postural por 20 minutos. A aspiração ocorria entre os ciclos de hiperinsuflação manual. Esta técnica era aplicada 2 vezes por dia. Neste estudo observou-se que não houve diferença significante em relação ao tempo de VM e tempo de internação na UTI quando comparados ao grupo controle. Hodgson et al. $(2000)^{6}$, também investigaram a hiperinsuflação manual associada ao posicionamento em pacientes de UTI sob ventilação mecânica e verificaram que houve melhora da complacência pulmonar estática e da higiene brônquica, sem comprometer a estabilidade cardiovascular ou troca gasosa. Paratz et al. $(2002)^{20}$ utilizaram, também em pacientes de UTI, a hiperinsuflação manual isolada e observaram melhora na mecânica respiratória e na troca gasosa em pacientes com doença pulmonar de causa extrapulmonar e não houve alterações significantes no sistema cardiovascular. Choi e Jones $(2005)^{21}$ compararam a hiperinsuflação manual associada à aspiração, com a aspiração isolada e 
notaram que o uso associado da hiperinsuflação manual e aspiração trazem benefícios para a mecânica respiratória de pacientes sob ventilação mecânica com pneumonia associada ao ventilador.

Muitas vezes as técnicas compressão torácica e hiperinsuflação manual (CT+HM) são usadas em conjunto, procedimento conhecido como "Bag Squeezing". Trata-se de manobra descrita em 1968, por Clement e Hubsch ${ }^{16}$, que é altamente eficaz na limpeza de secreção brônquica e re-insuflação das áreas colapsadas. A técnica foi originalmente aplicada em pacientes sedados e ventilados mecanicamente e era composta por posicionamento, hiperinsuflação / compressão torácica e aspiração das vias aéreas ${ }^{7,23}$. Em detalhe, a manobra era executada por um fisioterapeuta que realizava uma compressão torácica durante a expiração, enquanto que um anestesista realizava a hiperinsuflação pulmonar por meio do dispositivo de ventilação manual, de maneira coordenada e alternada. Consistia em séries de 4 a 6 insuflações e a aspiração traqueal ocorria no intervalo de cada série. A Bag Squeezing tem sido amplamente reportada, contudo, os autores não seguem a descrição original da técnica, tornando difícil avaliar seu benefício em pacientes criticamente doentes. Para nosso conhecimento, Stiller et al. (1990) ${ }^{8}$, foram os únicos a seguirem fielmente a técnica descrita em 1968. Eles utilizaram a Bag Squeezing da maneira como se segue. O paciente permanecia na posição de drenagem por 20 minutos e posteriormente, era realizado uma compressão manual na parede torácica associada a séries de 6 a 8 insuflações. A compressão torácica + hiperinsuflação manual que ocorria em aproximadamente 2 minutos era seguida por aspiração. A aplicação da manobra, realizada a cada hora por um período de 6 horas, resultou em significante resolução da atelectasia. Estudo prospectivo e sistemático, realizado por nosso grupo mostrou o benefício da Bag Squeezing (CT $+\mathrm{HM})$ em pacientes ventilados mecanicamente ${ }^{24}$. As manobras foram aplicadas duas vezes ao dia por cinco dias. O período de ventilação mecânica, período de internação e extensão de lesão pulmonar foram variáveis que apresentaram significante melhora, quando comparadas às de pacientes do grupo controle, que não receberam as manobras descritas ${ }^{24}$. O importante benefício ocorrido com a manobra $\mathrm{CT}+\mathrm{HM}$ realizada em nosso estudo prévio ${ }^{24}$ originou o seguinte questionamento: qual o papel da aplicação de cada técnica isolada no benefício identificado previamente?

Outro ponto a ser destacado é o número de profissionais necessário para realizar cada técnica. A técnica de Compressão Torácica (CT) e a Hiperinsuflação Manual (HM) quando aplicadas isoladamente exige apenas um profissional. Por outro lado, a técnica que associa CT + HM exige a presença de duas pessoas para sua realização. Seria interessante saber, 
portanto, se o paciente poderia se beneficiar com técnicas que pudessem ser aplicadas por apenas um profissional, o que agilizaria o trabalho do fisioterapeuta na unidade.

Há também que ser destacado que existem poucos estudos ${ }^{4,17,24}$ que avaliaram o efeito das técnicas de fisioterapia respiratória no período de internação e de ventilação mecânica, cujo prolongamento representa uma das principais causas de falta de vagas em UTI. Desta maneira, variáveis como, período de ventilação mecânica e período de internação na UTI, foram utilizadas para avaliar o efeito das técnicas CT e HM no presente estudo.

Diante do exposto, nossa hipótese é que a associação das técnicas (CT e HM) apresenta resultados superiores em comparação às técnicas utilizadas isoladamente. 
2. Objetivos 


\section{1 - Objetivo principal}

Comparar prospectivamente o efeito das técnicas compressão torácica e hiperinsuflação manual, e a associação de ambas, no período de internação e período de ventilação mecânica em pacientes internados em UTI.

\section{2 - Objetivos secundários}

Comparar o efeito das técnicas compressão torácica e hiperinsuflação manual, e a associação de ambas, em relação às seguintes variáveis:

- $\quad$ índice de gravidade, APACHE-II

- $\quad$ índice de extensão de lesão pulmonar, Murray

- relação $\mathrm{PaO}_{2} / \mathrm{FiO}_{2}$

- $\quad$ mecânica respiratória (complacência estática, frequência respiratória)

- $\quad$ repercussões hemodinâmicas (pressão arterial média, frequência cardíaca)

- $\quad$ saturação periférica de oxigênio $\left(\mathrm{SpO}_{2}\right)$ 
3. Pacientes e Métodos 


\section{1 - Pacientes e Desenho}

O estudo foi prospectivo e sistematizado e ocorreu utilizando três diferentes técnicas fisioterápicas que foram aplicadas durante 5 dias. O estudo foi desenhado para avaliar o efeito de três manobras no desfecho de pacientes ventilados mecanicamente. Foi conduzido durante 13 meses consecutivos (Junho 2007 a Julho 2008) na Unidade de Terapia Intensiva do Pronto Socorro (UTI-PS) do Hospital das Clínicas da Faculdade de Medicina de Botucatu/UNESP. O protocolo usado foi aprovado pelo Comitê de Ética em Pesquisa local (Of. 641/2006; Anexo 1). O Termo de Consentimento Livre e Esclarecido foi assinado pelo paciente e/ou seu responsável (Anexo 2). Pacientes adultos admitidos na UTI-PS foram avaliados por uma única observadora, autora deste estudo, para possível inscrição no estudo de acordo com critérios de inclusão e exclusão. Os critérios de inclusão foram idade igual ou superior a 18 anos e uso de ventilação mecânica por período superior a 24 horas. Os critérios de exclusão são apresentados no Quadro 1.

Quadro 1. Critérios de Exclusão ${ }^{1}$

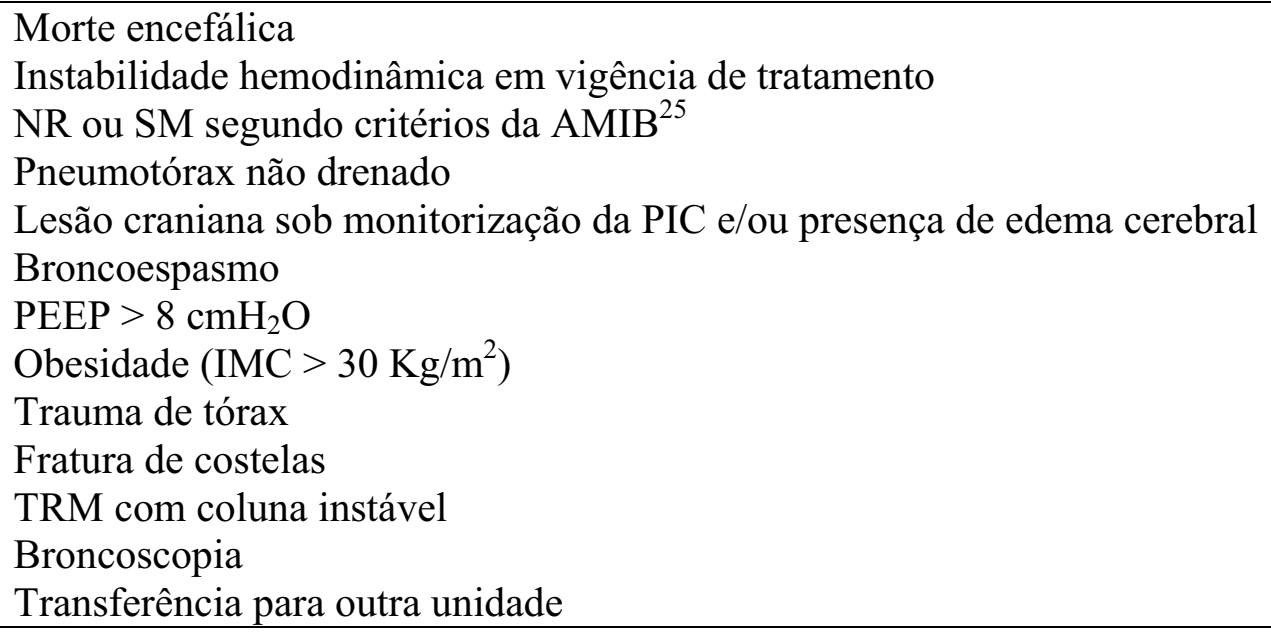

${ }^{1} \mathrm{NR}$, não reanimáveis; SM, suporte mínimo; AMIB, Associação de Medicina Intensiva Brasileira; PIC, pressão intracraniana; PEEP, pressão positiva expiratória final; IMC, índice de massa corpórea; TRM, trauma raqui-medular.

O processo de sistematização ocorreu como se segue. Após obtenção do consentimento assinado e seleção segundo critérios de inclusão e exclusão, os pacientes foram alocados em três grupos: Grupo compressão torácica (CT), Grupo hiperinsuflação manual (HM) e Grupo compressão torácica + hiperinsuflação manual $(\mathrm{CT}+\mathrm{HM})$. A alocação dos pacientes nos grupos (CT, HM e CT+HM) ocorreu de acordo com a ordem de admissão. Por exemplo, 
quando havia 4 pacientes elegíveis em um determinado dia, o primeiro admitido era alocado no Grupo CT, o segundo no Grupo HM, o terceiro, no Grupo CT+HM, o quarto alocado no Grupo CT, e assim sucessivamente. A mesma seqüência (CT, HM, CT+HM) foi mantida durante toda a fase de coleta de dados do presente estudo (13 meses). Os médicos que atenderam os pacientes não interferiram na elegibilidade ou na alocação nos grupos.

\section{2 - Variáveis estudadas}

A coleta das variáveis foi realizada por uma única observadora (autora deste estudo). Consideramos variáveis primárias, o período de ventilação mecânica e período de internação na UTI. As secundárias foram APACHE-II, Charlson, Murray, relação $\mathrm{PaO}_{2} / \mathrm{FiO}_{2}$, mecânica respiratória (complacência estática pulmonar e frequência respiratória), repercussões hemodinâmicas (pressão arterial média e frequência cardíaca) e saturação periférica de oxigênio. O APACHE-II (Acute Physiology and Chronic Health Evaluation) é um escore que permite classificar o nível de gravidade da doença e prognóstico, considerando as variáveis presentes na admissão ${ }^{26}$. O valor do APACHE-II resulta de um cálculo que utiliza variáveis como, diagnóstico de internação, resultados de exames laboratoriais e sinais vitais (Anexo 3). O APACHE-II foi calculado nos cinco dias de estudo para todos os pacientes e os dados necessários para seu cálculo foram coletados sempre no período da manhã, antes da primeira intervenção do dia. O Charlson, também é um índice prognóstico que, considera as comorbidades presentes no paciente. Seu cálculo é o resultado da soma dos pesos atribuídos a cada categoria da co-morbidade acrescido do peso da idade. Para cada década de idade acima de 40 anos foi adicionado 1 ponto (Anexo 4) ${ }^{27,28}$. Murray corresponde a uma escala (pesos de 0 a 2,5) utilizada para caracterizar a presença e extensão de lesão pulmonar. Murray foi calculado para cada paciente e resulta da avaliação individual dos seguintes parâmetros radiológicos e ventilatórios como se segue: consolidação alveolar radiológica de acordo com o número de quadrantes envolvidos; valor da hipoxemia $\left(\mathrm{PaO}_{2} / \mathrm{FiO}_{2}\right)$, nível de pressão positiva no final da expiração (PEEP) e complacência do sistema respiratório ${ }^{29}$. Os parâmetros radiológicos foram aferidos juntamente com os ventilatórios (Anexo 5). A relação $\mathrm{PaO}_{2} / \mathrm{FiO}_{2}$ corresponde ao índice de oxigenação que avalia o grau de disfunção pulmonar em relação à troca gasosa. $\mathrm{O}$ cálculo resulta da divisão da pressão parcial de oxigênio do sangue arterial $\left(\mathrm{PaO}_{2}\right)$ pela fração de oxigênio no ar inspirado $\left(\mathrm{FiO}_{2}\right)^{7,30}$. Os dados para o cálculo deste índice foram obtidos por meio de gasometria arterial, a qual era colhida diária e matinalmente antes da primeira intervenção do dia. Todas as variáveis foram diariamente registradas pela manhã durante os cinco dias de estudo exceto o índice de Charlson, que foi 
aferido apenas no primeiro dia. As variáveis foram comparadas entre os grupos de estudos e entre os momentos inicial (dia 1) e final (dia 5).

Com o objetivo de avaliar o efeito a curto prazo do tratamento fisioterápico, foram também analisadas as seguintes variáveis: complacência estática (Cest), frequência respiratória (FR), saturação periférica de oxigênio $\left(\mathrm{SpO}_{2}\right)$, pressão arterial média (PAM) e frequência cardíaca (FC). Todas essas variáveis foram duplamente colhidas ao dia [(intervenção 1 (manhã) e intervenção 2 (tarde)] nos seguintes momentos: imediatamente antes do procedimento; imediatamente após o procedimento; 15 minutos após procedimento e 30 minutos após procedimento. Isto ocorreu durante os cincos dias de estudo.

A complacência estática pulmonar (Cest) é definida como a variação do volume por unidade de pressão ${ }^{31-33}$ e é considerado um marcador importante da mecânica respiratória, pois avalia a gravidade e evolução da doença pulmonar ${ }^{33-35}$. A Cest foi aferida utilizando-se volume corrente (VC), pressão platô (Pplatô) e pressão positiva no final da expiração (PEEP). $\mathrm{O}$ cálculo apresentado abaixo ${ }^{31,36}$ inclui as variáveis $\mathrm{VC}$ médio (obtido por ventilometria manual durante um minuto), pressão de platô médio (obtida por leitura direta do ventilador mecânico durante um minuto) e PEEP (obtida por leitura direta do ventilador).

\section{Cest $=\ldots$ VC_médio \\ Pplatô médio - PEEP}

Cest, complacência estática pulmonar

$\mathrm{VC}$, volume corrente

Pplatô, pressão de platô

PEEP, pressão positiva no final da expiração

A frequência respiratória foi obtida juntamente com a ventilometria, já citada anteriormente. A frequência cardíaca (FC) e pressão arterial média (PAM) foram aferidas manualmente sempre pela mesma pessoa e a $\mathrm{SpO}_{2}$, verificada por meio de monitor (monitor cardíaco DIXTAL 920 e DX 2010).

Os pacientes que progrediram para o desmame da ventilação mecânica antes de completar os cinco dias foram extubados e avaliados em relação aos índices Murray e APACHE-II. A ocorrência de óbito e localização do paciente também foi verificada após 30 dias do início do estudo por meio de consulta pessoal ou por telefone. Para verificar a homogeneidade entre os grupos no início do estudo, foram registradas as seguintes características dos pacientes: idade, gênero, índice de massa corpórea (IMC), período de ventilação mecânica pré-estudo, parâmetros ventilatórios (FR, PEEP e $\mathrm{FiO}_{2}$ ), Charlson, 
APACHE-II, Murray, $\mathrm{PaO}_{2} / \mathrm{FiO}_{2}$, complacência estática, dose de drogas de sedação e indicação da VM. Os diagnósticos de internação e antecedentes pessoais de cada paciente selecionado para o estudo são apresentados nos apêndices 1, 2, 3, 4, 5 e 6.

\section{3 - Descrição do Tratamento}

Todos os pacientes foram ventilados mecanicamente (Respirador Takaoka - Monterey e Monterey Smart, São Paulo, SP, Brazil) com volume corrente padronizado (7 mL/Kg) após cálculo do peso ideal ${ }^{37}$ (Anexo 6). A modalidade ventilatória adotada foi a ventilação controlada a pressão (PCV), sendo esta mantida durante os 5 dias de estudo. Os parâmetros $\mathrm{FiO}_{2}$ e PEEP foram modificados sem a interferência da autora, de acordo com a necessidade de cada paciente.

Inicialmente, antes da execução das manobras, os pacientes eram avaliados clinicamente, sempre em posição supina e, coletados os parâmetros do ventilador (Anexos 7 e 8). A seguir, os pacientes eram submetidos às manobras fisioterápicas de acordo com o grupo a que pertenciam. Detalhes de cada manobra são descritos a seguir.

\subsection{1 - Compressão torácica}

Com as mãos posicionadas sobre o hemitórax do paciente realizou-se a compressão torácica expiratória (durante a expiração). Uma das mãos aplicou a compressão na direção ápice-base. Enquanto que a outra mão aplicou a compressão na direção oposta. O mesmo procedimento descrito acima foi aplicado no hemitórax contra-lateral.

Foram aplicadas 2 sessões em cada hemitórax sendo que cada sessão foi composta por 6 séries de compressão torácica.

\subsection{2 - Hiperinsuflação manual}

A manobra incluiu os seguintes passos: o paciente foi desconectado do respirador e imediatamente após, a insuflação aos pulmões foi aplicada por meio da compressão lenta do dispositivo de ventilação manual (limitado à pressão de $40 \mathrm{cmH}_{2} \mathrm{O}$ ), seguida por pausa inspiratória de 3 segundos. A seguir, foi aplicada rápida descompressão do dispositivo de ventilação manual, realizada com ambas as mãos e por uma única pessoa. Foram efetuadas 4 sessões de 6 insuflações.

O dispositivo de ventilação manual ( $a m b u)$ utilizado no presente estudo era da marca HUDSON, com limitador de pressão a $40 \mathrm{cmH}_{2} \mathrm{O}$. Durante todo o procedimento este dispositivo permaneceu conectado a um fluxo de $100 \%$ de oxigênio em $15 \mathrm{~L} / \mathrm{min}^{6,18,20,21}$. 


\subsection{3 - Compressão torácica + hiperinsuflação manual}

A manobra envolveu a associação das manobras descritas acima, as quais foram aplicadas simultaneamente e de maneira alternada e coordenada. Foram executadas 2 sessões em cada hemitórax. Cada sessão foi composta por 6 séries de insuflações associadas à compressão torácica expiratória.

Em todas as manobras, foi realizada a higiene de vias aéreas entre as sessões, por meio da aspiração traqueal. A aspiração ocorreu durante 15 segundos com cateter de tamanho $\mathrm{N}^{\mathrm{o}} 14$ e sob constante $\mathrm{FiO}_{2}$ de $100 \%{ }^{6,21}$. Instilou-se $2 \mathrm{~mL}$ de soro fisiológico no tubo traqueal com o intuito de provocar tosse e fluidificação de secreções $^{21,38}$. Nos grupos HM e CT+HM, a instilação do soro ocorreu previamente à aplicação da manobra, enquanto que no grupo CT ocorreu previamente à aspiração.

A intervenção fisioterápica nos três grupos foi realizada com o paciente em decúbito dorsal horizontal, 2 vezes ao dia, com intervalo de no mínimo 4 horas entre o atendimento da manhã e o da tarde, pelo período de 5 dias.

Além disso, todos receberam os cuidados regulares da equipe de enfermagem da UTIPS 4 vezes ao dia, que consistiram na mudança de decúbito a cada 2 horas, insuflação com dispositivo de ventilação manual (sem limitador de pressão) com posterior aspiração de secreção da cânula traqueal. Tais procedimentos são condutas padronizadas pela equipe de enfermagem da unidade que têm por objetivo prevenir a obstrução da prótese traqueal e que ocorrem 6 vezes/dia ou mais quando necessário. Como mencionado acima, os pacientes selecionados para o estudo receberam os cuidados da enfermagem apenas 4 vezes.

Os pacientes que foram extubados antes do $5^{\circ}$ dia de intervenção receberam duas vezes por dia as condutas padronizadas pelo serviço de fisioterapia do HC/FMB/UNESP. A conduta foi realizada pela autora do presente estudo e consistiu em aplicação de compressão torácica expiratória ( 2 sessões em cada hemitórax sendo que cada sessão foi composta por 6 séries de compressão torácica) acompanhada por estímulo de tosse. Tal conduta foi executada 2 vezes por dia.

O desmame da VM ocorreu de acordo com o protocolo adotado pela UTI-PS (Anexo 9).

\section{4 - Análise Estatística}

O cálculo da amostra foi realizado após um estudo piloto. Este cálculo utilizou nível de confiança de $95 \%(\alpha)$, poder de teste de $80 \%(\beta)$ e relevância clínica de apresentada pela 
diferença mínima igual a 46\% considerando-se as variáveis período de internação e período de VM. Chegou-se a conclusão que o número de pacientes a serem incluídos no estudo deveria ser 45 indivíduos.

Quanto aos procedimentos para os testes estatísticos, foram consideradas duas situações, variáveis quantitativas e qualitativas.

O estudo da associação entre grupos e variáveis qualitativas (gênero, sucesso no desmame da VM, sucesso da alta da UTI-PS, destino da UTI-PS, condições após 30 dias do estudo e local em que o paciente se encontra após 30 dias do estudo) foi realizado utilizando o teste de Goodman para contrastes entre e dentro de populações multinomiais ${ }^{39,40}$.

Foram utilizadas letras minúsculas para indicar os resultados das comparações entre grupos, fixada a categoria de resposta e, letras maiúsculas, nas comparações das categorias de respostas dentro do grupo. Para a interpretação das letras deve-se proceder da seguinte maneira:

- duas proporções seguidas de pelo menos uma mesma letra minúscula não diferem quanto aos respectivos grupos, na categoria de resposta em consideração;

- duas proporções seguidas de pelo menos uma mesma letra maiúscula não diferem quanto às respectivas categorias de resposta, dentro do grupo em consideração.

Em relação às variáveis quantitativas utilizou-se a técnica da análise de variância para o modelo de medidas repetidas em grupos independentes e, em algumas variáveis, avaliadas em momento único, a mesma técnica considerando o modelo com um fator. Ressaltamos que para a análise das variáveis, tempo de VM durante e após estudo, também foi utilizado o teste Qui-quadrado. A opção pelo procedimento paramétrico (resultados apresentados pela média e desvio-padrão) sempre ocorreu quando da aderência dos dados à distribuição normal de probabilidades e homogeneidade das variâncias. Na ausência desta aderência, optou-se pelo teste não paramétrico (resultados apresentados em mediana e semi-amplitude). Em todas as situações, a técnica foi complementada com o procedimento de comparações múltiplas, no nível de 5\% de significância ${ }^{41}$. Quanto à indicação da significância, o procedimento das letras foi semelhante ao das variáveis qualitativas. 
4. Resultados 
Durante os 13 meses de estudo foram admitidos na UTI-PS 327 pacientes. Atenderam aos critérios de inclusão 204 pacientes, que se encontravam intubados e em VM, a qual era a condição desejada para o estudo. Destes 204 pacientes, 144 foram excluídos ao serem avaliados e aplicados os critérios de exclusão. Os 60 pacientes restantes, que cumpriram todos os critérios de elegibilidade, foram distribuídos nos três grupos conforme processo de sistematização como descrito anteriormente. Cada grupo passou a ser composto por 20 pacientes. Durante o período de cinco dias de estudo foram excluídos 5 pacientes de cada grupo (causas de exclusão encontram-se na Figura 1). Desta forma, cada grupo passou a ser constituído por 15 pacientes. Durante os cinco dias de estudos alguns pacientes faleceram (2 pacientes do grupo CT; 1 paciente do grupo HM e 2 pacientes do grupo $\mathrm{CT}+\mathrm{HM})$. Dos pacientes que completaram o estudo, 13 eram do grupo CT, 14 do grupo HM e 13 do grupo $\mathrm{CT}+\mathrm{HM}$ (Figura 1).

Figura 1 - Fluxograma das etapas de seleção e alocação dos pacientes em seus respectivos grupos durante o período de 13 meses.

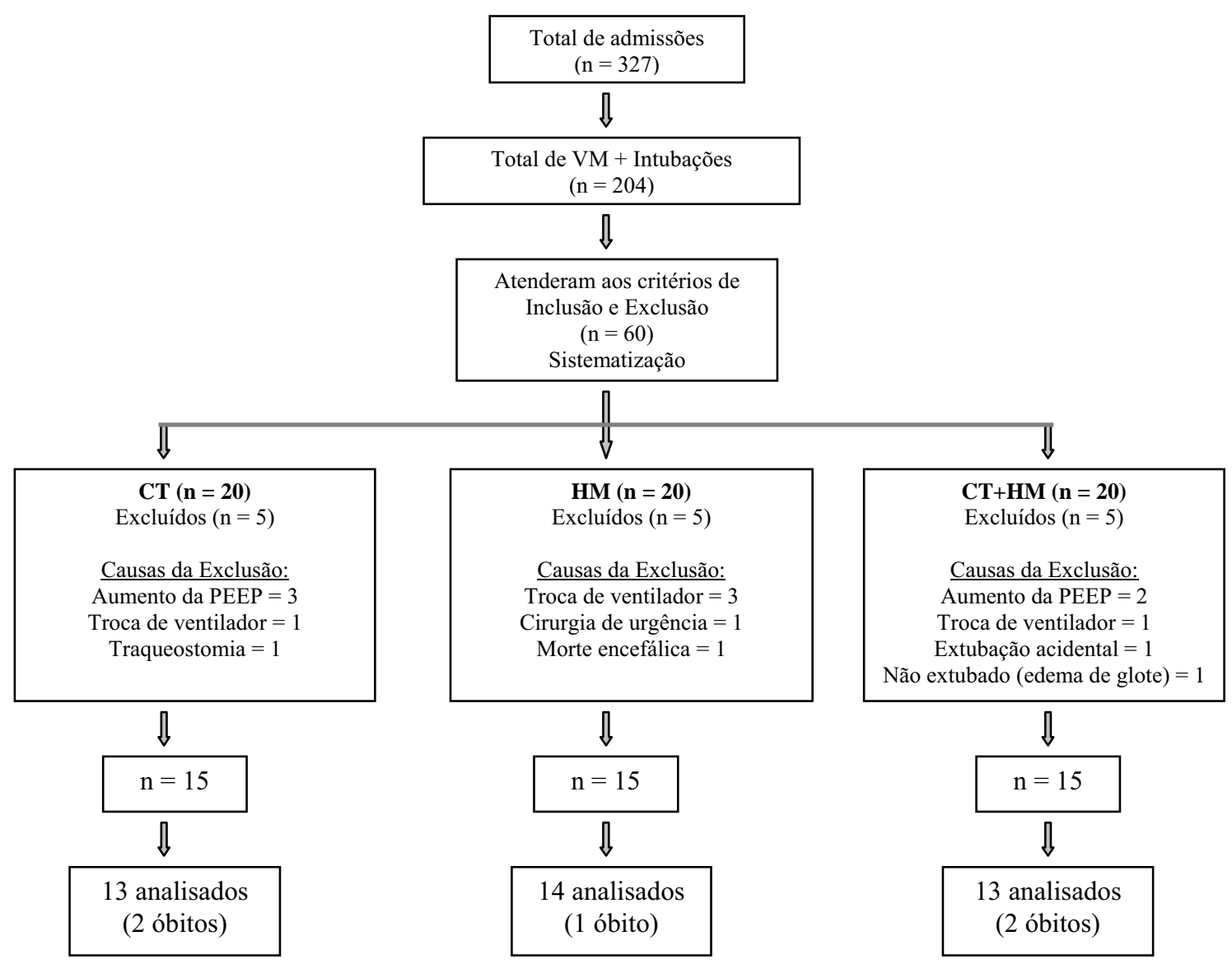


Para evitar erros de interpretação de dados (relacionados a benefício), decidimos não incluir os óbitos no estudo estatístico desde que um paciente que evolui para óbito apresenta um menor valor em relação ao período de internação, ao período de $\mathrm{VM}$ e ao sucesso do desmame. Contudo, tivemos o cuidado de descrever características desses pacientes, as quais são apresentadas no Apêndice 7.

\section{1 - Características da amostra no momento inicial}

A Tabela 1 mostra que os grupos não apresentavam diferenças entre si no momento inicial do estudo em relação a todas as variáveis estudadas (idade, gênero, IMC, período de ventilação mecânica pré-estudo, FR, PEEP, $\mathrm{FiO}_{2}$, Charlson, APACHE-II, Murray, $\mathrm{PaO}_{2} / \mathrm{FiO}_{2}$, Cest, dose de drogas de sedação). Destaca-se que, aproximadamente $65 \%$ dos pacientes apresentavam idade superior a 60 anos.

Tabela 1. Características dos pacientes segundo grupos no momento inicial do estudo ${ }^{1}$.

\begin{tabular}{|c|c|c|c|}
\hline & CT & $\mathrm{HM}$ & $\mathrm{CT}+\mathrm{HM}$ \\
\hline $\mathrm{n}$ total & 13 & 14 & 13 \\
\hline${ }^{*}$ Gênero M/F (n) & $9 / 4 \mathrm{a}$ & $7 / 7 \mathrm{a}$ & $5 / 8 \mathrm{a}$ \\
\hline - ${ }^{\$}$ Idade (anos) & $55,8 \pm 21,3 \mathrm{a}$ & $66,6 \pm 17,0 \mathrm{a}$ & $65,3 \pm 19,1 \mathrm{a}$ \\
\hline - ${ }^{\$} \mathrm{IMC}\left(\mathrm{Kg} / \mathrm{m}^{2}\right)$ & $22,3 \pm 2,4 \mathrm{a}$ & $24,1 \pm 2,9 \mathrm{a}$ & $23,2 \pm 3,6 \mathrm{a}$ \\
\hline - \$VM pré-estudo (horas) & $49,07 \pm 23,97 \mathrm{a}$ & $41,78 \pm 22,93 \mathrm{a}$ & $47,07 \pm 18,64 \mathrm{a}$ \\
\hline •, ${ }^{\ominus} \mathrm{FR}$ (ipm) & $15 \pm 4 \mathrm{a}$ & $15 \pm 2 \mathrm{a}$ & $16 \pm 3 a$ \\
\hline \#, \$PEEP & $5,00 \pm 1,05 \mathrm{a}$ & $5,20 \pm 0,80 \mathrm{a}$ & $5,00 \pm 0,80 \mathrm{a}$ \\
\hline$\bullet,{ }^{\$} \mathrm{FiO}_{2}$ & $0,43 \pm 0,12 \mathrm{a}$ & $0,41 \pm 0,08 \mathrm{a}$ & $0,36 \pm 0,07 \mathrm{a}$ \\
\hline - ${ }^{\$}$ Charlson & $4,15 \pm 3,28 \mathrm{a}$ & $4,36 \pm 3,10 \mathrm{a}$ & $3,61 \pm 2,53 \mathrm{a}$ \\
\hline •, ${ }^{\$}$ APACHE-II & $17,08 \pm 7,74 \mathrm{a}$ & $16,14 \pm 6,29 \mathrm{a}$ & $17,79 \pm 5,87 \mathrm{a}$ \\
\hline \#,\$ Murray & $1,25 \pm 0,50 \mathrm{a}$ & $1,38 \pm 1,25 \mathrm{a}$ & $1,38 \pm 1,00 \mathrm{a}$ \\
\hline$\#, \$ \mathrm{PaO}_{2} / \mathrm{FiO}_{2}$ & $267,10 \pm 69,10 a$ & $231,15 \pm 122,80 \mathrm{a}$ & $260,20 \pm 137,30 a$ \\
\hline - ${ }^{\ominus}$ Cest & $33,02 \pm 18,73 \mathrm{a}$ & $35,04 \pm 11,56 \mathrm{a}$ & $32,64 \pm 11,71 \mathrm{a}$ \\
\hline \#,\$ Fentanil $(\mathrm{mg} / \mathrm{d})$ & $0,36 \pm 0,96 \mathrm{a}$ & $0,22 \pm 0,48 \mathrm{a}$ & $0,59 \pm 0,84 \mathrm{a}$ \\
\hline \#, \$ Midazolan $(\mathrm{mg} / \mathrm{d})$ & $64,00 \pm 192,00 \mathrm{a}$ & $44,00 \pm 96,00 \mathrm{a}$ & $117,00 \pm 240,00 \mathrm{a}$ \\
\hline
\end{tabular}

${ }^{1}$ Esta tabela apresenta os valores apenas dos pacientes que completaram os cinco dias de estudo. Valores apresentados em: • média \pm desvio-padrão; ${ }^{\#}$ mediana \pm semi-amplitude; $\mathrm{n}$, número de pacientes; M, masculino; F, feminino; IMC, índice de massa corpórea; VM, tempo de ventilação mecânica; FR, frequência respiratória; ipm, incursões respiratórias por minuto; PEEP, pressão positiva expiratória final; $\mathrm{FiO}_{2}$, fração inspirada de oxigênio; $\mathrm{PaO}_{2} / \mathrm{FiO} 2$, relação da pressão parcial de oxigênio arterial com a fração inspirada de oxigênio; Cest, complacência estática pulmonar; *Teste de Goodman; ${ }^{\$}$ ANOVA complementada com o Teste de Tukey; ${ }^{\ominus}$ ANOVA complementada com o Teste de comparações múltiplas de Bonferroni. As diferenças estatísticas são apontadas por presença de letras diferentes. Letras minúsculas comparam grupos (CT vs. HM vs. CT+HM). 
A Tabela 2 apresenta o número total de pacientes e o principal diagnóstico que motivou a ventilação mecânica (VM). As indicações principais no grupo CT foram doença cérebro-vascular (DCV) (40\%) e choque séptico (33\%); no grupo HM foram DCV (27\%), insuficiência respiratória de origem pulmonar (IR-pulmonar) (27\%) e choque séptico (20\%); no grupo $\mathrm{CT}+\mathrm{HM}$ foram DCV (33\%), parada cardiorrespiratória (PCR) (27\%) e choque séptico $(20 \%)$. As características diagnósticas individuais de cada paciente são apresentadas nos Apêndices 1,2 e 3.

Tabela 2. Diagnósticos que motivaram a ventilação mecânica na admissão na unidade ${ }^{1}$.

\begin{tabular}{lccc}
\hline \multicolumn{1}{c}{ Diagnóstico-Indicação de VM } & $\begin{array}{c}\mathrm{CT} \\
\text { n/n total }(\%)\end{array}$ & $\begin{array}{c}\mathrm{HM} \\
\text { n/n total }(\%)\end{array}$ & $\begin{array}{c}\mathrm{CT}+\mathrm{HM} \\
\text { n/n total (\%) }\end{array}$ \\
\hline DCV & $6 / 15(40)$ & $4 / 15(27)$ & $5 / 15(33)$ \\
Choque séptico & $5 / 15(33)$ & $3 / 15(20)$ & $3 / 15(20)$ \\
PCR & $0 / 15(0)$ & $2 / 15(13)$ & $4 / 15(27)$ \\
IR-pulmonar & $0 / 15(0))$ & $4 / 15(27)$ & $0 / 15(0)$ \\
IR-por anafilaxia & $0 / 15(0)$ & $0 / 15(0)$ & $1 / 15(7)$ \\
IR-cardiogênica & $2 / 15(13)$ & $1 / 15(7)$ & $2 / 15(13)$ \\
Choque hipovolêmico & $0 / 15(0)$ & $1 / 15(7)$ & $0 / 15(0)$ \\
Intoxicação exógena & $1 / 15(7)$ & $0 / 15(0)$ & $0 / 15(0)$ \\
PO gastrointestinal & $1 / 15(7)$ & $0 / 15(0)$ & $0 / 15(0)$ \\
\hline
\end{tabular}

${ }^{1}$ Esta tabela inclui o $\mathrm{n}$ total de pacientes (pacientes que completaram os cinco dias de estudo e os que foram a óbito durante estudo); $\mathrm{n} / \mathrm{n}$; número de pacientes/número total de pacientes; $\%$, porcentagem de pacientes; DCV, doença cérebro-vascular; PCR, parada cárdio-respiratória; IR-pulmonar, insuficiência respiratória de origem pulmonar (tromboembolismo pulmonar, pneumonia, doença obstrutiva crônica, hipertensão pulmonar); IR-por anafilaxia, insuficiência respiratória por anafilaxia; IR-cardiogênica, insuficiência respiratória de origem cardiogênica (edema agudo de pulmão, choque cardiogênico); PO gastrointestinal, pós-operatório gastrointestinal.

\section{2 - Características evolutivas dos pacientes durante os cinco dias de intervenção}

No período de cinco dias foram coletados dados sobre o tempo de VM, sucesso no desmame da VM e na alta da UTI-PS. Os resultados mostraram ausência de diferença entre os grupos em relação as variáveis citadas. Em comparação aos outros grupos, destaca-se que embora o grupo $\mathrm{CT}+\mathrm{HM}$ tenha apresentado melhores valores em relação ao tempo de VM, sucesso no desmame da VM e sucesso da alta da UTI-PS, as diferenças entre os grupos não foram significantes em relação a essas variáveis, tanto na análise realizada por meio do teste ANOVA complementada com teste de Tukey e Goodman (Figuras 2, 3 e 4) como pelo teste do Qui-quadrado (Apêndice 8 e 9). 
Figura 2. Efeito da intervenção na duração da VM ao longo dos 5 dias de estudo ${ }^{1,2,3}$

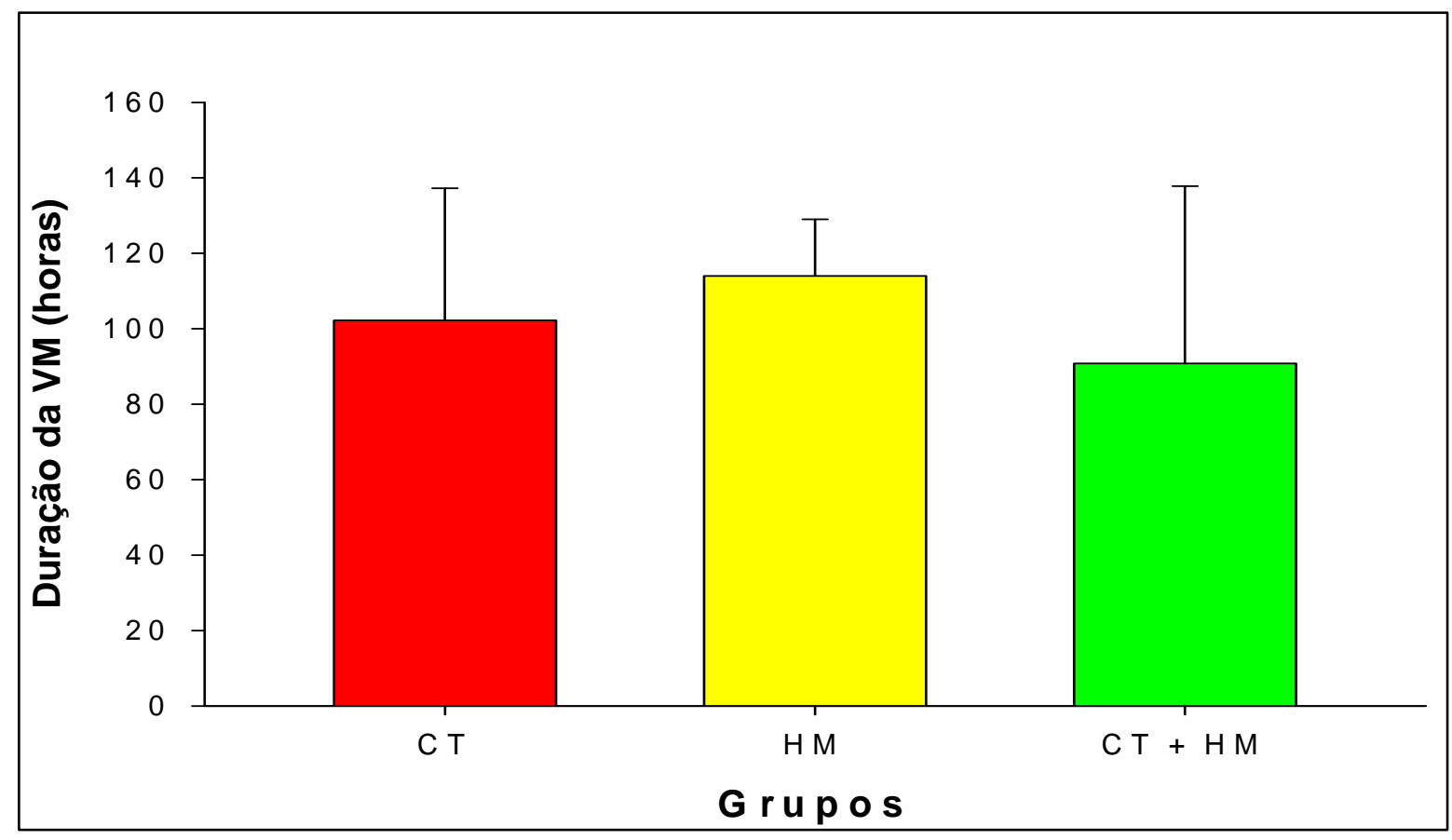

${ }^{1}$ Valores representam a média e desvio-padrão da duração da ventilação mecânica (horas);

${ }^{2} \mathrm{VM}$, ventilação mecânica; CT, grupo compressão torácica; HM, grupo hiperinsuflação manual; $\mathrm{CT}+\mathrm{HM}$, grupo compressão torácica associada à hiperinsuflação manual;

${ }^{3}$ Teste estatístico: ANOVA complementada com teste de Tukey $(p>0.05)$.

Figura 3. Efeito da intervenção no desmame da VM ao longo dos 5 dias de estudo ${ }^{1,2,3}$
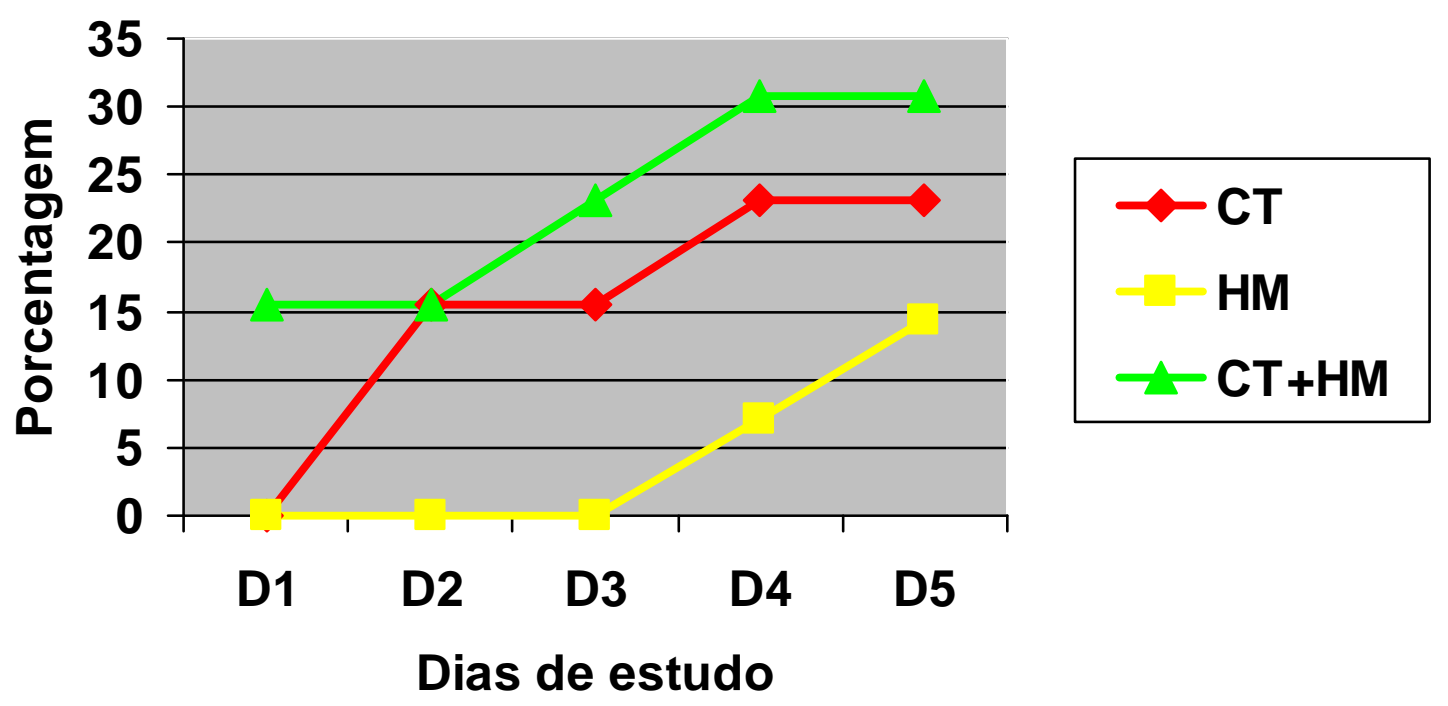

${ }^{1}$ Valores representam à porcentagem dos pacientes que obtiveram sucesso no desmame da ventilação mecânica;

${ }^{2} \mathrm{VM}$, ventilação mecânica; $\mathrm{D}$, dia; $\mathrm{CT}$, grupo compressão torácica; HM, grupo hiperinsuflação manual; $\mathrm{CT}+\mathrm{HM}$, grupo compressão torácica associada à hiperinsuflação manual;

${ }^{3}$ Teste de Goodman utilizado para a comparação entre os grupos em cada dia, $\mathrm{p}>0.05$. 
Figura 4. Efeito da intervenção na alta da UTI-PS ao longo dos 5 dias de estudo ${ }^{1,2,3}$

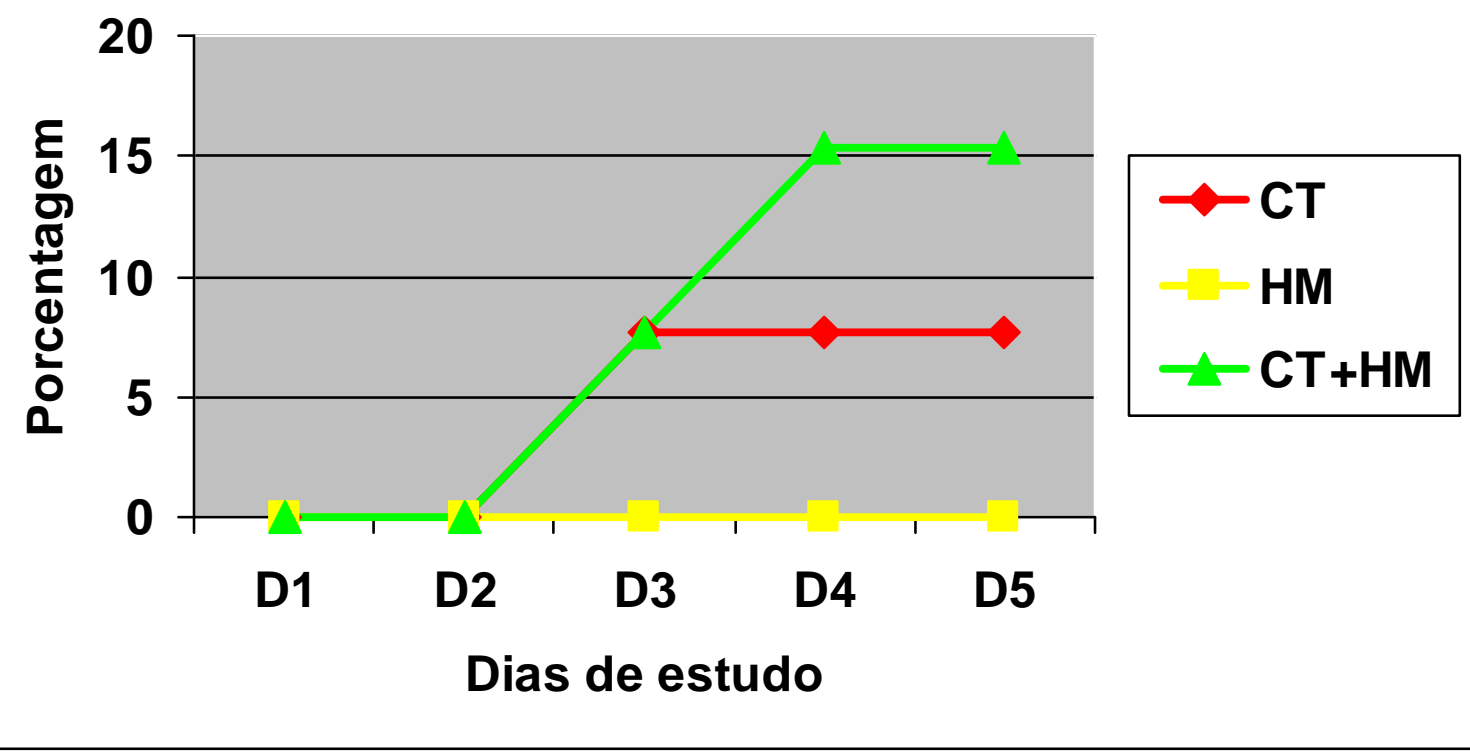

${ }^{1}$ Valores representam à porcentagem dos pacientes que obtiveram sucesso na alta da UTI;

${ }^{2} \mathrm{D}$, dia; $\mathrm{CT}$, grupo compressão torácica; $\mathrm{HM}$, grupo hiperinsuflação manual; $\mathrm{CT}+\mathrm{HM}$, grupo compressão torácica associada à hiperinsuflação manual.

${ }^{3}$ Teste de Goodman utilizado para a comparação entre os grupos em cada dia, $p>0.05$.

Os índices APACHE-II, Murray e $\mathrm{PaO}_{2} / \mathrm{FiO}_{2}$ foram registrados diariamente nos cincos dias de estudo (Apêndices 10, 11 e 12). Comparações foram realizadas entre os momentos inicial e final dentro de cada grupo e entre os grupos. Ao analisarmos a variável APACHE-II observamos que não houve diferença estatística entre os três grupos tanto no momento inicial como no momento final. Em relação à comparação entre os momentos, observamos que ocorreu melhora significativa do índice APACHE-II no grupo CT. Este aparente benefício não foi observado nos outros grupos (Tabela 3).

Tabela 3. Medidas de APACHE-II segundo grupo e momentos de avaliação ${ }^{1}$.

\begin{tabular}{ccc}
\multirow{2}{*}{ Grupos } & \multicolumn{2}{c}{ Momentos } \\
\cline { 2 - 3 } & Inicial & Final \\
\hline $\mathrm{CT}$ & $17,08 \pm 7,74 \mathrm{aB}$ & $11,62 \pm 6,19 \mathrm{aA}$ \\
\hline $\mathrm{HM}$ & $16,14 \pm 6,29 \mathrm{aA}$ & $14,86 \pm 6,76 \mathrm{aA}$ \\
\hline $\mathrm{CT}+\mathrm{HM}$ & $17,79 \pm 5,87 \mathrm{aA}$ & $15,21 \pm 8,04 \mathrm{aA}$
\end{tabular}

${ }^{1} \overline{\text { Valores apresentados em média } \pm \text { desvio-padrão; Comparações foram realizadas por ANOVA }}$ complementada com teste de Tukey; As diferenças estatísticas são apontadas por presença de letras diferentes; letras minúsculas comparam grupos (CT vs. HM vs. CT+HM); letras maiúsculas comparam momentos (Inicial vs. Final). 
$\mathrm{O}$ estudo das variáveis Murray e $\mathrm{PaO}_{2} / \mathrm{FiO}_{2}$ mostrou que não houve diferença tanto entre os grupos como entre os momentos inicial e final (Tabelas 4 e 5).

Tabela 4. Medidas de Murray segundo grupo e momentos de avaliação ${ }^{1}$.

\begin{tabular}{ccc}
\multirow{2}{*}{ Grupos } & \multicolumn{2}{c}{ Momentos } \\
\cline { 2 - 3 } & Inicial & Final \\
\hline $\mathrm{CT}$ & $1,25 \pm 0,50 \mathrm{aA}$ & $1,50 \pm 0,81 \mathrm{aA}$ \\
\hline $\mathrm{HM}$ & $1,38 \pm 1,25 \mathrm{aA}$ & $1,38 \pm 0,75 \mathrm{aA}$ \\
\hline $\mathrm{CT}+\mathrm{HM}$ & $1,38 \pm 1,00 \mathrm{aA}$ & $1,63 \pm 0,25 \mathrm{aA}$
\end{tabular}

${ }^{1}$ Valores apresentados em mediana \pm semi-amplitude; Comparações foram realizadas por ANOVA complementada com teste de Tukey; As diferenças estatísticas são apontadas por presença de letras diferentes; letras minúsculas comparam grupos (CT vs. HM vs. CT+HM); letras maiúsculas comparam momentos (Inicial vs. Final).

Tabela 5. Medidas de $\mathrm{PaO}_{2} / \mathrm{FiO}_{2}$ de acordo com o grupo e momentos de avaliação ${ }^{1}$.

\begin{tabular}{ccc} 
Grupos & \multicolumn{2}{c}{ Momentos } \\
\cline { 2 - 3 } & \multicolumn{1}{c}{ Inicial } & Final \\
\hline $\mathrm{CT}$ & $267,10 \pm 69,10 \mathrm{aA}$ & $257,00 \pm 120,75 \mathrm{aA}$ \\
\hline $\mathrm{HM}$ & $261,15 \pm 122,80 \mathrm{aA}$ & $276,30 \pm 142,70 \mathrm{aA}$ \\
\hline $\mathrm{CT}+\mathrm{HM}$ & $260,20 \pm 137,30 \mathrm{aA}$ & $262,10 \pm 61,30 \mathrm{aA}$ \\
\hline${ }^{1}$ Valores apresentados em mediana \pm semi-amplitude; Comparações foram realizadas por ANOVA \\
$\begin{array}{l}\text { complementada com teste de Tukey; As diferenças estatísticas são apontadas por presença de letras } \\
\text { diferentes; letras minúsculas comparam grupos (CT vs. HM vs. CT+HM); letras maiúsculas comparam } \\
\text { momentos (Inicial vs. Final). }\end{array}$
\end{tabular}

Com o objetivo de verificar efeitos indesejáveis de cada intervenção nos parâmetros respiratórios e hemodinâmicos, as variáveis (complacência estática, frequência respiratória, $\mathrm{SpO}_{2}$, frequência cardíaca e pressão arterial média) foram registradas em diversos momentos. Para facilitar o entendimento, utilizamos as letras $\mathrm{M}$ e $\mathrm{T}$ para nos referirmos à intervenção ocorrida no período da manhã e da tarde, respectivamente. Da mesma forma utilizamos os números zero, 1, 15 e 30 para nos referirmos aos momentos de registro imediatamente antes, imediatamente após, 15 minutos após e 30 minutos após intervenção, respectivamente. Assim, M0, M1, M15 e M30 correspondem às medidas da manhã. Ao passo, que T0, T1, T15 e T30 correspondem às medidas da tarde. 
Para estudar o efeito da intervenção na variável ao longo da manobra, os momentos foram comparados entre si dentro de cada grupo individualmente. A interferência do momento de avaliação foi estudada comparando-se os grupos entre si dentro de cada momento individualmente (momentos M0, M1, M15 e M30 e nos momentos T0, T1, T15 e T30). Com o objetivo de verificar se a segunda manobra diária (a da tarde) poderia modificar a variável, foram também comparados os momentos M30 e T30 dentro de cada grupo.

Os resultados mostraram em primeiro lugar que, os grupos foram semelhantes quando comparados em cada momento tanto no período da manhã como no período da tarde. Isto ocorreu na análise de todas as variáveis estudadas. Em segundo lugar, o momento M30 foi semelhante ao T30 em todos os grupos. Isto ocorreu na análise de todas as variáveis estudadas. Mostraremos a seguir as alterações relevantes ocorridas em cada variável ao longo da manobra fisioterapêutica.

Complacência Estática (Cest). Os resultados mostraram que a Cest não foi modificada ao longo da intervenção (CT, HM e CT+HM) tanto no período da manhã como no da tarde (Apêndice 13).

Frequência Respiratória (FR). Foi observado que a FR (ipm) foi modificada pela manobra fisioterapêutica ao longo da intervenção apenas no grupo HM. De fato, foi observado que houve uma redução da FR no momento T30 (15 ipm) tanto em relação ao momento T0 (16 ipm) como em relação ao momento T1 (16 ipm). Não foi observada modificação da FR no período da manhã neste grupo (Apêndice 14).

Saturação Periférica de Oxigênio $\left(\mathrm{SpO}_{2}\right)$. Em resumo, pode se afirmar que, embora de modo não sustentado, as manobras $\mathrm{HM}$ e $\mathrm{CT}+\mathrm{HM}$ induziram melhora da $\mathrm{SpO}_{2}$ no momento imediatamente após intervenção tanto no procedimento da manhã (M1) como no da tarde (T1). Em detalhe, os resultados mostraram que houve modificação da $\mathrm{SpO}_{2}$ (\%) ao longo da intervenção nos grupos $\mathrm{HM}$ e $\mathrm{CT}+\mathrm{HM}$. De modo geral, a $\mathrm{SpO}_{2}$ aumenta no momento imediatamente após a intervenção, mas este aumento não é sustentado nos momentos posteriores. Em detalhe, verificamos que durante o período da manhã no grupo HM, a maior $\mathrm{SpO}_{2}$ ocorreu no momento M1 $(97,10)$ em relação a $\mathrm{M} 0(96,47)$, M15 $(96,30)$ e M30 $(96,54)$. Ainda no grupo $\mathrm{HM}$, observamos que, o maior valor de $\mathrm{SpO}_{2}$ ocorreu no momento $\mathrm{T} 1(97,00)$ em relação ao T0 (96.21), T15 (96,37) e T30 (96,36). No grupo CT+HM observamos um comportamento semelhante ao identificado no grupo HM. O maior valor de $\mathrm{SpO}_{2}$ do período da manhã ocorreu no M1 $(96,69)$ em relação ao M0 (96.09) e M15 $(95,94)$. E no período da tarde, o maior valor de $\mathrm{SpO}_{2}$ ocorreu no momento T1 $(97,08)$ em relação ao T0 $(96,44)$, T15 $(96,50)$ e T30 $(96,53)$. No grupo $\mathrm{CT}$, a $\mathrm{SpO}_{2}$ não foi modificada durante o período da manhã. 
Contudo, ocorreu melhora não sustentada desta variável no período da tarde, no momento T1 em relação aos outros momentos $(\mathrm{T} 1>\mathrm{T} 0, \mathrm{~T} 15, \mathrm{~T} 30 ; \mathrm{T} 15=\mathrm{T} 30=\mathrm{T} 0)$ (Apêndice 15).

Frequência Cardíaca (FC). Em resumo, pode se afirmar que embora de modo fugaz, as manobras HM e CT+HM executadas no período da tarde comprometeram a FC. Isto também ocorreu no período da manhã durante a manobra HM. Em detalhe, no grupo HM observamos que, em relação ao momento M0 ocorreu um aumento da FC (bpm) no momento M1, o qual não foi sustentado nos momentos posteriores (M1, 88,97 > M0, 83,51, M15, 85,28 e M30, 84,83). O mesmo comportamento foi identificado no período da tarde (T1, 90,69 > T0, 87,49, T15, 86,57 e T30, 86,00). No grupo CT+HM também ocorreu aumento da FC apenas no período da tarde. Em comparação com o T0, esse aumento ocorreu no momento T1, o qual foi sustentado até T15 com retorno a valores semelhantes ao do momento inicial $[\mathrm{T} 1(95,24)=$ T15 $(92,61)>$ T0 $(91,12)=$ T30 $(90,54)]$. A FC não foi modificada no grupo CT (Apêndice 16).

Pressão Arterial Média (PAM). Em resumo, as manobras CT e CT+ HM não comprometeram a PAM tanto durante o procedimento da manhã, como no da tarde. Contudo, a manobra HM foi associada a um comprometimento desta variável no procedimento da manhã (no M15, que foi sustentada até o momento M30) e no da tarde (T30 < T1). Em detalhe, no grupo HM foi identificada queda da PAM no M15 que foi sustentada até o momento posterior $[\mathrm{M} 0(92,63)=\operatorname{M} 1(92,01)>\operatorname{M} 15(89,01)=\operatorname{M} 30(88,68)]$. No período da tarde do grupo HM, não foi observada alteração da PAM ao longo da manobra [(T30 $(88,77)$ $=\mathrm{T} 0(91,97)=\mathrm{T} 15(89,39)]$, com exceção da redução desta variável no T30 em relação ao T1 $[(\mathrm{T} 30(88,77)<\mathrm{T} 1(92,63)]$ (Apêndice 17).

Em geral, não foram observados efeitos clínicos adversos importantes das manobras em relação à mecânica respiratória e saturação periférica de oxigênio em nenhum dos grupos no decorrer do estudo. Além disso, nenhum caso de barotrauma foi detectado. Contudo, é relevante mencionar que, ao contrário da $\mathrm{CT}$, as manobras $\mathrm{HM}$ e $\mathrm{CT}+\mathrm{HM}$ induziram repercussões hemodinâmicas (FC e PAM).

\section{3 - Condições após 30 dias de estudo}

Após 30 dias do início do estudo foram coletadas informações sobre a condição (vivo ou morto) em que os pacientes se encontravam. Também foi registrado o local onde os pacientes se encontravam (residência, UTI-PS, enfermaria). Os resultados mostraram que não houve diferença entre os grupos em relação ao desfecho (vivo; morto), mostrando que o número de pacientes vivos foi semelhante nos 3 grupos. $\mathrm{O}$ mesmo ocorreu para o desfecho 
morte. Já na comparação entre vivos e mortos dentro do próprio grupo, foi observado que o grupo CT apresentou um número significantemente maior de pacientes vivos do que mortos, o que não ocorreu nos grupos HM e CT+HM (Tabela 6).

Tabela 6. Distribuição das condições após 30 dias de estudo segundo grupo ${ }^{1}$.

\begin{tabular}{lccc} 
& \multicolumn{2}{c}{ CONDIÇÕES APÓS 30 DIAS } & \\
\cline { 2 - 4 } GRUPOS & MORTO & VIVO & TOTAL \\
\hline CT & $\mathrm{n}(\%)$ & $\mathrm{n}(\%)$ & 13 \\
HM & $2(15,4) \mathrm{aA}$ & $11(84,6) \mathrm{Ab}$ & 14 \\
CT+HM & $5(35,7) \mathrm{aA}$ & $9(64,3) \mathrm{aA}$ & 13 \\
\hline
\end{tabular}

${ }^{1}$ Valores apresentados em (n) número de pacientes; (\%), porcentagem do $\mathrm{n}$ de pacientes; Comparações foram realizadas pelo teste de Goodman; As diferenças estatísticas são apontadas por presença de letras diferentes; letras minúsculas comparam grupos (CT vs. HM vs. CT+HM); letras maiúsculas comparam condições (Morto, Vivo).

Em relação à localização dos pacientes (UTI-PS, enfermaria, residência) após 30 dias de estudo, verificamos que dos 11 pacientes vivos do grupo CT, 5 estavam em casa, 4 na UTIPS e 2 na enfermaria do HC. Dos 9 pacientes vivos do grupo HM, 4 encontravam-se em casa, 4 na UTI-PS e 1 na enfermaria. Dos 8 pacientes vivos do grupo CT+HM, 4 estavam na UTIPS, 3 em casa e 1 na enfermaria (Tabela 7). O estudo estatístico mostrou ausência de diferenças entre os grupos em relação à localização do paciente. E, também mostrou ausência de diferenças entre as diferentes localizações em relação a cada grupo isoladamente.

Tabela 7. Localização dos pacientes após 30 dias de estudo ${ }^{1}$.

\begin{tabular}{lcccc}
\hline & \multicolumn{4}{c}{ LOCAL } \\
\cline { 2 - 5 } \multicolumn{1}{c}{ GRUPOS } & UTI-PS & Enfermaria & Residência & Total \\
\hline CT & $\mathrm{n}(\%)$ & $\mathrm{N}(\%)$ & $\mathrm{n}(\%)$ & 11 \\
HM & $4(36,3) \mathrm{aA}$ & $2(18,2) \mathrm{aA}$ & $5(45,5) \mathrm{aA}$ & 9 \\
CT+HM & $4(44,4) \mathrm{aA}$ & $1(11,2) \mathrm{aA}$ & $4(44,4) \mathrm{aA}$ & 8 \\
\hline
\end{tabular}

${ }^{1}$ Valores apresentados em (n) número de pacientes; (\%), porcentagem do $\mathrm{n}$ de pacientes; Comparações foram realizadas pelo teste de Goodman; As diferenças estatísticas são apontadas por presença de letras diferentes; letras minúsculas comparam grupos (CT vs. HM vs. CT+HM); letras maiúsculas comparam locais (UTI-PS, enfermaria, residência). 
5. Discussão 
Embora a fisioterapia respiratória (FR) pareça ser parte fundamental do tratamento multidisciplinar na maioria das unidades de terapia intensiva, existem poucos estudos que examinaram sua eficácia no período de ventilação mecânica (VM) e no período de internação ${ }^{4,17,24}$.

Tendo em vista resultados anteriores de nosso grupo ${ }^{24}$ que, identificaram benefício da aplicação da associação CT+HM em pacientes ventilados mecanicamente, o presente estudo foi desenvolvido objetivando verificar o efeito isolado e associado de cada manobra em relação à duração da VM e ao tempo de internação. Ao contrário do esperado, o presente estudo mostrou que tanto a associação $\mathrm{CT}+\mathrm{HM}$ como cada manobra isolada não modificou o período de ventilação mecânica e de internação na UTI-PS

\section{1 - Efeito das intervenções no período de internação e no período de ventilação mecânica}

Os resultados do presente trabalho estão de acordo com prévios estudos ${ }^{4,17}$ que mostraram que a manobra de compressão torácica isoladamente não alterou o período de VM e o de internação na $\mathrm{UTI}^{4}$. Assim, como na manobra de compressão torácica, estudo randomizado não mostrou beneficio da aplicação da hiperinsuflação manual no período de VM e internação na UTI, quando comparado ao grupo controle, que recebeu apenas cuidados da enfermagem, que consistia em mudança de decúbito a cada 2 horas e aspiração ${ }^{17}$. A aplicação da compressão torácica associada à hiperinsuflação manual $(\mathrm{CT}+\mathrm{HM})$ mostrou benefício em estudo anterior realizado por nosso grupo ${ }^{24}$. Neste estudo a CT+HM era precedida por percussão torácica em pacientes ventilados mecanicamente e aplicada duas vezes ao dia por cinco dias. Ao contrário do presente trabalho, os resultados identificaram significante encurtamento tanto do período de VM como o de internação, quando comparados aos de pacientes do grupo controle, que não receberam as manobras descritas ${ }^{24}$.

\section{2 - Efeito das intervenções nos índices de gravidade, de extensão da lesão pulmonar e oxigenação}

Em relação à gravidade do paciente, à extensão de lesão pulmonar e ao índice de oxigenação, aferidas respectivamente pelos índices APACHE-II, Murray e $\mathrm{PaO}_{2} / \mathrm{FiO}_{2}$, nossos resultados mostraram que os três grupos foram semelhantes no momento final (dia 5). Isto sugere que o desfecho em relação a tais variáveis é o mesmo independente da manobra aplicada. Por outro lado, a aplicação da CT resultou em melhora significativa do APACHE-II no momento final do estudo (dia 5) em relação ao inicial (dia 1), o que não ocorreu nos outros 
grupos. Este é um importante resultado tendo em vista a alta gravidade (média, CT 17,08; HM 16,14; CT+HM 17,79) de nossa casuística no momento inicial. Já bem documentado na literatura, o valor de APACHE-II está associado à taxa de mortalidade ${ }^{26}$. Estudo realizado na mesma unidade ${ }^{42}$ mostrou que a faixa de APACHE-II entre 15 a 20 apresenta $60 \%$ de chance de óbito. Para o nosso conhecimento, existe apenas um estudo que avaliou o efeito da intervenção no valor de APACHE-II ${ }^{24}$ que, mostrou ausência de efeito da intervenção no valor de tal índice após manobra (percussão+HM+CT) realizada durante cinco dias. Ntoumenopoulos et al. $(2002)^{4}$ mostraram que pacientes com alto valor $(19,5)$ de APACHE-II foram beneficiados pela fisioterapia respiratória (drenagem postural, vibração e aspiração) dada a menor incidência de pneumonia associada ao ventilador identificada naquele estudo.

Assim como APACHE-II há poucos relatos sobre o efeito da fisioterapia respiratória sobre o índice de Murray. Para nosso conhecimento, apenas um estudo ${ }^{24}$ realizou tal avaliação identificando melhora da extensão da lesão pulmonar após cinco dias de fisioterapia respiratória (percussão+HM+CT) comparado com o grupo controle $(\mathrm{p}<0,01)$. Há também relatos mostrando valores de Murray do momento basal superiores $(1,60$ e 1,62) ao identificado no nosso estudo ${ }^{19,20}$.

Em relação à $\mathrm{PaO}_{2} / \mathrm{FiO}_{2}$, há vários trabalhos que avaliaram o efeito da intervenção no índice de oxigenação com resultados conflitantes ${ }^{6-8,11,18-20,22,43}$. Nossos resultados estão de acordo com alguns estudos que mostraram ausência de benefício no índice de oxigenação ou nos valores de gasometria tanto utilizando a manobra $\mathrm{CT}^{7}$, como a $\mathrm{HM}^{6,22,43}$ ou a $\mathrm{CT}+\mathrm{HM}^{8}$. Contudo, estão em desacordo com outros autores que mostraram benefício da HM na relação $\mathrm{PaO}_{2} / \mathrm{FiO}_{2}{ }^{19,20}$. Em detalhe, a $\mathrm{CT}$ não beneficiou pacientes $(\mathrm{n}=47)$ portadores de atelectasia sob ventilação mecânica e PEEP de 5 a $10 \mathrm{cmH}_{2}{ }^{7}$. O mesmo ocorreu em relação à manobra $\mathrm{HM}$ aplicada em pacientes $(\mathrm{n}=18)$ sob $\mathrm{VM}^{6}$, e também em relação à manobra $\mathrm{CT}+\mathrm{HM}$ (Bag Squeezing) aplicada em pacientes $(\mathrm{n}=14)$ com atelectasia lobar aguda ${ }^{8}$. O tratamento utilizado no último estudo ${ }^{8}$ incluiu 20 minutos de drenagem de secreção pulmonar (decúbito lateral oposto ao da atelectasia) seguida por compressão manual da parede torácica associada a séries de 6 a 8 hiperinsuflações, seguida por aspiração. A manobra foi realizada a cada hora por um período de 6 horas. Por outro lado, outros estudos mostraram benefício das manobras na oxigenação. Clarke et al. (1999) ${ }^{19}$ aplicaram a HM em 25 pacientes sedados e ventilados mecanicamente, e foi observado melhora da troca gasosa nestes pacientes após a intervenção. Paratz et al. $(2002)^{20}$ também obtiveram o mesmo resultado ao aplicar a HM, realizada por 3 minutos, com pausa inspiratória de 2 segundos e rápida descompressão do dispositivo de ventilação manual, em pacientes sob VM com doença pulmonar de causa extrapulmonar. 


\section{3 - Efeito das intervenções na mecânica respiratória, na saturação periférica de $\mathrm{O}_{2} \mathrm{e}$ na condição hemodinâmica}

Em geral, não foram observados efeitos clínicos adversos importantes das manobras em relação à mecânica respiratória e saturação periférica de oxigênio em nenhum dos grupos no decorrer do estudo. Contudo, as manobras HM e CT+HM resultaram em repercussões hemodinâmicas.

\subsection{1 - Mecânica Respiratória}

A complacência estática (Cest) não foi modificada por nenhuma das três manobras. Para o nosso conhecimento, não há estudos que tenham avaliado o efeito de da CT ou da $\mathrm{CT}+\mathrm{HM}$ na Cest. Por outro lado, tem sido mostrado que a HM resulta em melhora da Cest $^{6,19,20}$.

O presente estudo identificou que a manobra HM melhorou (diminuiu) a frequência respiratória (FR) no momento $\mathrm{T} 30$ em relação ao T0 e T1. O fato da melhora da FR do grupo HM não ter sido identificada no período da manhã e sim no da tarde sugere que uma manobra adicional pode ter beneficiado pacientes tratados com o procedimento HM, embora não tenha ocorrido diferença entre o momento M30 e o T30. Não encontramos até o momento estudos que tenham avaliado o efeito de manobras fisioterápicas na FR, o que impossibilita comparações com o presente estudo.

\subsection{2 - Saturação periférica de $\mathrm{O}_{2}$}

Embora de modo não sustentado, as manobras HM e CT+HM induziram melhora da $\mathrm{SpO}_{2}$ no momento imediatamente após o procedimento tanto no procedimento da manhã (M1) como no da tarde (T1). O mesmo foi observado no grupo CT, mas a melhora ocorreu apenas no período da tarde. Não encontramos estudos que tenham avaliado o efeito de manobras fisioterápicas na $\mathrm{SpO}_{2}$, o que impossibilita comparações com o presente estudo.

\subsection{3 - Condição Hemodinâmica}

Assim como o observado em relação à $\mathrm{SpO}_{2}$, as manobras $\mathrm{HM}$ e $\mathrm{CT}+\mathrm{HM}$ resultaram em comprometimento (aumento) da FC. O aumento não sustentado foi observado nos dois períodos (manhã e tarde) do grupo HM e apenas em um dos períodos (tarde) do grupo CT+HM. Nossos resultados estão de acordo com Stone et al. (1989) ${ }^{44}$ que verificaram um aumento da FC após HM dos pulmões. Por outro lado, vários trabalhos, ${ }^{6,20-22,45}$ que também estudaram a HM, não observaram alterações importantes na FC. Não encontramos estudos 
que avaliaram a $\mathrm{FC}$ quando as manobras $\mathrm{CT}$ ou $\mathrm{CT}+\mathrm{HM}$ foram utilizadas, o que impede comparações com o presente estudo.

Em relação à PAM, foi identificado que as manobras $\mathrm{CT}$ e $\mathrm{CT}+\mathrm{HM}$ não comprometeram a PAM tanto durante o procedimento da manhã, como no da tarde. Contudo, a manobra HM foi associada a uma redução desta variável identificada tanto no procedimento da manhã (no M15, que foi sustentada até o momento M30) como no da tarde (T30< T1). Muitos estudos ${ }^{6,20-22,45}$ verificaram o efeito da HM na PAM e todos concluíram que a PAM não sofreu alterações com esta manobra. Não achamos estudos que tenham avaliado o efeito das manobras CT e CT+HM na PAM.

É relevante mencionar que, ao contrário da $\mathrm{CT}$, as manobras $\mathrm{HM}$ e $\mathrm{CT}+\mathrm{HM}$ induziram repercussões hemodinâmicas. Embora clinicamente irrelevantes, as alterações verificadas no grupo HM foram mais importantes do que no CT+HM, uma vez que os aumentos da FC identificados no grupo HM não foram suficientes para evitar a redução da PAM. Esta redução da PAM é consequência do aumento da pressão intra-torácica promovida pela hiperinsuflação manual pulmonar, que gera uma redução do débito cardíaco e consequentemente da PAM.

\section{4 - Efeito das intervenções nas condições do paciente após 30 dias do estudo}

Não foram observadas diferenças entre os grupos em relação ao desfecho (vivo ou morto) após 30 dias do estudo. A discussão deste resultado é bastante limitada, visto que, há poucos estudos ${ }^{4,24}$ que verificaram o desfecho de seus pacientes após 30 dias de estudo. Tais estudos também não mostraram benefício da intervenção na mortalidade em $28 \operatorname{dias}^{4}$ ou em $30 \operatorname{dias}^{24}$. Estudando pneumonia associada ao uso do ventilador, Ntoumenopoulos et al. $(2002)^{4}$ não identificaram diferença na taxa de mortalidade em 28 dias entre o grupo intervenção com drenagem de secreção seguida por vibração manual e aspiração (28\%) e o grupo controle (24\%). Da mesma forma, estudo anterior de nosso grupo utilizando desenho semelhante não identificou benefício na mortalidade em 30 dias utilizando manobras CT+HM $(12,5 \%)$ em relação ao grupo controle $(21 \%)^{24}$. No presente estudo, foi observado que apenas no grupo CT houve uma porcentagem maior de pacientes vivos $(84,6 \%)$ quando comparado a pacientes mortos $(15,4 \%)$ dentro do próprio grupo $(p<0,05)$. Não encontramos na literatura estudos que realizaram este tipo de comparação, o que impossibilita comparações com o presente estudo.

Considerando um marcador de sucesso o local onde o paciente se encontra (após 30 dias do estudo), nosso estudo falhou em mostrar o benefício das manobras adotadas a longo 
prazo. Para nosso conhecimento, não há estudos que tenham estudado o efeito a longo prazo das manobras adotadas, o que impossibilita comparações com o presente estudo.

\section{5 - Características iniciais da população estudada}

O presente estudo apresenta homogeneidade na amostra, o que confirma o adequado processo de sistematização utilizado para seleção dos pacientes. De fato, as características gerais da população não apresentaram diferenças estatísticas no momento inicial do estudo em relação a todas variáveis estudadas [idade, gênero, IMC, período de VM pré-estudo, FR, PEEP, $\quad \mathrm{FiO}_{2}$, APACHE-II, Murray, $\mathrm{PaO}_{2} / \mathrm{FiO}_{2}$, complacência estática pulmonar e concentração de sedação administrada (fentanil e midazolan)]. Além disso, a semelhança das amostras também pode ser constatada em relação às causas de internação e índice de comorbidade, Charlson. Deste modo, pode ser inferido que a semelhança entre os grupos identificada no momento inicial suporta a afirmação de que todos os pacientes partiram de um mesmo ponto, não havendo, portanto vantagens e desvantagens dentro da população estudada que pudessem interferir nos resultados finais do estudo.

Em relação à idade, estudos prévios apresentam características demográficas relacionadas com a especialidade de cada unidade estudada. Por exemplo, as UTIs de trauma mostram predomínio de jovens ${ }^{17}$, enquanto que as UTIs gerais apresentam predomínio de idosos. A média de idade (62 anos) com variação de 19 a 95 anos identificada no presente trabalho é muito semelhante ao nosso prévio estudo ${ }^{24}$ e ao relatado por Wong et al. $(1999)^{46}$. Comparado com estudos brasileiros realizados em UTIs gerais, nossa população foi mais idosa. Nossa casuística geral mostrou que aproximadamente $65 \%$ dos pacientes apresentavam idade superior a 60 anos, diferente de Feijó et al. (2006) ${ }^{47}$ que relataram apenas $43 \%$ e de Paiva et al. $(2002)^{48}$ que mostraram apenas $45 \%$.

Em relação ao gênero, a maioria dos estudos mostra predomínio de homens ${ }^{4,6,8,20,42,49}$, o que difere de nossos resultados que identificou na casuística geral uma semelhança entre os dois gêneros.

Considerando o IMC, a casuística geral apresentou valores médios inferiores aos indicativos de ocorrência de obesidade $\left(\mathrm{IMC}>30 \mathrm{Kg} / \mathrm{m}^{2}\right)^{50}$. Esta é uma importante consideração dada à interferência do peso no sucesso da intervenção fisioterápica. De fato, é descrito que indivíduos obesos apresentam complacência pulmonar reduzida ${ }^{51-53}$ o que pode comprometer o seu resultado da intervenção. 
Foi observado também que no momento inicial do estudo não houve diferença entre os

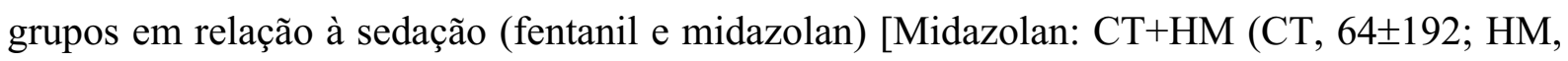

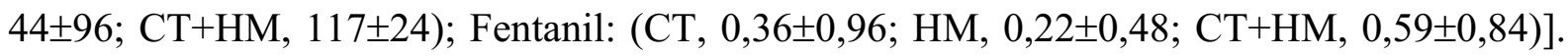
Este é outro dado relevante visto que tais medicamentos interferem no processo de desmame da ventilação mecânica ${ }^{54-59}$. Prévio estudo avaliando o efeito da interrupção da sedação (midazolan + morfina + propofol) no período de ventilação mecânica (e em outras variáveis) identificou que a dose de midazolan foi de $0,054 \mathrm{mg} / \mathrm{Kg} / \mathrm{dia}$ e $0,032 \mathrm{mg} / \mathrm{kg} / \mathrm{dia}$ no grupo controle e grupo intervenção, respectivamente ${ }^{56}$. Considerando que o peso corpóreo daqueles pacientes tenha sido aproximadamente $60 \mathrm{Kg}$, pode ser sugerido que, exceto para o grupo $\mathrm{CT}+\mathrm{HM}$, os valores encontrados por estes autores (grupo controle, 77,76 mg/dia; grupo intervenção, 46,08 mg/dia) são semelhantes aos nossos. Comparando a eficácia e segurança de diversos sedativos em pacientes ventilados mecanicamente, recente estudo ${ }^{59}$ mostrou concentração mediana de $1,31 \mathrm{mg} / \mathrm{Kg} / \mathrm{dia}$ e $9,6 \mu \mathrm{g} / \mathrm{Kg} / \mathrm{dia}$ de midazolan e fentanil, respectivamente. Considerando-se peso corpóreo de $60 \mathrm{Kg}$, pode ser sugerido que a concentração de sedação diária (midazolan e fentanil) identificada no presente estudo foi semelhante ao estudo de Ricker et al. $(2009)^{59}$ (Midazolan: 78,60 mg/dia; Fentanil: 0,576 $\mathrm{mg} / \mathrm{dia})$.

A análise dos dados mostrou que não houve diferença no momento inicial do estudo em relação à complacência estática e aos índices Charlson, APACHE-II, Murray e $\mathrm{PaO}_{2} / \mathrm{FiO}_{2}$. Alguns trabalhos que incluíram a HM em suas manobras ${ }^{6,21}$ avaliaram a Cest, cujo cálculo foi realizado com os pacientes em posição supina, no modo SIMV, VC de $8 \mathrm{~mL} / \mathrm{Kg}$, com fluxo zero e pausa inspiratória de 2 segundos, em ambos os estudos e, mostraram valores de $36,5^{6} \mathrm{e}$ $35,2^{21}$ que correspondem a valores ligeiramente superiores ao encontrado em nosso estudo, onde a média geral inicial da Cest foi de $33,6 \mathrm{~mL} / \mathrm{cmH}_{2} \mathrm{O}$.

Em relação a $\mathrm{PaO}_{2} / \mathrm{FiO}_{2}$, nós identificamos uma média geral da oxigenação da população estudada de 267,76 que se mostrou superior a de outros estudos que também utilizaram este índice para avaliar suas populações no momento inicial ${ }^{6,11,18,20}$.

O grau de lesão pulmonar, avaliado pelo índice de Murray ${ }^{29}$ mostrou média de 1,47 em nossa casuística. Este resultado está de acordo com nosso estudo prévio ${ }^{24}$ que identificou mediana de 1 , contudo, se mostrou inferior a de outros ${ }^{19,20}$ que apresentaram escore de Murray de 1,6 e 1,62.

Por tratar-se de uma população com diagnóstico variado, optamos por calcular o índice APACHE-II, visto que este índice é o mais utilizado em pacientes de UTI geral e 
heterogênea, como em nosso caso. No presente estudo, a média do APACHE-II no momento inicial foi de 17,15, resultado este semelhante ao encontrado por Berti et al. $(2009)^{24}$, Berney e Denehy $(2003)^{49}$ e por Savian et al. (2006) $)^{22}$ que apresentaram na admissão da UTI valor de APACHE-II de 17,0, 17,8 e 17,5 respectivamente. Por outro lado, há estudos que mostraram valores de APACHE-II inferior $(16)^{11}$ e superior $(21,8)^{20}$ aos encontrados em nosso estudo.

Sabemos também que co-morbidades presentes em pacientes podem interferir na evolução de sua doença aguda. Assim, decidimos aplicar também o índice de Charlson, cuja análise estatística não mostrou diferença entre os pacientes incluídos no estudo, o que também confirma a homogeneidade da amostra estudada. Nosso resultado (média, 4.05) foi aparentemente superior ao identificado em prévio estudo ${ }^{24}$ de nosso grupo, que mostrou mediana de 2. É relevante mencionar que a maioria dos pacientes (do presente trabalho) que apresentavam índice de Charlson superior a 3,0 evoluiu para óbito, resultado semelhante ao verificado por outro estudo ${ }^{60}$ (Apêndice 18).

Nossos resultados relacionados ao diagnóstico que motivou a VM estão de acordo com a literatura. Estudos realizados em unidade com perfil semelhante ao de nossa unidade apresentam a doença cérebro-vascular ${ }^{2,8,24}$ e insuficiência respiratória de origem pulmonar como as principais causas de $\mathrm{VM}^{24}$.

Estudo prévio realizado por nosso grupo ${ }^{24}$ mostrou que quando comparado ao grupo controle, a manobra CT+HM encurtou o período de desmame, de internação e melhorou o índice de extensão de lesão pulmonar (Murray). Contudo, quando a comparação ocorreu entre o momento inicial (dia 1) e o final (dia 5), o benefício da manobra CT $+\mathrm{HM}$ foi significante apenas para a variável Murray. Por motivos éticos, o presente estudo não utilizou grupo controle (ausência de tratamento) e, portanto, não podemos comparar os resultados atuais com os anteriores ${ }^{24}$. Contudo, intrigou-nos o fato de que o sucesso da intervenção CT+HM no índice Murray identificado em nosso prévio estudo ${ }^{24}$ não tenha se repetido no presente trabalho. E por essa razão decidimos apresentar diferenças entre os dois estudos selecionando apenas o grupo $\mathrm{CT}+\mathrm{HM}$ do presente estudo e o grupo $\mathrm{CT}+\mathrm{HM}$ seguida de percussão do estudo prévio. $\mathrm{O}$ insucesso poderia estar associado às características iniciais dos pacientes entre o presente e anterior estudo. Contudo, esta possibilidade não se confirmou tendo em vista a semelhança entre os dois estudos (Estudo-Presente, média; Estudo-Anterior, mediana) em relação à idade (65,3 anos; 61 anos), APACHE-II $(17,79 ; 17,00)$, Murray $(1,38 ; 1,00)$ e Charlson $(3,61 ; 2,0)$. Por outro lado, identificamos diferenças importantes entre os estudos (Estudo-Presente, \% de pacientes; Estudo-Prévio, \% de pacientes) em relação aos 
diagnósticos dos pacientes no ato da admissão (Apêndice 3) [(Choque Séptico: 40\%; 6,25\%), (PCR: 27\%; 6,25\%), (Pneumonia: 53,3\%; 87,5\%), (Doença cérebro-vascular: 33\%; 62,5\%), (Edema Agudo de Pulmão: 13,3\%; 6,25\%)]. É relevante destacar o menor número de portadores de Pneumonia e Doenças Cérebro-Vascular bem como o maior número de pacientes vítimas de Choque Séptico e PCR do presente estudo em comparação ao prévio ${ }^{24}$. O fato de que portadores de pneumonia tendem a apresentar sucesso no processo de lesão pulmonar na vigência de adequada antibioticoterapia ${ }^{61,62}$, pode sugerir que os pacientes do prévio estudo apresentavam melhores condições basais do que os do presente. É bem documentada tanto em nível nacional ${ }^{63}$ como mundial $^{64}$ a alta gravidade e letalidade do choque séptico. É bem conhecido também que o alto valor de APACHE-II ( 17), habitual nos pacientes portadores de choque séptico, corresponde a um dos motivos que compromete a possibilidade de recuperação rápida de seqüelas ${ }^{63}$. Da mesma forma, vítimas de parada cardio-respiratória internados em UTI apresentam pobre evolução ${ }^{65}$, como confirmado em prévios estudos ${ }^{42,66}$. Baseado no exposto pode ser inferido que, a maior ocorrência de choque séptico e parada cárdio-respiratória e a menor ocorrência de pneumonia identificada no presente estudo correspondem a fatores que podem em parte justificar a ausência de sucesso, em comparação ao prévio estudo ${ }^{24}$. 
6. Consideraesões Finais 


\section{1 - Limitações do estudo}

As limitações do estudo incluem: 1) Tamanho da amostra. Embora o número de pacientes tenha sido baixo, o cálculo amostral foi realizado apoiado em instrumentação estatística apropriada. 2) O estudo não foi cego. As intervenções adotadas não permitiram que o estudo fosse cego. 3) Ausência de grupo controle. Motivos éticos justificam a não inclusão de um grupo de pacientes sem intervenção fisioterapêutica. 4) Não randomização. O uso do método randomizado não foi possível, pois o número de admissões era insuficiente para realizar um sorteio. Para contornar esta limitação, utilizamos o processo de sistematização para a alocação dos pacientes.

Considerando essas limitações, nós concluímos que este pequeno prospectivo e sistematizado estudo desenvolvido em pacientes intubados e ventilados mecanicamente mostrou que não existe diferença entre as três diferentes manobras (compressão torácica e hiperinsuflação manual, e a associação de ambas) aplicadas duas vezes ao dia durante cinco dias em relação ao período de ventilação mecânica e ao tempo de internação. Embora a aplicação da técnica CT tenha sido associada à melhora significante do índice APACHE-II do momento final, de modo geral o estudo mostrou ausência de superioridade de qualquer das três manobras em relação à oxigenação pulmonar e à extensão de lesão pulmonar. Em conjunto, esses resultados podem indicar que tanto a etapa CT como a HM foram importantes para explicar os benefícios identificados em nosso prévio trabalho, embora não tenhamos utilizado um grupo controle no presente estudo. Não foram observados efeitos clínicos adversos importantes das manobras em relação à mecânica respiratória e saturação periférica de oxigênio em nenhum dos grupos no decorrer do estudo. Contudo, as manobras HM e $\mathrm{CT}+\mathrm{HM}$ resultaram em repercussões hemodinâmicas. Embora clinicamente irrelevantes, as alterações verificadas no grupo HM foram mais importantes do que no CT+HM, uma vez que os aumentos da FC identificados no grupo HM não foram suficientes para evitar a redução da PAM. Futuros estudos clínicos, controlados utilizando um maior número de pacientes, serão de grande importância para confirmar os resultados identificados no presente estudo. Entretanto, nosso estudo representa uma contribuição para o conhecimento vigente sobre a relevância clínica da fisioterapia respiratória em pacientes mecanicamente ventilados. 
7. Referêneias Bibliográfieas 
1. Konrad F, Schreiber T, Brecht-Kraus D, Georgieff M. Mucociliary transport in ICU patients. Chest. 1994;105:237-41.

2. Berney S, Denehy L, Pretto J. Head-down tilt and manual hyperinflation enhance sputum clearance in patients who are intubated and ventilated. Aust J Physiother. 2004;50: 9-14.

3. Bowton DL. Nosocomial pneumonia in the ICU-year 2000 and beyond. Chest. $1999 ; 115: 28 \mathrm{~S}-33 \mathrm{~S}$.

4. Ntoumenopoulos G, Presneill JJ, McElholum M, Cade JF. Chest physiotherapy for the prevention of ventilator-associated pneumonia. Intensive Care Med. 2002;28:850-6.

5. Mackenzie CF, Shin B, Hadi F, Imle PC. Changes in total lung/thorax compliance following chest physiotherapy. Anesth Analg. 1980;59:207-10.

6. Hodgson C, Denehy L, Ntoumenopoulos G, Santamaria J, Carroll S. An investigation of the early effects of manual lung hyperinflation in critically ill patients. Anaesth Intensive Care. 2000;28:255-61.

7. Mackenzie CF, Shin B, McAslan TC. Chest physiotherapy: the effects on arterial oxygenation. Anesth Analg. 1978;57:28-30.

8. Stiller K, Geake T, Taylor J, Grant R, Hall B. Acute lobar atelectasis. A comparison of two chest physiotherapy regimens. Chest. 1990;98:1336-40.

9. Velloso M. Fisioterapia respiratória - aspectos do atendimento hospitalar, ambulatorial e home care. In: Atualização e reciclagem em pneumologia. São Paulo: Vivali; 2001. v. IV.

10. Gallon A. The use of percussion. Physiotherapy. 1992;78:85-9.

11. Raoof S, Chowdhrey N, Raoof S, Feuerman M, King A, Sriraman R, et al. Effect of combined kinetic therapy and percussion therapy on the resolution of atelectasis in critically ill patients. Chest. 1999;115:1658-66. 
12. Windsor HM, Harrison GA, Nicholson TJ. Bag Squeezing: a physiotherapeutic technique. Med J Aust. 1972;2:829-32.

13. Stiller K. Physiotherapy in intensive care: towards an evidence-based practice. Chest. 2000;118:1801-13.

14. Consenso de Lyon. As pressões manuais torácicas e abdominais que visam a remoção de secreções brônquicas no adulto. In: Proceedings da I Conferência de Consenso em Fisioterapia Respiratória; 1994 dez 2-3; Lyon.

15. Denehy L. The use of manual hyperinflation in airway clearance. Eur Respir J. 1999;14:958-65.

16. Clement AJ, Hubsch SK. Chest physiotherapy by the "Bag Squeezing" method: a guide to technique. Physiotherapy. 1968;54:355-9.

17. Ntoumenopoupos G, Gild A, Cooper DJ. The effect of manual lung hyperinflation and postural drainage on pulmonary complications in mechanically ventilated trauma patients. Anaesth Intensive Care. 1998;26:492-96.

18. Maa SH, Hung TJ, Hsu KH, Hsieh Y, Wang KY, Wang $\mathrm{CH}$, et al. Manual hyperinflation improves alveolar recruitment in difficult-to-wean patients. Chest $2005 ; 128: 2714-21$.

19. Clarke RCN, Kelly BE, Convery PN, Fee JPH. Ventilatory characteristics in mechanically ventilated patients during manual hyperinflation for chest physiotherapy. Anaesthesia. 1999;54:936-40.

20. Paratz J, Lipman J, McAuliffe M. Effect of manual hyperinflation on hemodynamics, gas exchange, and respiratory mechanics in ventilated patients. J Intensive Care Med. $2002 ; 17: 317-24$. 
21. Choi JSP, Jones AYM. Effects of manual hyperinflation and suctioning on respiratory in mechanically ventilated patients with ventilator-associated pneumonia. Aust J Physiother. 2005;51:25-30.

22. Savian C, Paratz J, Davies A. Comparison of the effectiveness of manual and ventilator hyperinflation at different levels of positive end-expiratory pressure in artificially ventilated and intubated intensive care patients. Heart Lung. 2006;35:33441.

23. King D, Morrell A. A survey on manual hyperinflation as a physiotherapy technique in intensive care units. Physiotherapy. 1992;78:747-50.

24. Berti JSW, Tonon E, Berti HW, de Stefano LM, Gut AL, Reis RAS, et al. Manual hyperinflation combined with expiratory chest compression for reduction of stay length in critically ill patients on mechanical ventilation. Croatian Med J. In press.

25. Fórum de humanização, ética e qualidade: a busca de conceitos. In: I Congresso Nordestino de Medicina Intensiva; 1998 out 31; Maceió, AL.

26. Knauss WA, Draper EA, Wagner DP, Zimmerman JE. APACHE II: a severity of disease classification system. Crit Care Med. 1985;13:818-29.

27. Charlson ME, Pompei P, Ales KL, Mackenzie CR. A new method of classification of prognostic comorbidity for longitudinal studies: development and validation. J Chron Dis. $1987 ; 40: 373-83$.

28. Charlson M, Szatrowski TP, Peterson J, Gold J. Validation of a combined comorbidity index. J Clin Epidemiol. 1994;47:1245-51.

29. Murray JF, Matthay MA, Luce JM, Flick MR. An expanded definition of the adult respiratory distress syndrome. Am Rev Respir Dis. 1988;138:720-3.

30. Carvalho CRR. Controle do paciente em ventilação mecânica. In: Relatório do II Consenso Brasileiro de Ventilação Mecânica. Rio de Janeiro: Atheneu; 2000. 337-48. 
31. Rossi A, Gottfried SB, Zocchi L, Higgs BD, Lennox S, Calverley PM, et al. Measurement of static compliance of the total respiratory system in patients with acute respiratory failure during mechanical ventilation. The effect of intrinsic positive endexpiratory pressure. Am Rev Respir Dis. 1985;131:672-7.

32. Zin WA. Métodos e técnicas para a monitorização das propriedades elásticas e resistivas dos pulmões e da parede torácica na insuficiência respiratória aguda. J Pneumol. 1990;16: 91-6.

33. Ruiz VC, Oliveira LC, Christovan JC, Rugolo LMSS. Avaliação da complacência e resistência em pacientes entubados na unidade de terapia intensiva. Rev Bras Terap Intens. 1998;10:170-6.

34. Gottfried SB, Rossi A, Higgs BD, Calverley PM, Zocchi L, Bozic C, et al. Noninvasive determination of respiratory system mechanics during mechanical ventilation for acute respiratory failure. Am Rev Respir Dis. 1985;131:414-20.

35. Vieira SRR. Curvas de complacência ou curvas pressão-volume na insuficiência respiratória aguda. J Pneumol. 1999;25:335-9.

36. Broseghini C, Brandolese R, Poggi R, Polese G, Manzin E, Milic-Emili J, et al. Respiratory mechanics during the first day of mechanical ventilation in patients with pulmonary edema and chronic airway obstruction. Am Rev Respir Dis. 1988;138:35561.

37. Frisancho AR. Anthropometric standards for the assessment of growth and nutritional status. Ann Arbor: University of Michigan Press; 1993.

38. Caruso P, Denari S, Ruiz SAL, Demarzo SE, Deheinzelin D. Saline instillation before tracheal suctioning decreases the incidence of ventilator-associated pneumonia. Crit Care Med. 2009;37:32-8. 
39. Goodman LA. Simultaneous confidence intervals for contrasts among multinomial populations. Ann Math Stat. 1964;35:716-25.

40. Goodman LA. On simultaneous confidence intervals for multinomial proportions. Technometrics. 1965;7:247-54.

41. Zar JH. Biostatistical analysis. $4^{\text {th }}$ ed. New Jersey: Practice-Hall; 1999.

42. Matsui M, Sampaio E, Gut L, Padovani CR, Matsubara LS, Ferreira ALA. Identificação das variáveis associadas à mortalidade de pacientes internados em unidade de terapia intensiva adulto [dissertação]. Botucatu: Faculdade de Medicina, Universidade Estadual Paulista; 2008.

43. Stiller K, Jenkins S, Grant R, Geake T, Taylor J, Hall B. Acute lobar atelectasis: a comparison of five physiotherapy regimens. Physiother Theory Pract. 1996;12:197209.

44. Stone KS, Vorst EC, Lanham B, Zahn S. Effects of lung hyperinflation on mean arterial pressure and postsuctioning hypoxemia. Heart Lung. 1989;18:377-85.

45. Singer M, Vermaat J, Hall G, Latter G, Patel M. Hemodynamic effects of manual hyperinflation in critically ill mechanically ventilated patients. Chest. 1994;106:11827.

46. Wong DT, Gomez M, McGuire GP, Kavanagh BMB. Utilization of intensive care days in a Canadian medical-surgical intensive care unit. Crit Care Med. 1999;27:131924.

47. Feijó CAR, Leite Júnior FO, Martins ACS, Furtado Júnior AH, Cruz LLS, Meneses FA. Gravidade dos pacientes admitidos à unidade de terapia intensiva de um hospital universitário brasileiro. Rev Bras Ter Intens. 2006;18:18-21. 
48. Paiva SAR. Análise de uma população de doentes atendidos em unidade de terapia intensiva - estudo observacional de sete anos (1992 - 1999). Rev Bras Ter Intens. $2002 ; 14: 73-80$.

49. Berney S, Denehy L. The effect of physiotherapy treatment on oxygen consumption and haemodynamics in patients who are critically ill. Aust J Physiother. 2003;49:99105.

50. World Health Organization. Obesity: preventing and managing the global epidemic. Report of a WHO consultation of obesity. Geneva: WHO; 1997.

51. Dumont L, Mattys M, Mardirosoff C, Vervloesem N, Allé JL, Massaut J. Changes in pulmonary mechanics during laparoscopic gastroplasty in morbidly obese patients. Acta Anaesthesiol Scand. 1997;41:408-13.

52. Auler JOC, Miyoshi E, Fernandes CR, Benseñor FE, Elias L, Bonassa J. The effects of abdominal opening on respiratory mechanics during general anesthesia in normal and morbidly obese patients: a comparative study. Anesth Analg. 2002;94:741-8.

53. Sancho J, Severa E, Marin J, Vergara P, Belda FJ, Bach JR. Effect of lung mechanics on mechanically assisted flows and volumes. Am J Phys Med Rehabil. 2004;83:698703.

54. Kollef MH, Levy NT, Ahrens TS, Schaiff RP, Prentice D, Sherman G. The use of continuous IV sedation is associated with prolongation of mechanical ventilation. Chest. 1998;114:541-8.

55. Brook AD, Ahrens TS, Schaiff RP, Prentice D, Sherman G, Shannon W, et al. Effect of a nursing-implemented sedation protocol on the duration of mechanical ventilation. Crit Care Med. 1999;27:2609-15. 
56. Kress JP, Pohlman AS, O’Connor MF, Hall JB. Daily interruption of sedative infusions in critically ill patients undergoing mechanical ventilation. N Engl J Med. 2000;342:1471-7.

57. Schweickert WD, Gehlbach BK, Pohlman AS, Hall JB, Kress JP. Daily interruption of sedative infusions and complications of critical illness in mechanically ventilated patients. Crit Care Med. 2004;32:1272-6.

58. Girard TD, Kress JP, Fuchs BD, Thomason JWW, Schweickert WD, Pun BT, et al. Efficacy and safety of a paired sedation and ventilator weaning protocol for mechanically ventilated patients in intensive care (Awakening and Breathing Controlled trial): a randomised controlled trial. Lancet. 2008;371:126-34.

59. Riker RR, Shehabi Y, Bokesch PM, Ceraso D, Wisemandle W, Koura F, et al. Dexmedetomidine vs Midazolam for sedation of critically ill patients: a randomized trial. JAMA. 2009;301:489-99.

60. Wehler M, Martus P, Geise A, Bost A, Mueller A, Hahn EG, et al. Changes in quality of life medical intensive care. J Intensive Care Med. 2001;27:154-9.

61. Torres A, Aznar R, Gatell Jm. Incidence, risk, and prognosis factors of nosocomial pneumonia in mechanically ventilated patients. Am Rev Respir Dis. 1990;142:523-8.

62. Nachtigall I, Tamarkin A, Tafelski S, Deja M, Halle E, Gastmeier P, et al. Impact of adherence to standard operating procedures for pneumonia on outcome of intensive care unit patients. Crit Care Méd. 2009;37:159-66.

63. Silva E, Pedro MA, Sogayar ACB, Mohovic T, Silva CLO, Janiszewski M, et al. Brazilian sepsis epidemiológica study (BASES study). Crit Care. 2004;8:R251-60.

64. Dellinger RP, Levy MM, Carlet JM, Bion J, Parker MM, Jaeschke R, et al. Surviving sepsis campaign: international guidelines for management of severe sepsis ans septic shock. Intensive Care Med. 2008;34:17-60. 
65. Dichtwald S, Matot I, Einav S. Improving the outcome of in-hospital cardiac arrest: the importance of being EARNEST. Semin Cardiothorac Vasc Anesth. 2009; 13: 1930.

66. Carr BG, Kahn JM, Merchant RM, Kramer AA, Neumar RW. Inter-hospital variability in post-cardiac arrest mortality. Resuscitation. 2009; 80: 30-4. 
8. Apêndieess 


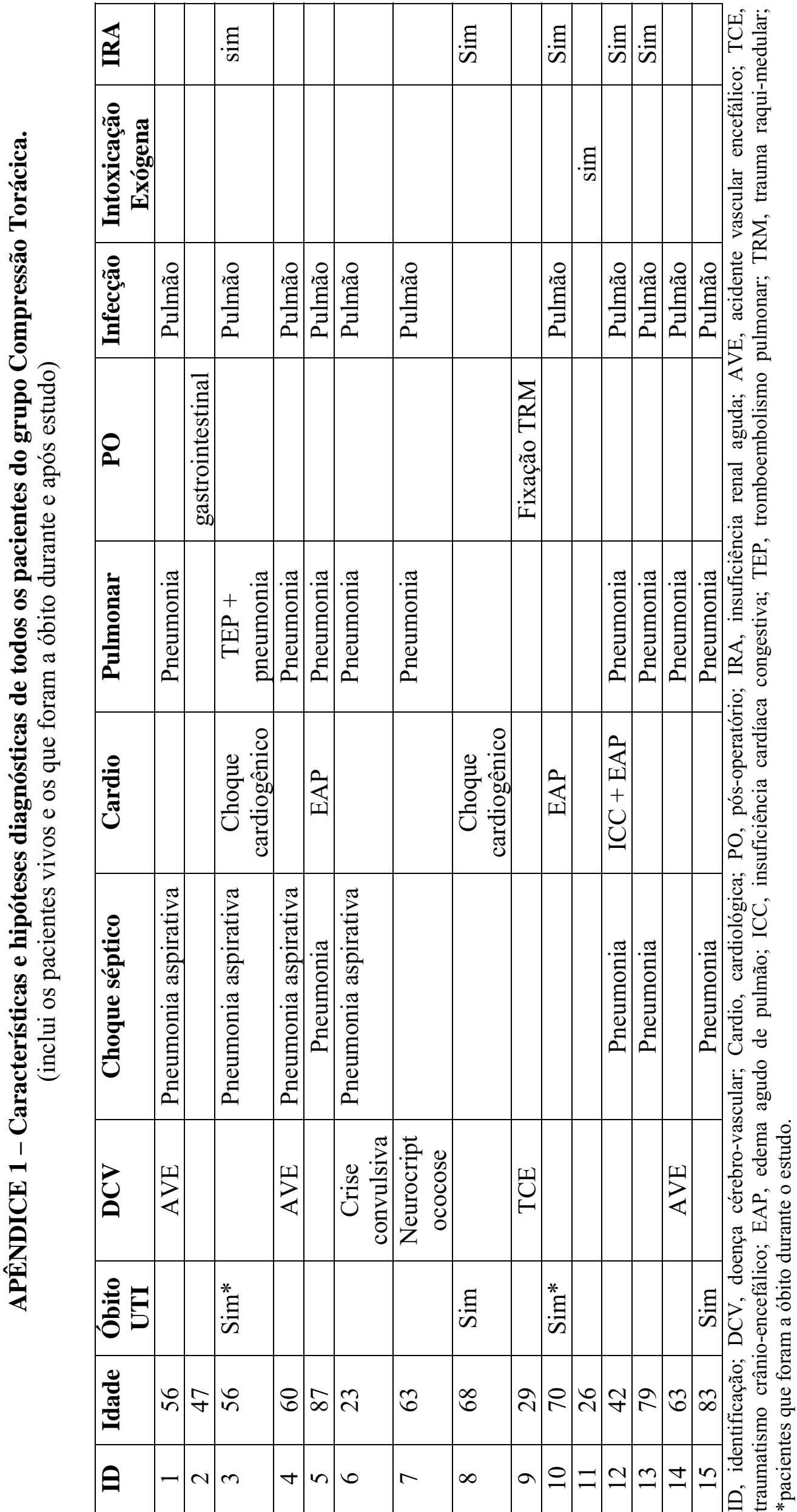




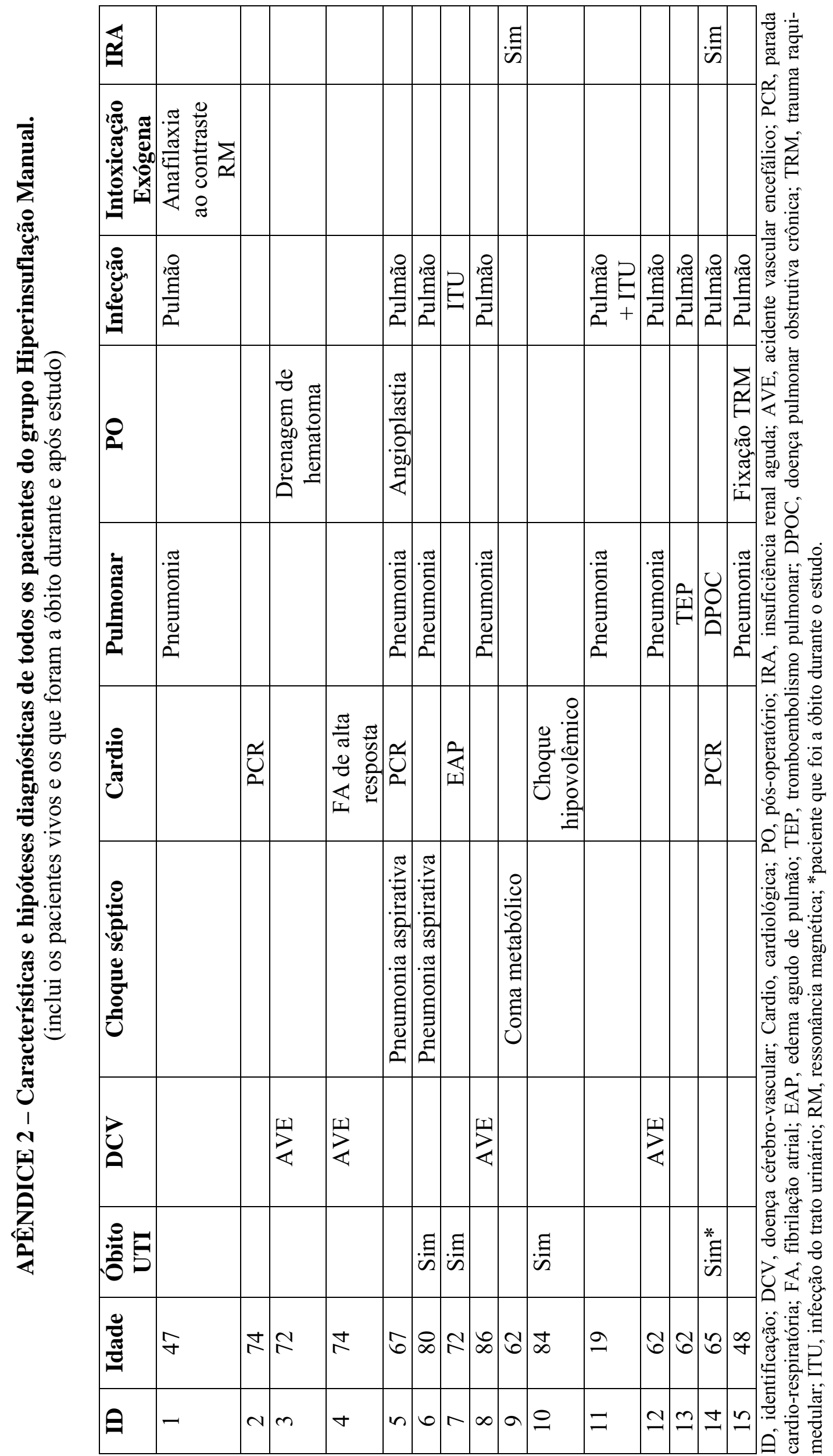




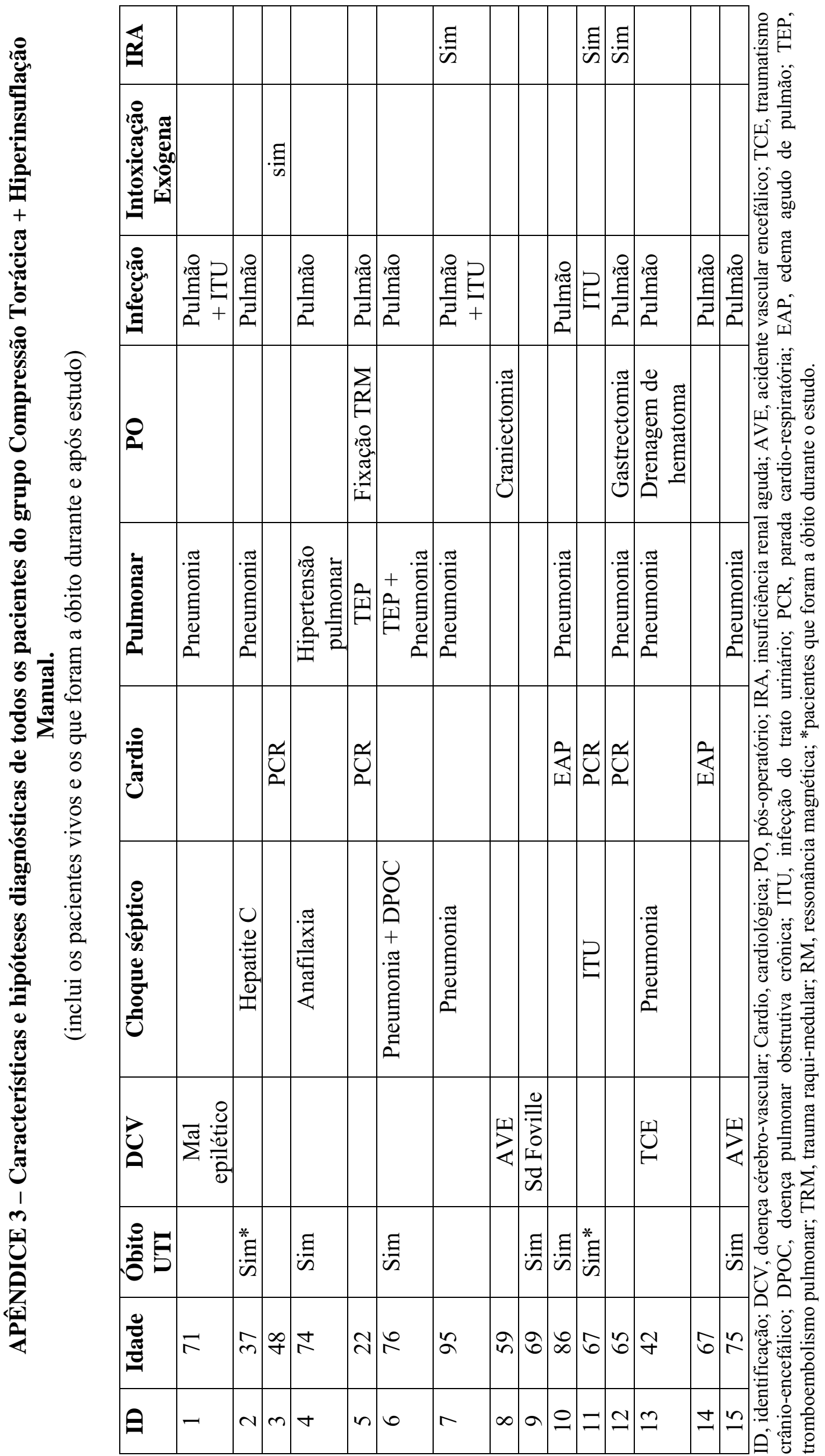




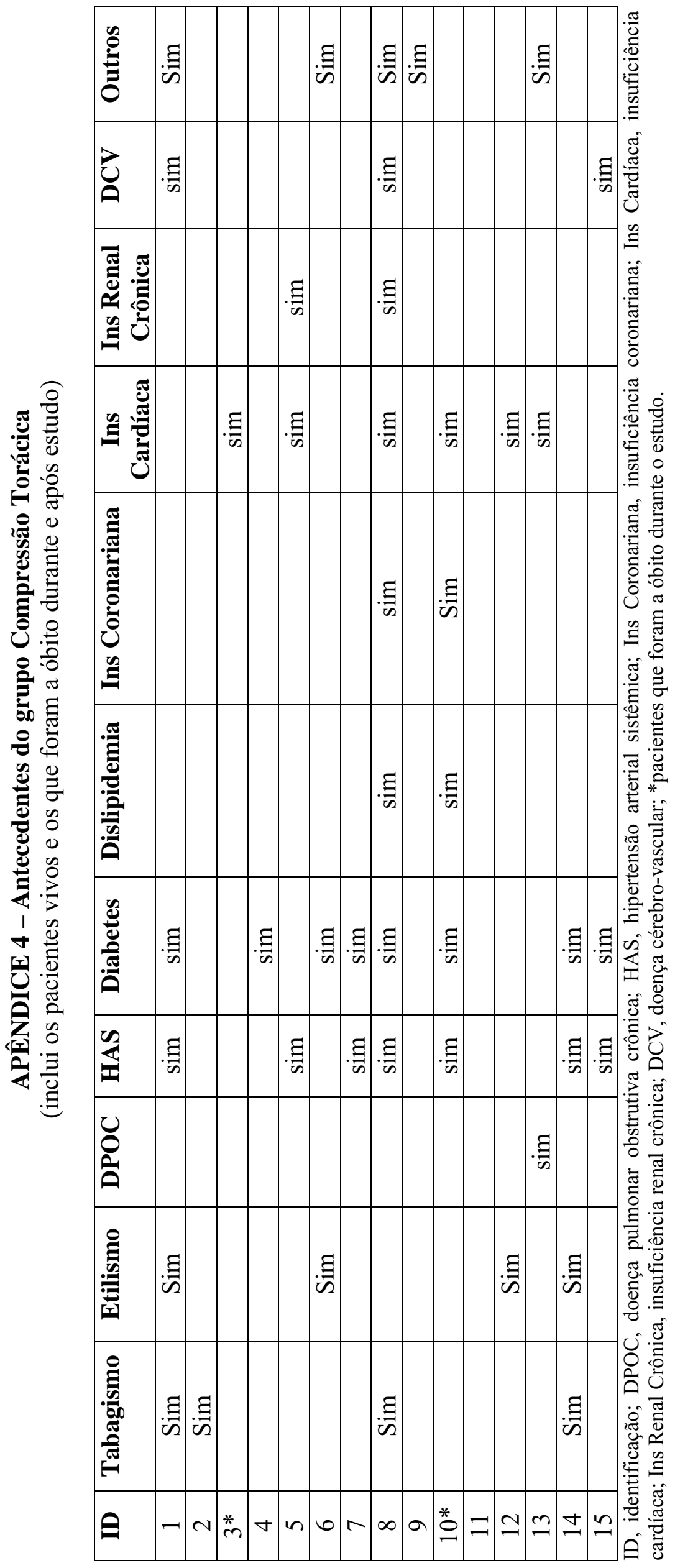









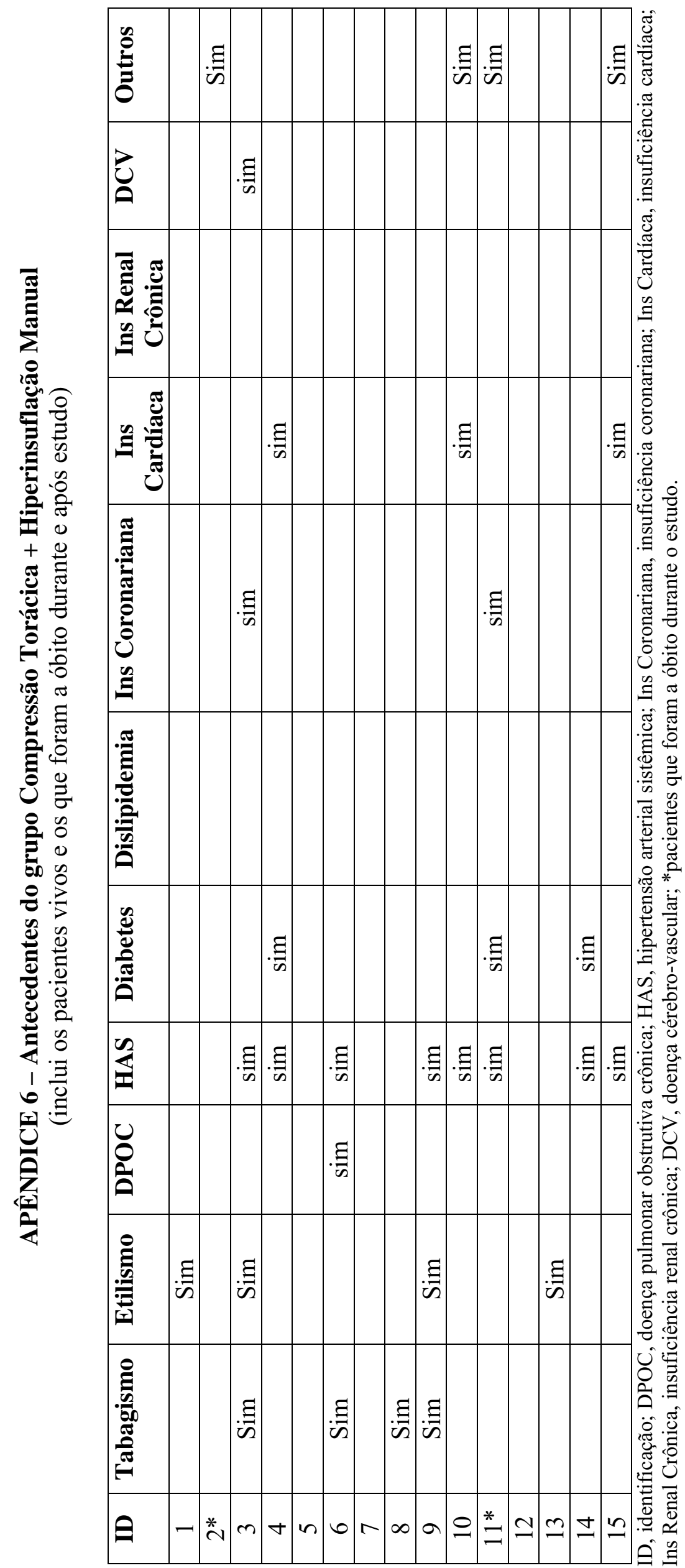




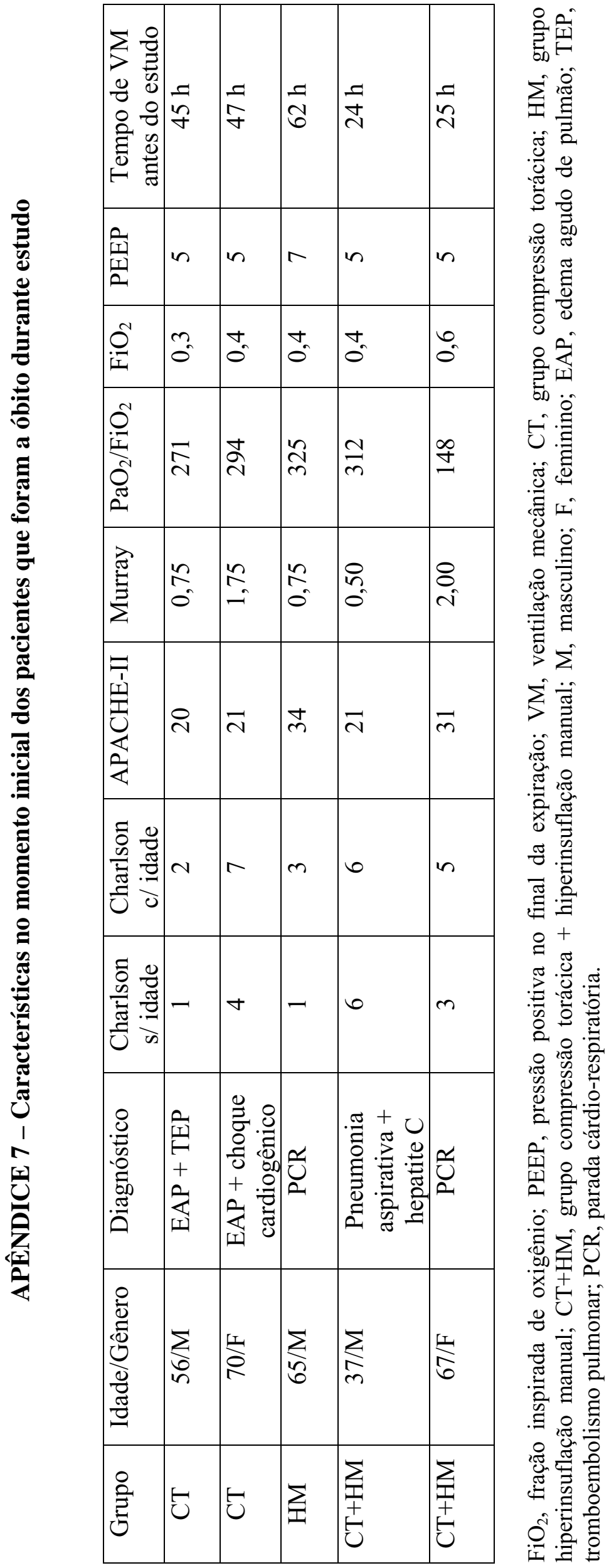


APÊNDICE 8 - Sobrevida atuarial de pacientes de UTI submetidos a diferentes manobras de fisioterapia respiratória durante o período de estudo.

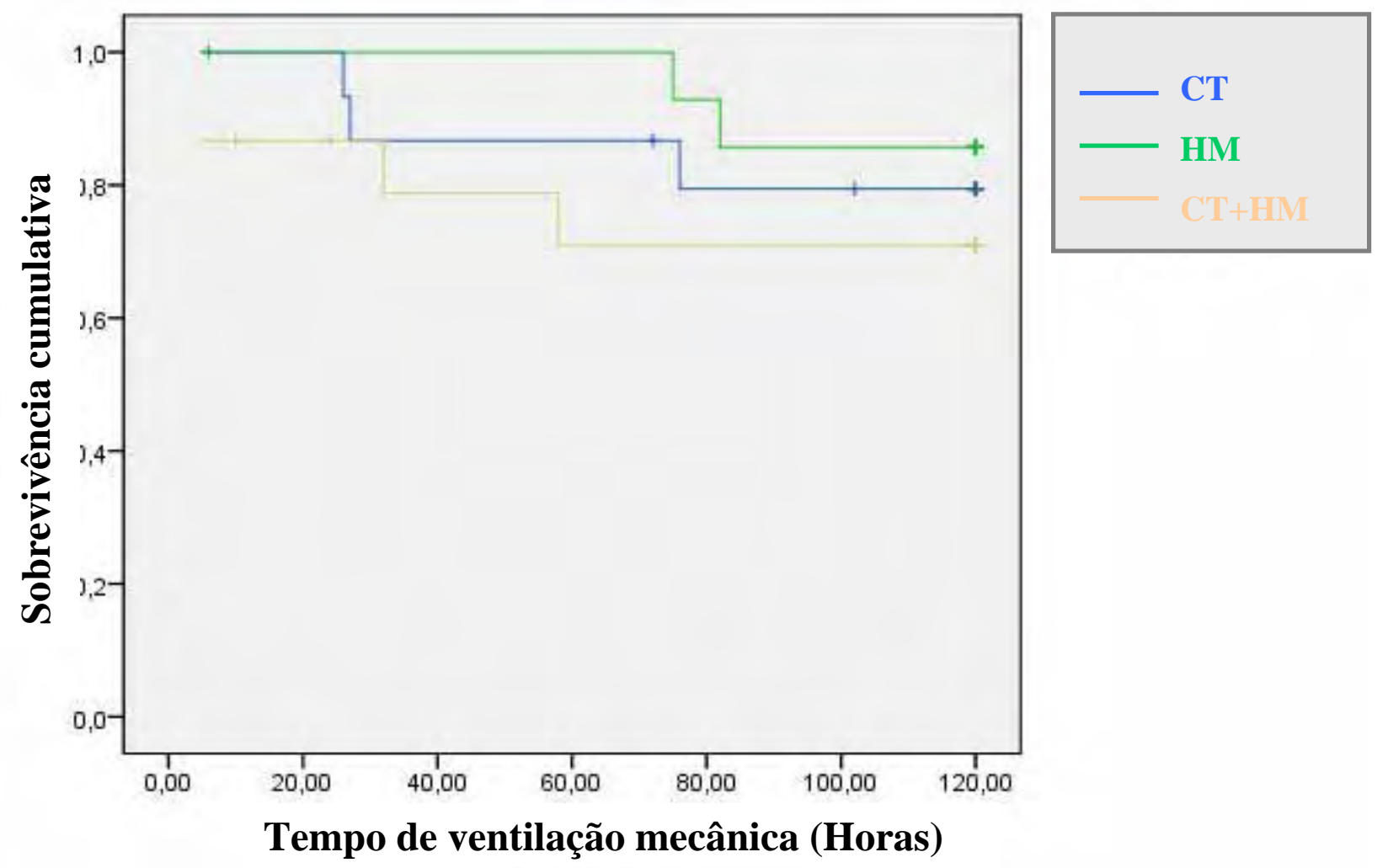


APÊNDICE 9 - Sobrevida atuarial de pacientes de UTI submetidos a diferentes manobras de fisioterapia respiratória durante o tempo de permanência hospitalar.

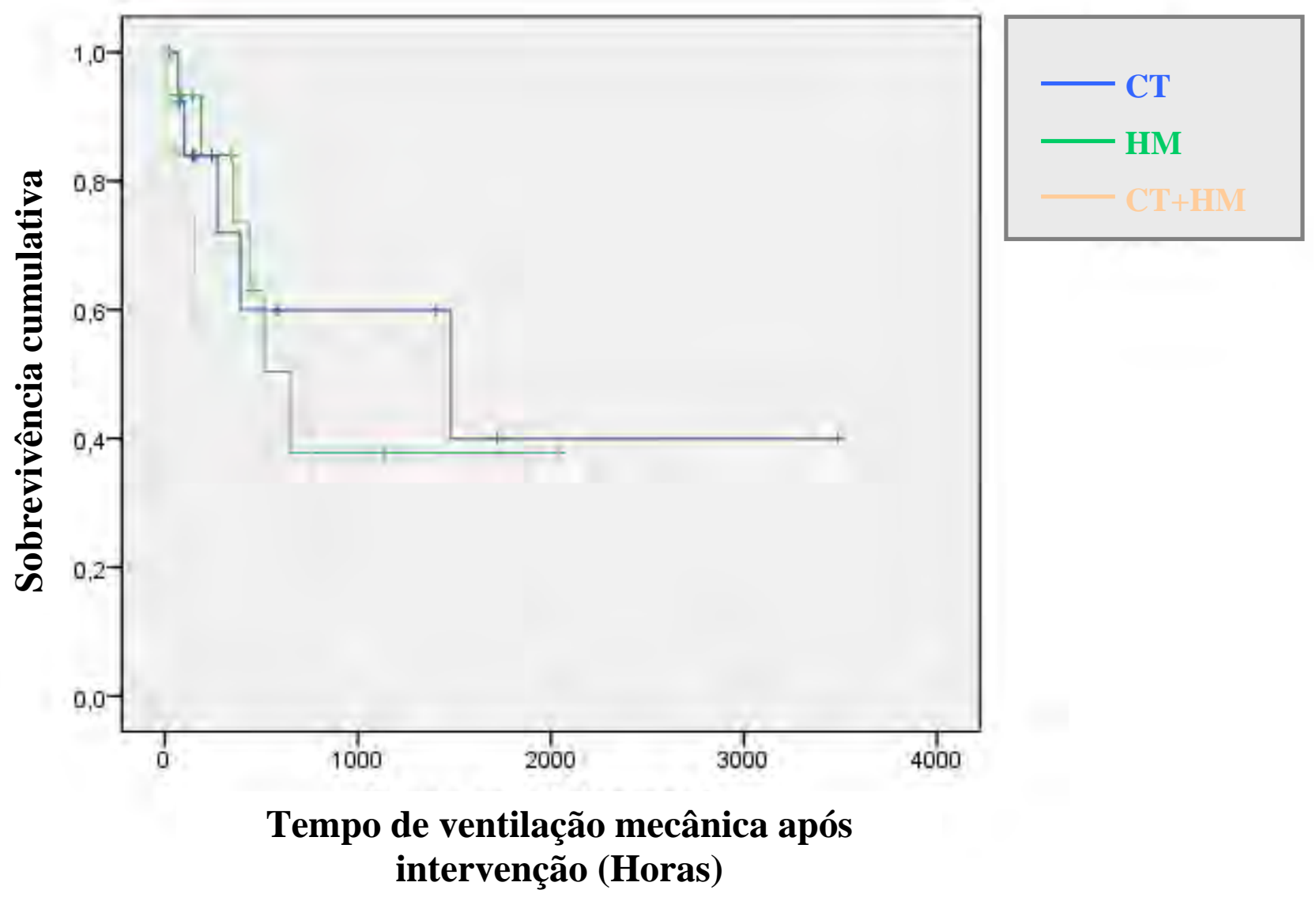




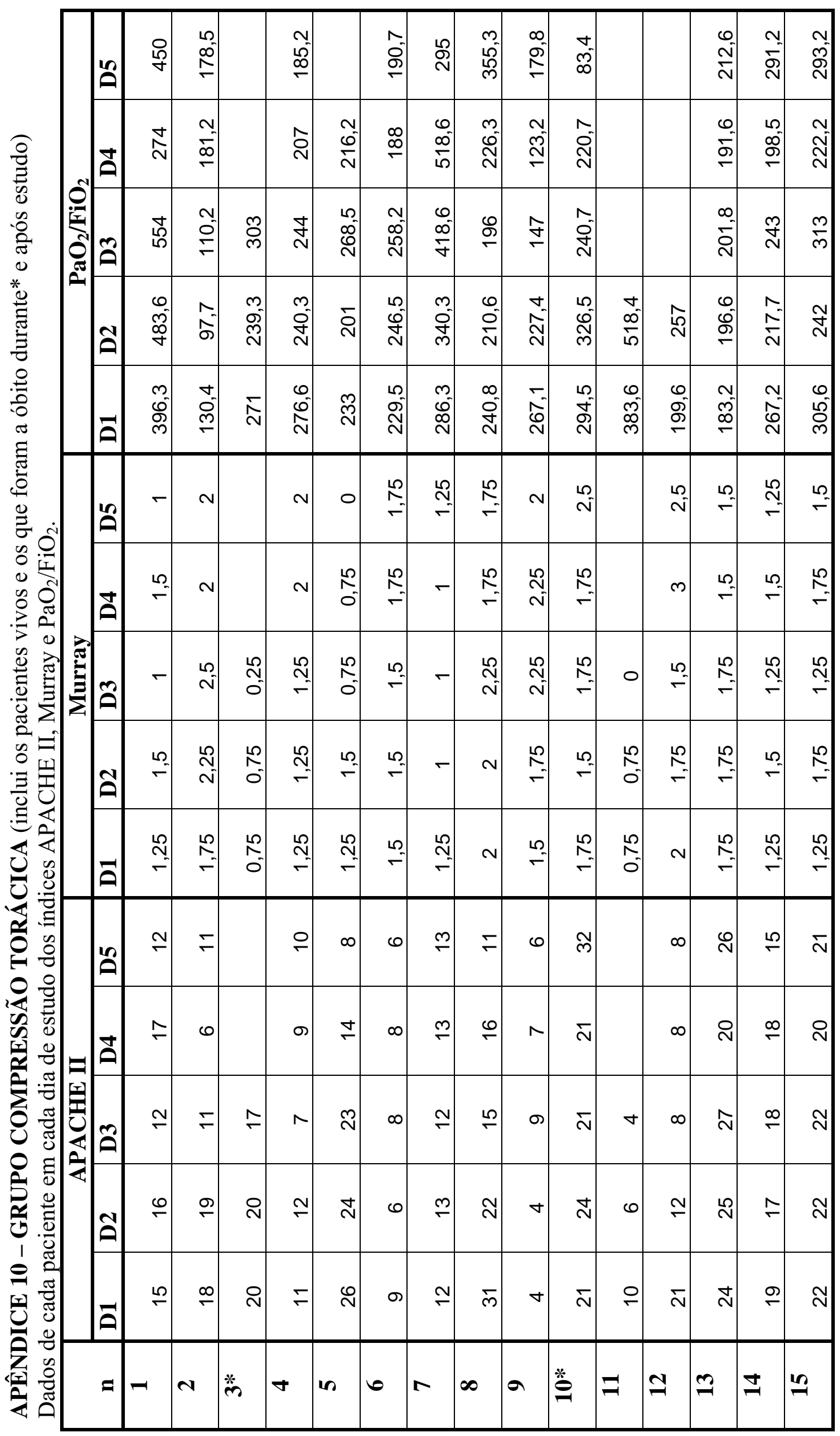




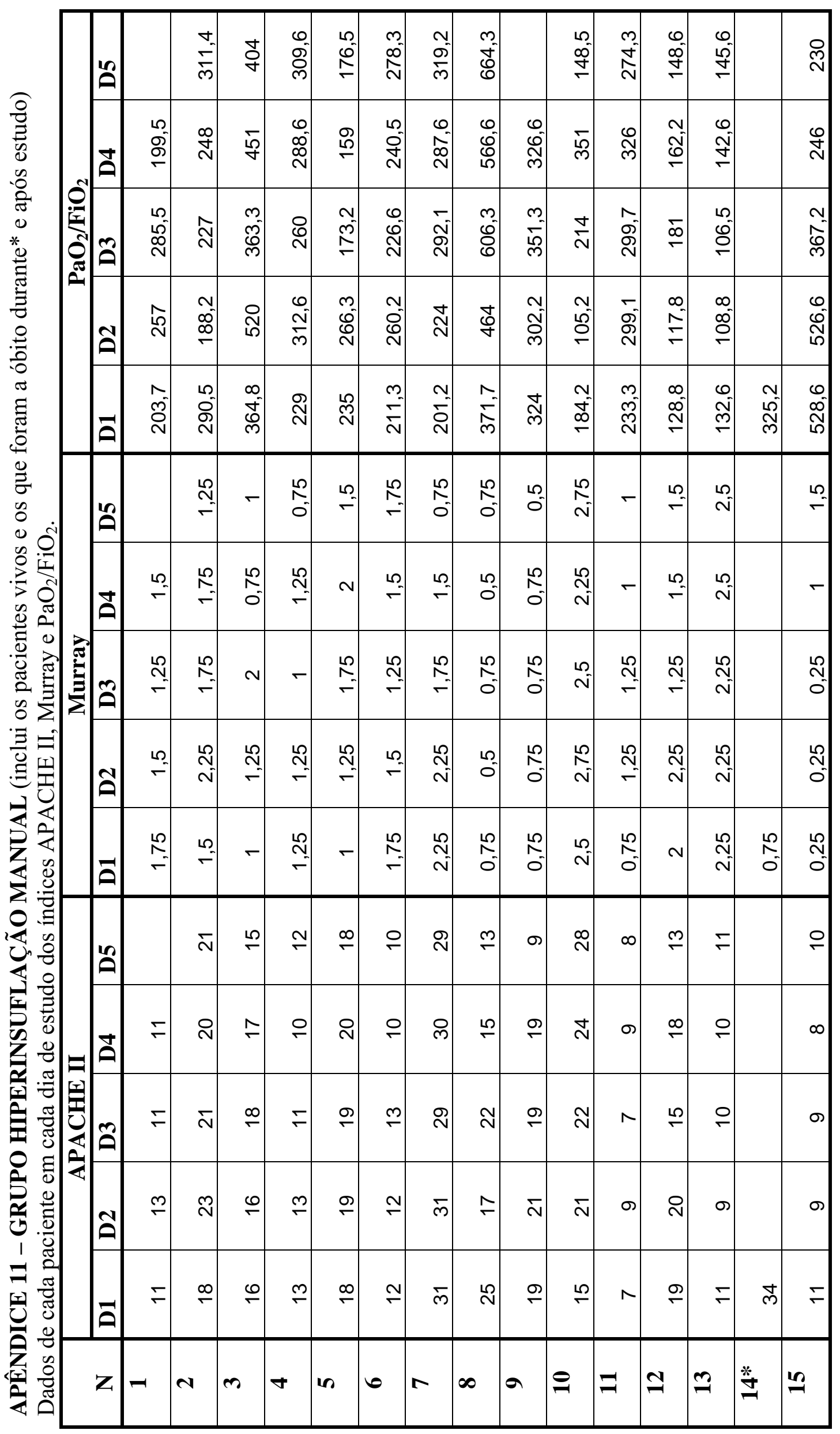




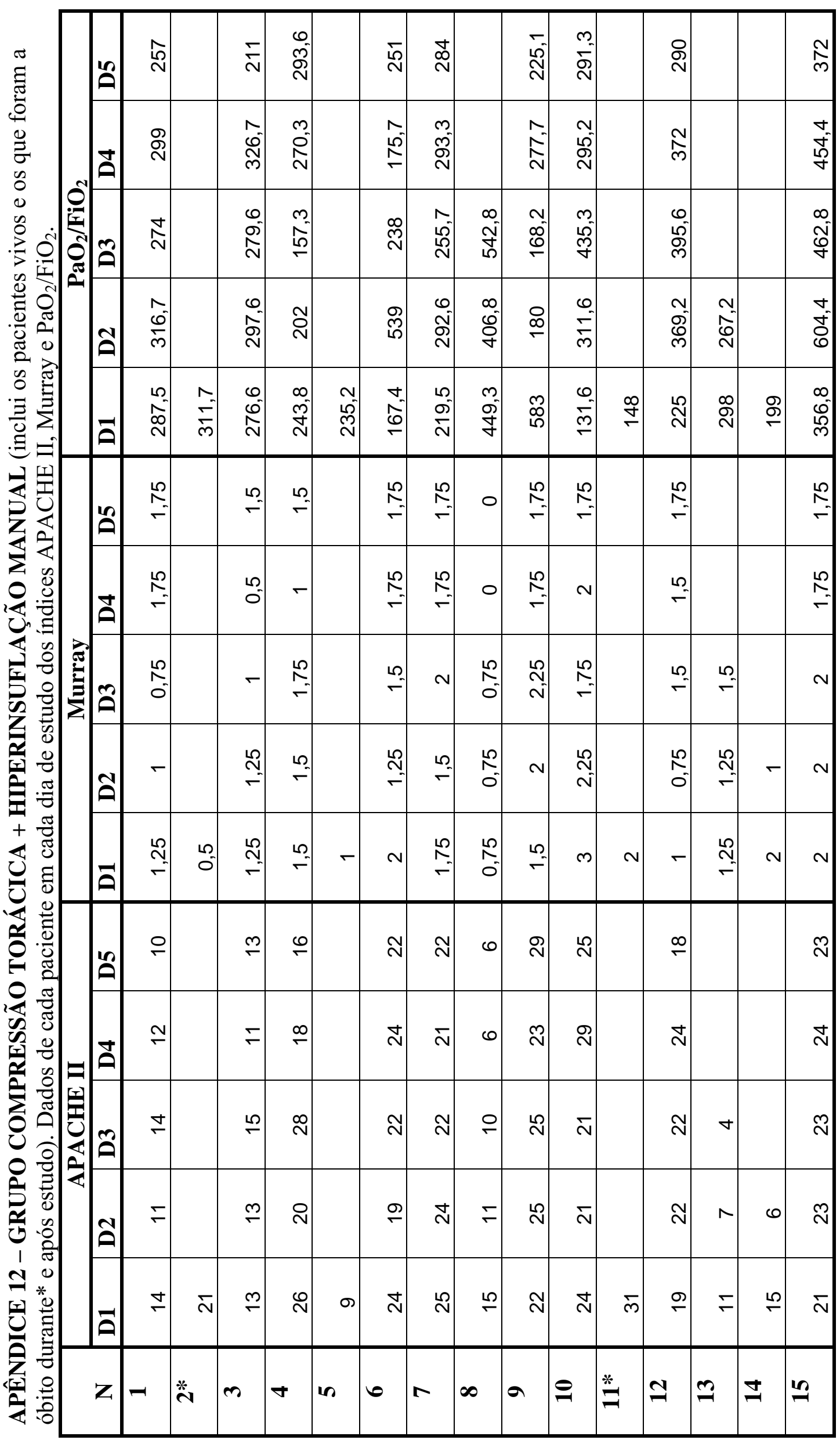




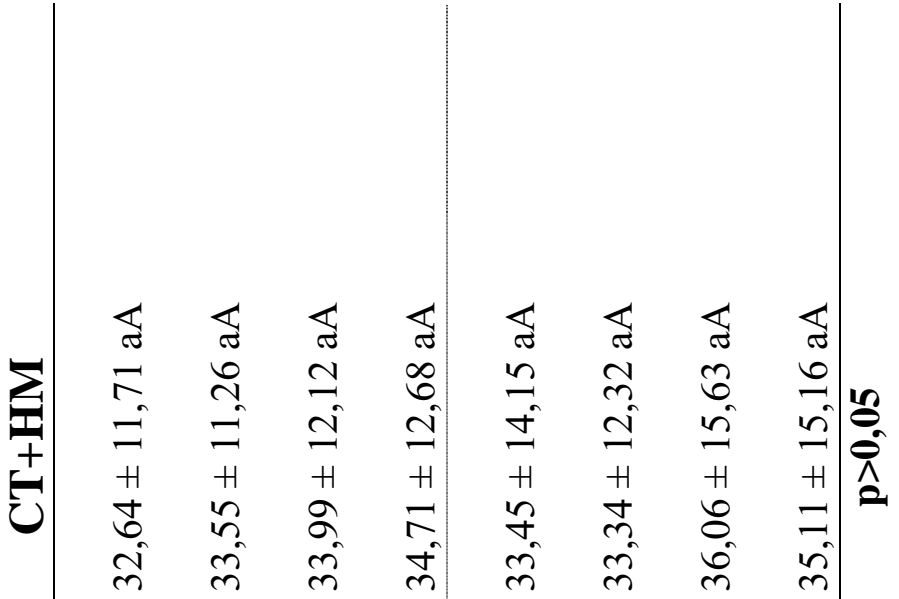

电记

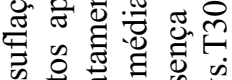



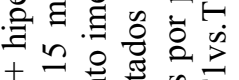

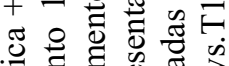

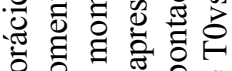
워

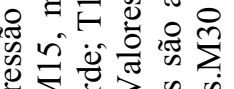



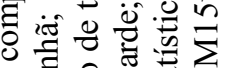

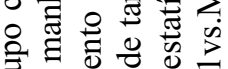

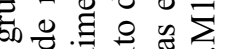

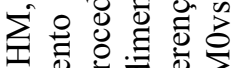

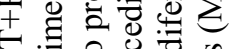

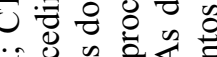

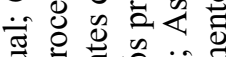

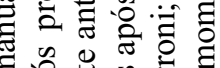

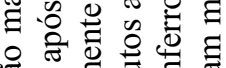

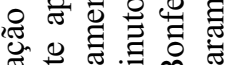

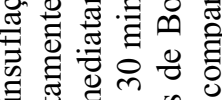

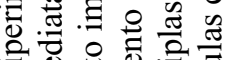

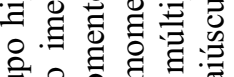

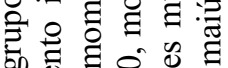

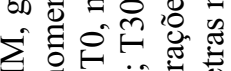
在

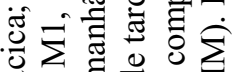

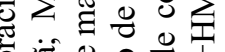

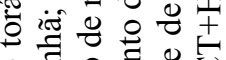

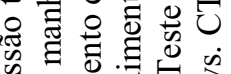
0 : 7 능

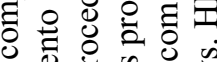
․․ㄹ.

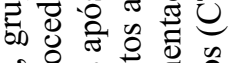

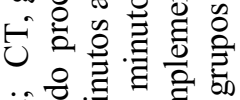

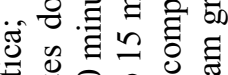

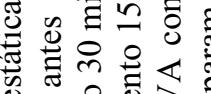

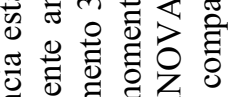
ए 氖 向




용 iี 롤

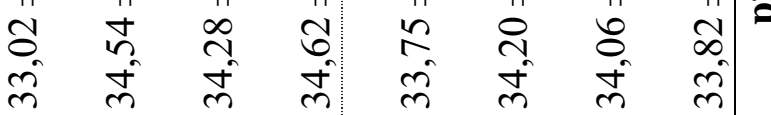

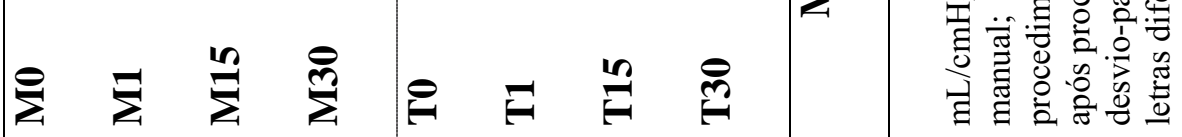




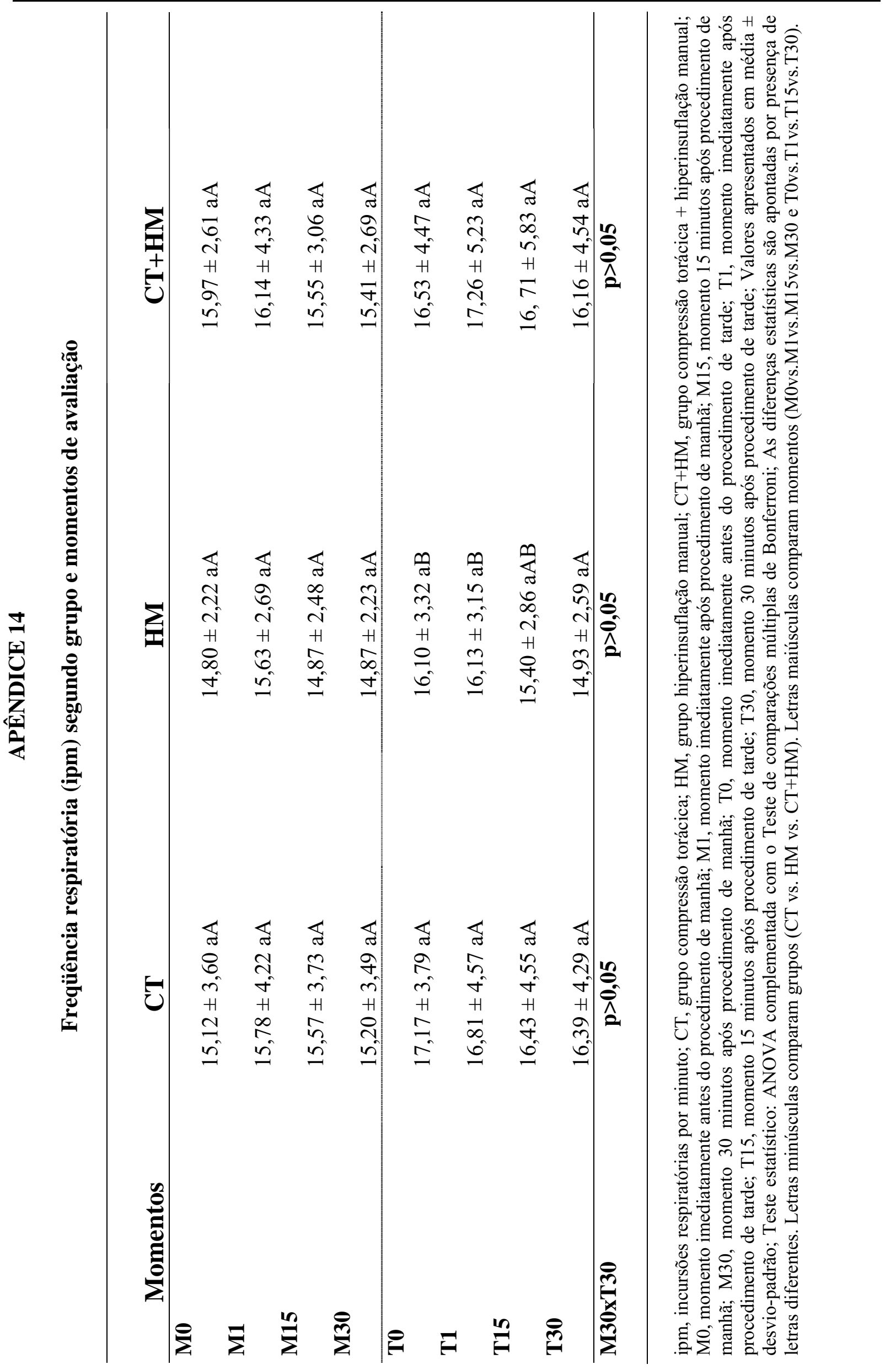




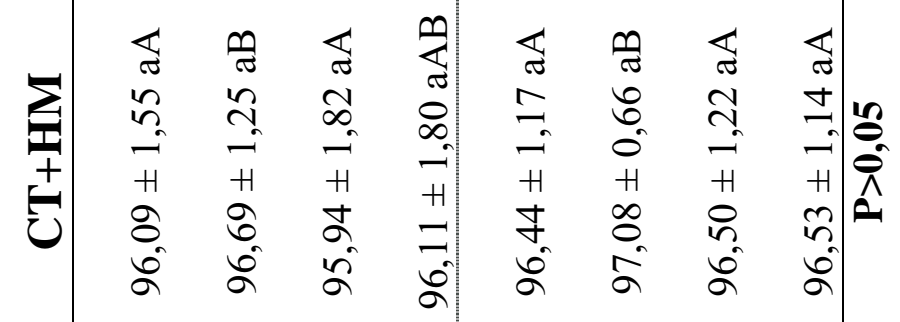

$+n$ 윰율

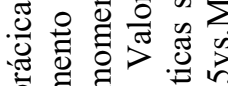

o 0 o

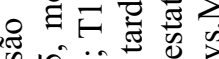

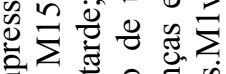

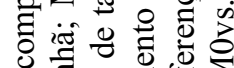

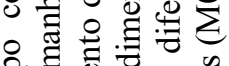

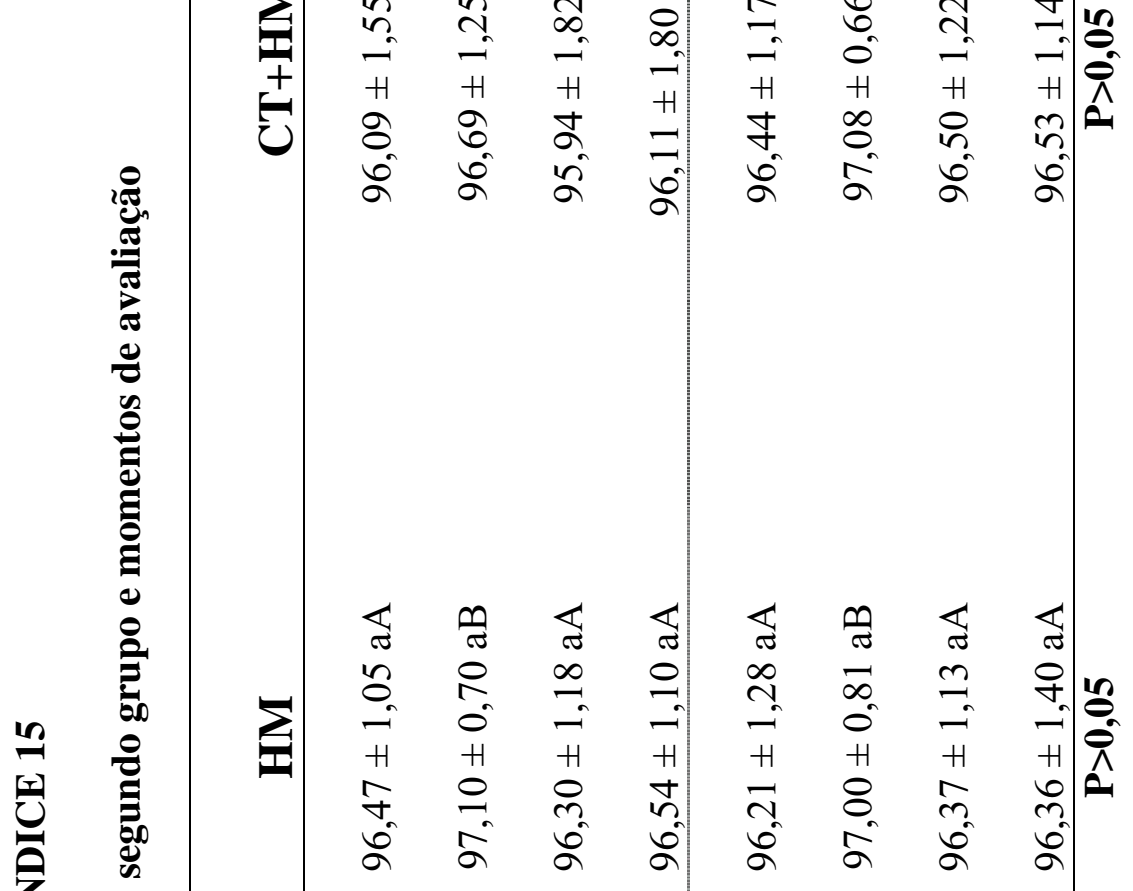

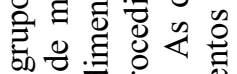

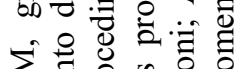

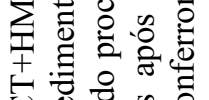

过 용



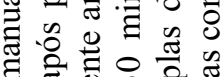

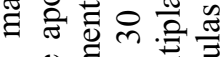

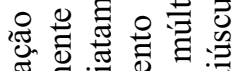

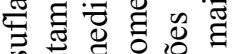

$\exists . \Xi \Xi \Xi$



응

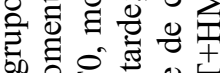

क力 0 无艺

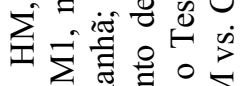

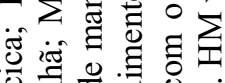

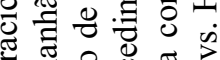

혀용 융

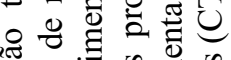

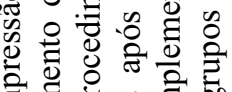

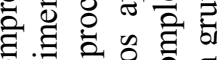

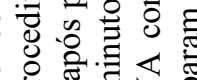

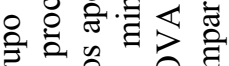

吉过造的完

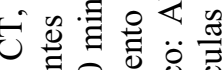

a 월

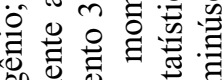

政的岕

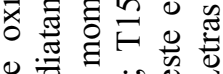

ช :

o.

牙 웜 8

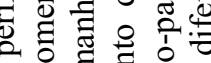

요 $\exists$ ह

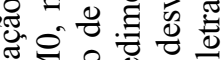

政过

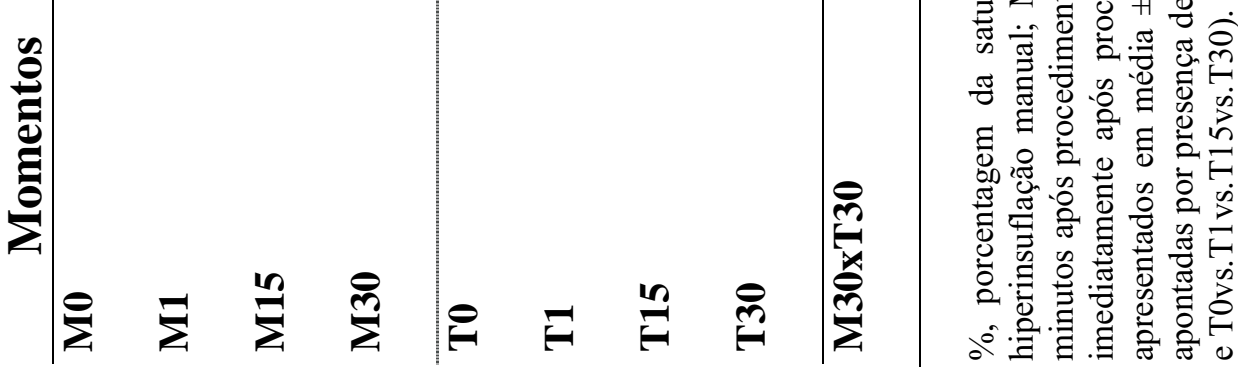

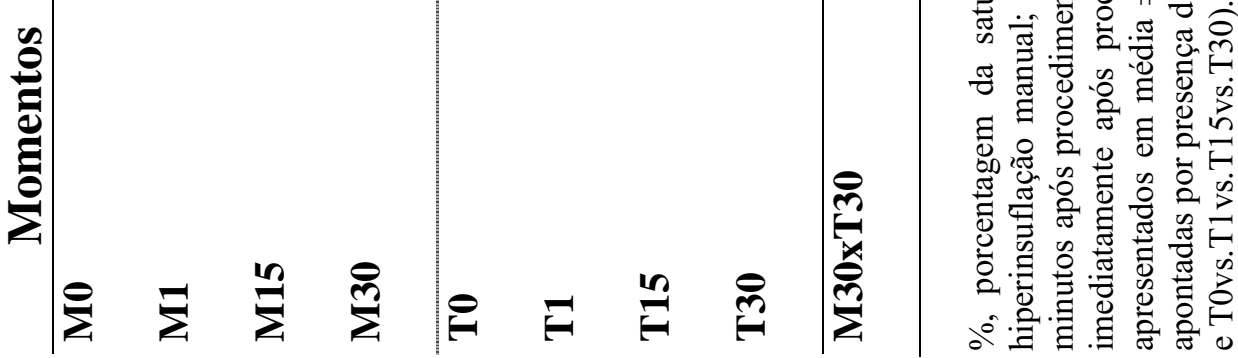




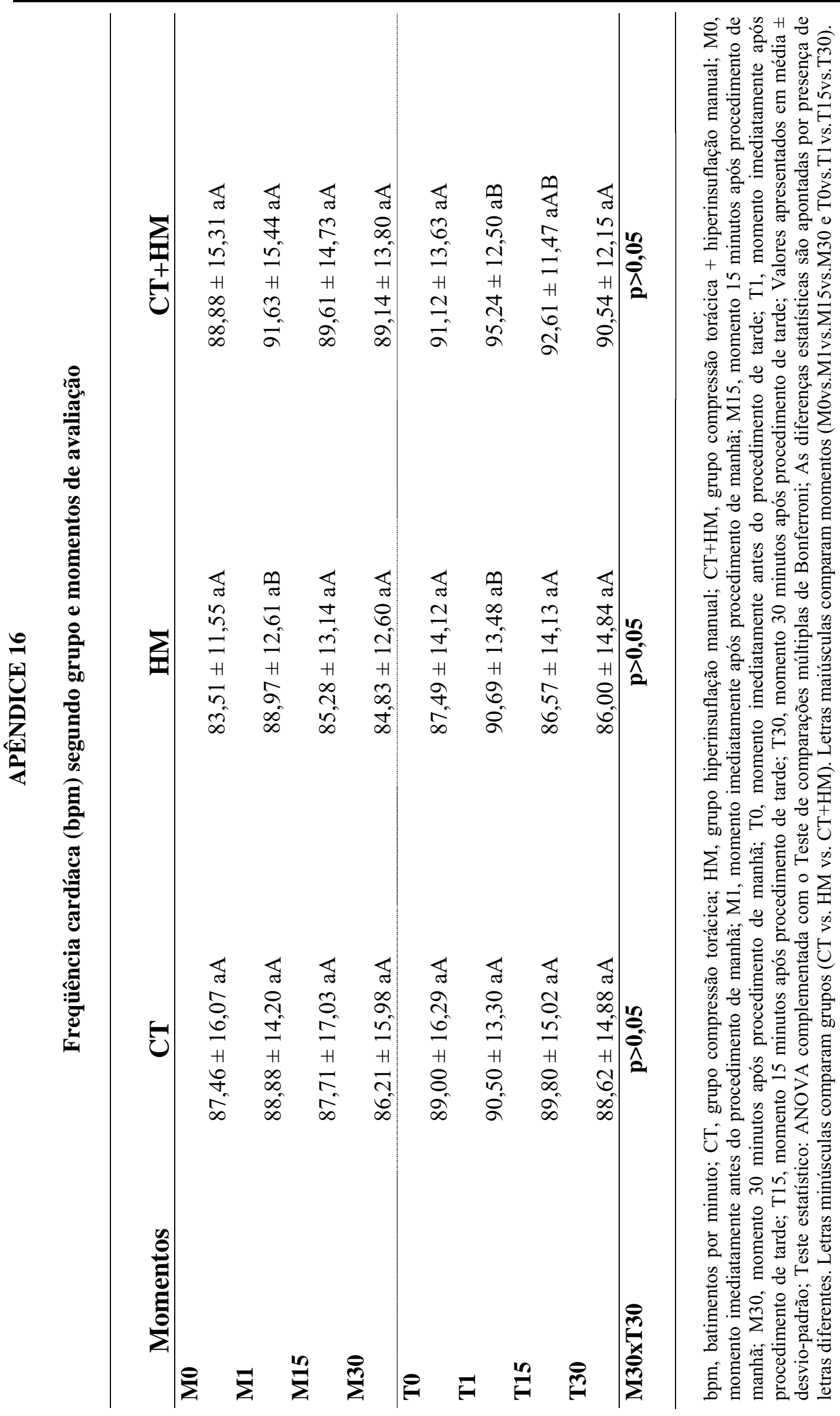




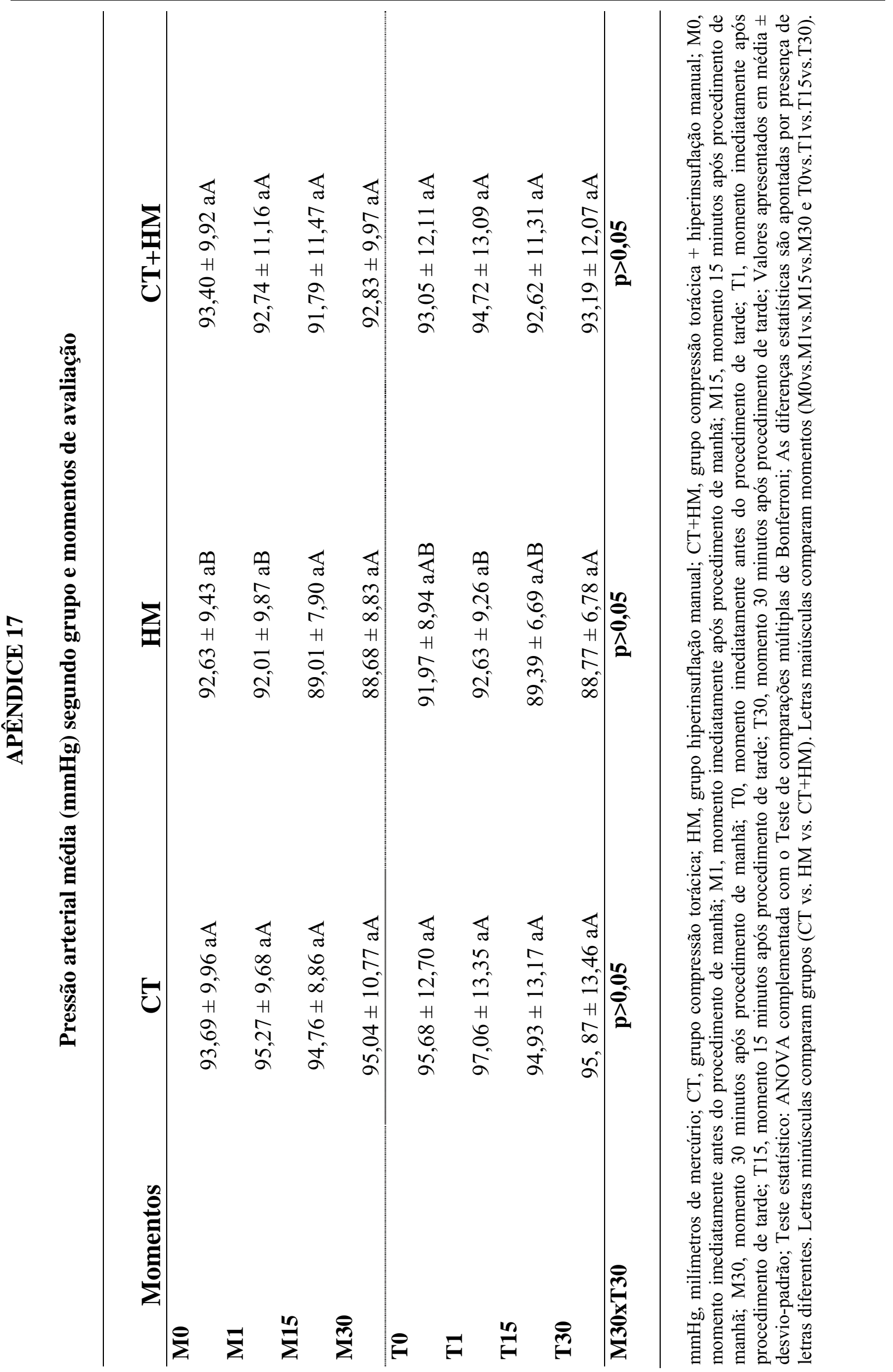




\section{APÊNDICE 18}

Resultados individuais do Índice de Charlson combinado com idade

\begin{tabular}{cccc}
\hline & \multicolumn{3}{c}{ Indice de Charlson } \\
\cline { 2 - 4 } n pacientes & CT & HM & CT+HM \\
\hline 1 & 7 & 0 & 4 \\
2 & 0 & 3 & $6^{\dagger}$ \\
3 & $2^{\dagger}$ & 6 & 2 \\
4 & 4 & 5 & 7 \\
5 & 8 & 4 & 0 \\
6 & 2 & 5 & 5 \\
7 & 5 & 12 & 5 \\
8 & 9 & 4 & 1 \\
9 & 0 & 5 & 3 \\
10 & $7^{\dagger}$ & 7 & 8 \\
11 & 0 & 1 & $5^{\dagger}$ \\
12 & 1 & 3 & 2 \\
13 & 5 & 6 & 0 \\
14 & 5 & $3^{\dagger}$ & 5 \\
15 & 8 & 0 & 5 \\
\hline
\end{tabular}

n, número de pacientes; grupo CT, grupo compressão torácica; grupo HM, grupo hiperinsuflação manual; grupo $\mathrm{CT}+\mathrm{HM}$, grupo compressão torácica + hiperinsuflação manual; ${ }^{\dagger}$, pacientes que foram a óbito durante o estudo. 
9. Anexos 


\section{ANEXO 1

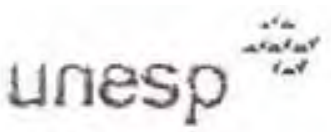 \\ Universidade Estadual Paulista Faculdade de Medicina de Botucatu}

Distrito Rubiåo Junior, $s / n^{\circ}$ - Botucatu - S.P.

CEP $18.618-970$

Fone/Fax: (0xx14) 3811-6143

e-mail secretaria: capellup(a)fmb unesp.br

Ilustrissima Senhora

Proff $f^{\prime \prime} r^{a}$ Ana Licia dos Anjos Ferreira

Departamento de Clinica Médica

Faculdade de Medicina de Botucalu

Prezada Dr"Ana Lícia,

De ordem da Senhora Coordenadora deste CEP informo que o Projeto de Pesquisa "Efeito da manobra de compressäo torúcica em pacientes sob ventilaçüo mecânica" a ser conduzialo por Elisiane Tonon, orientada por Vossa Senhoria, com a participação de Carlos Fernando Ronchi, recebeu do relator parecer favorável, aprovado em reunião de 04/12/2006. (cópia em anexo).

Siluaçăo do Projeto: APROVADO.

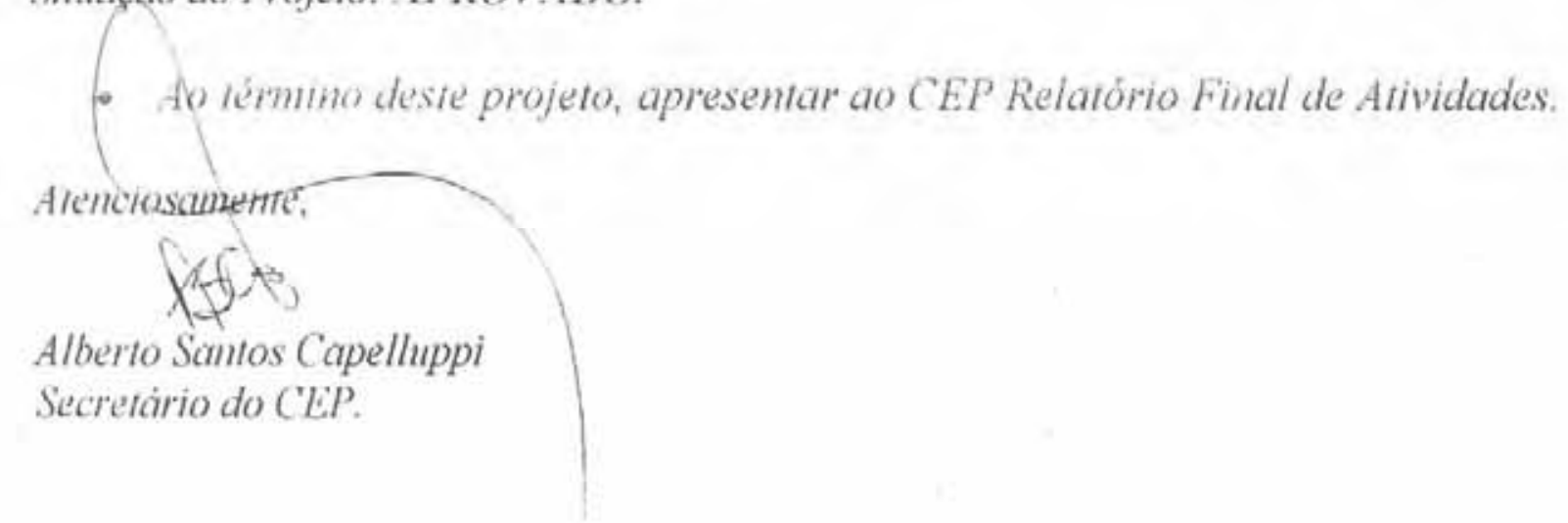




\section{ANEXO 2 \\ Termo de Consentimento Livre e Esclarecido (Paciente)}

Você está sendo convidado a participar voluntariamente de um estudo de pesquisa cujo título é: "Avaliação dos efeitos de diferentes manobras de Fisioterapia Respiratória no desfecho de pacientes ventilados mecanicamente". Neste estudo você será submetido a uma conduta fisioterápica por 5 dias: técnica de compressão torácica ou de hiperinsuflação manual, ou ambas.

Compressão torácica: "você será posicionado em decúbito dorsal (barriga para cima) e o fisioterapeuta com as mãos sobre seu tórax realizará uma compressão durante a expiração".

Hiperinsuflação manual: "você será posicionado em decúbito dorsal (barriga para cima) e o fisioterapeuta irá insuflar os pulmões lentamente com ambú e após realizará uma descompressão abrupta do ambú aumentando o fluxo expiratório".

Diante do exposto cabe a você decidir se pretende participar ou não deste estudo.

A proposta deste termo de consentimento é o de solicitar sua permissão para participar de um estudo cujos objetivos são: 1) verificar a eficácia da Fisioterapia Respiratória e quais seus benefícios para os pacientes internados na Unidade de Terapia Intensiva; 2) prestar assistência fisioterápica visando melhorar a qualidade de vida e reduzir o período de internação.

As informações obtidas a partir deste estudo, poderão trazer benefícios para o atendimento dos pacientes internados na Unidade de Terapia Intensiva do Pronto Socorro.

Todos os registros que dizem respeito à sua participação serão mantidos em sigilo, ou seja, em nenhum momento, dados que o identifiquem serão utilizados.

Sua participação neste estudo é voluntária. Portanto, você pode optar por não participar, assim como pode desistir a qualquer momento. Caso seja esta a tua vontade, você não sofrerá qualquer dano ou discriminação quanto ao tratamento. Este documento apresentase em 2 vias, uma para você e outra para o pesquisador. Caso queira obter maiores detalhes sobre este estudo, você poderá fazê-los, entrando em contato com a Fisioterapeuta Elisiane Tonon ou com a Prof ${ }^{a}$ Dra. Ana Lúcia dos Anjos Ferreira, por meio dos endereços abaixo.

$\mathrm{Eu}$, portador(a) do RG: , aceito participar deste estudo e também autorizo a apresentação dos resultados do projeto em eventos científicos e revistas.

Paciente

Pesquisador

\section{Endereços:}

Pesquisador: Fisioterapeuta Elisiane Tonon

Rua Quintino Bocaiúva, 1291, Vila Padovan, Botucatu - SP, CEP: 18607-720, fone (14) 97420036, e-mail: ellisse@,bol.com.br

Orientadora: Prof ${ }^{\mathrm{a}}$. Dra. Ana Lúcia dos Anjos Ferreira

Departamento de Clínica Médica, Faculdade de Medicina de Botucatu, Unesp, Botucatu - SP, CEP: 18618-970, fone (14) 3882-2969 / 97987637, e-mail: ferreira@,fmb.unesp.br 


\section{ANEXO 2 \\ Termo de Consentimento Livre e Esclarecido (Paciente após alta)}

\section{Título: "Avaliação dos efeitos de diferentes manobras de Fisioterapia Respiratória no desfecho de pacientes ventilados mecanicamente".}

Em acordo e com a autorização de seus familiares, durante o período em que esteve internado na UTI, você foi submetido a uma conduta fisioterápica por 5 dias: técnica de compressão torácica ou de hiperinsuflação manual, ou ambas.

Compressão torácica: "você foi posicionado em decúbito dorsal (barriga para cima) e o fisioterapeuta com as mãos sobre seu tórax realizou uma compressão durante a expiração".

Hiperinsuflação manual: "você foi posicionado em decúbito dorsal (barriga para cima) e o fisioterapeuta insuflou-o lentamente com ambú e após realizou uma descompressão abrupta do ambú aumentando o fluxo expiratório".

Portanto, a proposta deste termo de consentimento é o de solicitar a sua permissão para que os dados coletados durante sua internação na UTI sejam utilizados neste estudo cujos objetivos são: 1) verificar a eficácia da Fisioterapia Respiratória e quais seus benefícios para os pacientes internados na Unidade de Terapia Intensiva; 2) prestar assistência fisioterápica visando melhorar a qualidade de vida e reduzir o período de internação.

Estas informações colhidas poderão trazer benefícios para o atendimento dos pacientes internados na Unidade de Terapia Intensiva do Pronto Socorro.

Todos os seus registros serão mantidos em sigilo, ou seja, em nenhum momento, dados que o identifiquem serão utilizados.

Por tratar-se de um estudo voluntário você pode optar por não autorizar a utilização de seus dados neste estudo. Este documento apresenta-se em 2 vias, uma para você e outra para o pesquisador. Caso queira obter maiores detalhes sobre este estudo, você poderá fazê-los, entrando em contato com a Fisioterapeuta Elisiane Tonon ou com a Prof ${ }^{a}$ Dra. Ana Lúcia dos Anjos Ferreira, por meio dos endereços abaixo.

$\mathrm{Eu}$,

portador(a) do $\mathrm{RG}$ :

autorizo a utilização dos dados colhidos e também a apresentação dos resultados do projeto em eventos científicos e revistas.

Paciente

Pesquisador

\section{Endereços:}

Pesquisador: Fisioterapeuta Elisiane Tonon

Rua Quintino Bocaiúva, 1291, Vila Padovan, Botucatu - SP, CEP: 18607-720, fone (14) 97420036, e-mail: ellisse@,bol.com.br

Orientadora: Prof ${ }^{\mathrm{a}}$. Dra. Ana Lúcia dos Anjos Ferreira

Departamento de Clínica Médica, Faculdade de Medicina de Botucatu, Unesp, Botucatu - SP, CEP: 18618-970, fone (14) 3882-2969 / 97987637, e-mail: ferreira@,fmb.unesp.br 


\section{ANEXO 2 \\ Termo de Consentimento Livre e Esclarecido (Responsável)}

Diante das condições em que o paciente se encontra impossibilitando-o de ler este termo de consentimento e, portanto não podendo decidir se participa ou não deste estudo, você, como responsável pelo mesmo, poderá assinar este termo de consentimento autorizando a participação do paciente, de modo voluntário, deste estudo, cujo título é: "Avaliação dos efeitos de diferentes manobras de Fisioterapia Respiratória no desfecho de pacientes ventilados mecanicamente". Neste estudo o paciente será submetido a uma conduta fisioterápica por 5 dias: técnica de compressão torácica ou hiperinsuflação manual, ou ambas.

Compressão torácica: "paciente será posicionado em decúbito dorsal (barriga para cima) e o fisioterapeuta com as mãos sobre o tórax realizará uma compressão durante a expiração".

Hiperinsuflação manual: "paciente será posicionado em decúbito dorsal (barriga para cima) e o fisioterapeuta irá insuflar lentamente os pulmões do paciente com ambú e após realizará uma descompressão abrupta do ambú, aumentando o fluxo expiratório".

A proposta deste termo de consentimento é o de solicitar sua permissão, para que o paciente sob sua responsabilidade possa participar deste estudo, cujos objetivos são: 1) verificar a eficácia da Fisioterapia Respiratória e quais seus benefícios para os pacientes internados na Unidade de Terapia Intensiva; 2) prestar assistência fisioterápica visando melhorar a qualidade de vida e reduzir o período de internação.

As informações obtidas a partir deste estudo, poderão trazer benefícios para o atendimento dos pacientes internados na Unidade de Terapia Intensiva do Pronto Socorro. Todos os registros que dizem respeito à participação do paciente serão mantidos em sigilo, ou seja, em nenhum momento, dados que o identifiquem serão utilizados.

Por tratar-se de um estudo, cuja participação é voluntária, você, sendo o responsável pelo paciente, pode optar por não autorizar que o paciente participe do estudo e também poderá desistir a qualquer momento caso você autorize. Se você optar por não autorizar, pode estar seguro que o paciente não sofrerá qualquer dano ou discriminação quanto ao tratamento. Este documento apresenta-se em 2 vias, uma para você, responsável pelo paciente, e outra para o pesquisador. Caso queira obter maiores detalhes sobre este estudo, você poderá fazêlos, entrando em contato com a Fisioterapeuta Elisiane Tonon ou com a Prof ${ }^{a}$ Dra. Ana Lúcia dos Anjos Ferreira, por meio dos endereços abaixo.

$\mathrm{Eu}$, , portador (a) do RG: , como

responsável pelo paciente autorizo a participação do mesmo neste estudo e também a apresentação dos resultados do projeto em eventos científicos e revistas.

\section{Endereços:}

Responsável

Pesquisador

Pesquisador: Fisioterapeuta Elisiane Tonon

Rua Quintino Bocaiúva, 1291, Vila Padovan, Botucatu - SP, CEP: 18607-720, fone (14) 97420036, email: ellisse@bol.com.br Orientadora: Prof ${ }^{\mathrm{a}}$. Dra. Ana Lúcia dos Anjos Ferreira

Departamento de Clínica Médica, Faculdade de Medicina de Botucatu, Unesp, Botucatu - SP, CEP: 18618-970, fone (14) 3882-2969 / 97987637, e-mail: ferreira@,fmb.unesp.br 


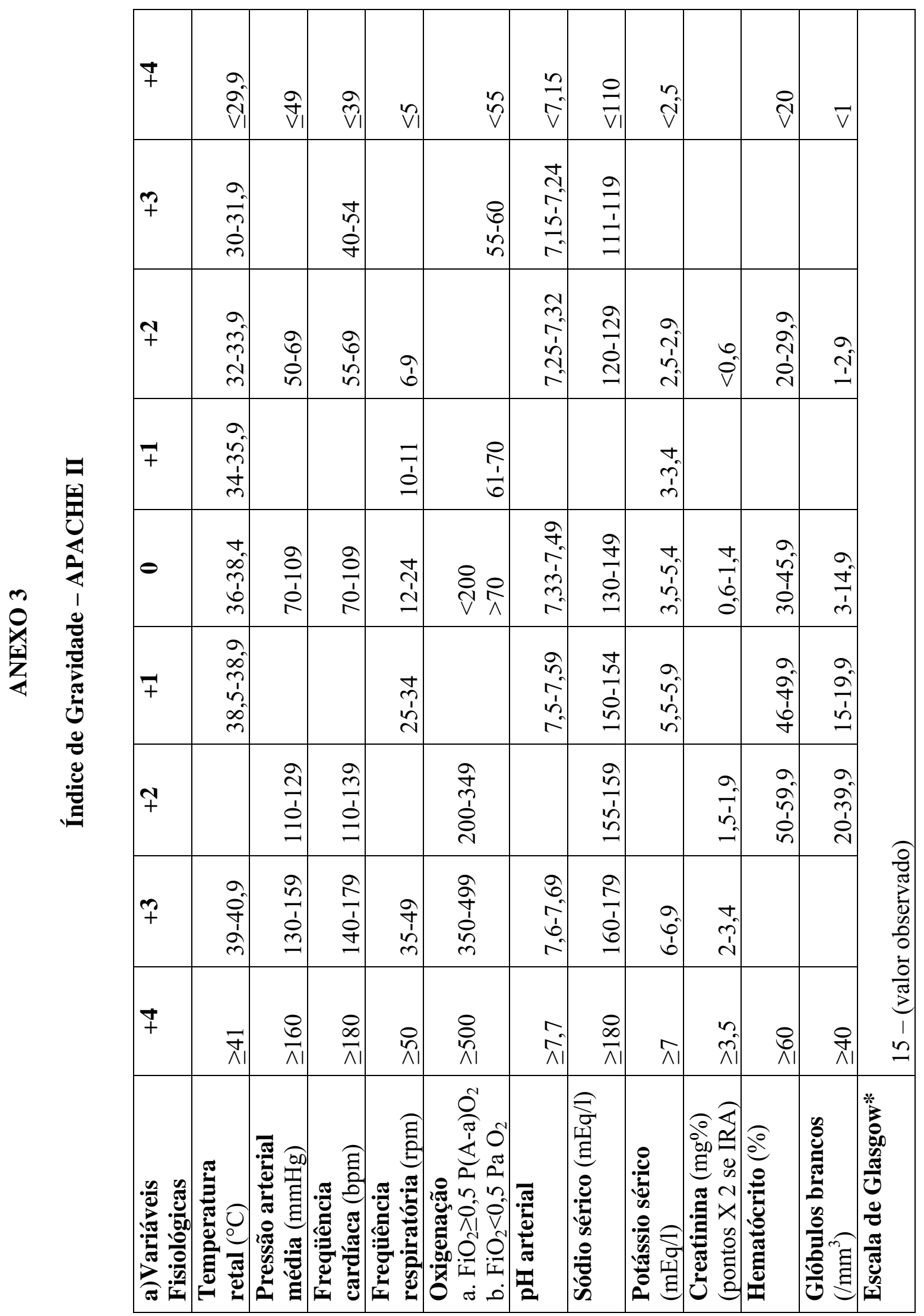




\section{ANEXO 3}

\section{Continuação do anexo anterior}

\section{b) Pontuação para idade}

Idade (anos)

$\leq 44$

$45-54$

Pontos

0

$55-64$

2

$65-74$

3

$\geq 75$

5

6

\section{c) Pontuação para doença crônica}

Se o paciente possui história de insuficiência orgânica severa ou é imunocomprometido, atribuir os seguintes pontos:

a. para não cirúrgico ou para pós-operatório de cirurgia de urgência - 5 pontos

b. para pós-operatório de cirurgia eletiva -2 pontos

\section{APACHE II = Soma de $a+b+c$}

Adaptado de Knauss WA, Draper EA, Wagner DP, Zimmerman JE. APACHE II: a severity of disease classification system. Crit Care Med. 1985;13:818-29. 


\section{ANEXO 3}

OBS: esta escala foi utilizada para calcular o Glasgow dos pacientes, cujo valor é necessário para realizar o cálculo do índice APACHE-II.

\section{*Escala de Coma de Glasgow}

\section{ABERTURA OCULAR}

Espontânea

Com estímulo verbal

Com estímulo doloroso

Nenhuma resposta

\section{PONTOS}

4

3

2

1

\section{MELHOR RESPOSTA VERBAL}

Orientado

Confuso

Palavras impróprias

Sons incompreensíveis

Nenhuma resposta

\section{MELHOR RESPOSTA MOTORA}

Obedece aos comandos

Localiza e retira os estímulos

Localiza o estímulo

Responde em flexão

Responde em extensão

Nenhuma resposta

Ely EW, Truman B, Shintani A, Thomason JWW, Wheeler AP, Gordon S et al. Monitoring sedation status over time in ICU patients: reability of the Richmond Agitation-Sedation Scale (RASS). JAMA. 2003; 289: 2983-91.

OBS: Para a avaliação dos pacientes segundo a escala de Glasgow a sedação era desligada todo dia no período da manhã e após 6 horas era aplicada a escala. A sedação só foi religada antes de completar às 6 horas nos casos em que o paciente ficou muito agitado e, consequentemente gerou uma assincronia paciente-ventilador. 


\section{ANEXO 4 \\ Índice de Co-morbidade de Charlson}

\begin{tabular}{|l|c|}
\hline \multicolumn{1}{|c|}{ CONDIÇÃO } & PESO \\
\hline Infarto do miocárdio & $\mathbf{1}$ \\
Insuficiência cardíaca congestiva & \\
Doença vascular periférica & \\
Doença cérebro-vascular & \\
Demência & \\
Doença pulmonar crônica & \\
Doença do tecido conectivo & \\
Doença ulcerosa gástrica & \\
Doença hepática leve & \\
Diabetes & \\
\hline $\begin{array}{l}\text { Hemiplegia } \\
\text { Doença renal moderada ou grave }\end{array}$ & \\
Diabetes com lesão de órgão alvo & $\mathbf{2}$ \\
Doenças malignas & \\
\hline Doença hepática moderada ou grave & \\
\hline Tumor sólido metastático & $\mathbf{3}$ \\
AIDS & $\mathbf{6}$ \\
\hline IDADE & \\
\hline $50-59$ anos & $\mathbf{1}$ \\
\hline $60-69$ anos & $\mathbf{2}$ \\
\hline $70-79$ anos & $\mathbf{3}$ \\
\hline $80-89$ anos & $\mathbf{4}$ \\
\hline
\end{tabular}


ANEXO 5. Componentes e valores individuais da Escala de Lesão Pulmonar Escala de Murray

\section{1) Escala do raio-X de tórax}

Valores

\begin{tabular}{|l|l|}
\hline Sem consolidação alveolar & 0 \\
\hline Consolidação alveolar confinado 1 quadrante & 1 \\
\hline Consolidação alveolar confinado 2 quadrantes & 2 \\
\hline Consolidação alveolar confinado 3 quadrantes & 3 \\
\hline Consolidação alveolar confinado 4 quadrantes & 4 \\
\hline
\end{tabular}

\section{2) Escala da Hipoxemia}

\begin{tabular}{|c|c|c|}
\hline $\mathrm{PaO}_{2} / \mathrm{FiO}_{2}$ & Maior ou igual 300 & 0 \\
\hline $\mathrm{PaO}_{2} / \mathrm{FiO}_{2}$ & $225-299$ & 1 \\
\hline $\mathrm{PaO}_{2} / \mathrm{FiO}_{2}$ & $175-224$ & 2 \\
\hline $\mathrm{PaO}_{2} / \mathrm{FiO}_{2}$ & $100-174$ & 3 \\
\hline $\mathrm{PaO}_{2} / \mathrm{FiO}_{2}$ & Menor 100 & 4 \\
\hline
\end{tabular}

\section{3) Escala da PEEP}

\begin{tabular}{|c|c|c|}
\hline PEEP & Menor ou igual $5 \mathrm{cmH}_{2} \mathrm{O}$ & 0 \\
\hline PEEP & $6-8 \mathrm{cmH}_{2} \mathrm{O}$ & 1 \\
\hline PEEP & $9-11 \mathrm{cmH}_{2} \mathrm{O}$ & 2 \\
\hline PEEP & $12-14 \mathrm{cmH}_{2} \mathrm{O}$ & 3 \\
\hline PEEP & Maior ou igual $15 \mathrm{cmH}_{2} \mathrm{O}$ & 4 \\
\hline
\end{tabular}

\section{4) Escala da Complacência do Sistema Respiratório}

\begin{tabular}{|c|c|c|}
\hline Complacência & Maior ou igual $80 \mathrm{~mL} / \mathrm{cmH}_{2} \mathrm{O}$ & 0 \\
\hline Complacência & $60-79 \mathrm{cmH}_{2} \mathrm{O}$ & 1 \\
\hline Complacência & $40-59 \mathrm{cmH}_{2} \mathrm{O}$ & 2 \\
\hline Complacência & $20-39 \mathrm{cmH}_{2} \mathrm{O}$ & 3 \\
\hline Complacência & Menor ou igual $19 \mathrm{cmH}_{2} \mathrm{O}$ & 4 \\
\hline
\end{tabular}

\section{CLASSIFICAÇÃO}

Sem lesão pulmonar

Lesão pulmonar de média a moderada

Grave lesão pulmonar

\section{NOTA}

0

$0,1-2,5$

$$
>2,5
$$

Murray JF, Matthay MA, Luce JM, Flick MR. An expanded definition of the adult respiratory distress syndrome. Am Rev Respir Dis. 1988;138:720-3. 
ANEXO 6. Adequação de Peso para a Estatura segundo Compleição

1 - Relação entre Perímetro de Pulso e Estatura

\begin{tabular}{|c|c|c|c|c|}
\hline \multicolumn{2}{|c|}{ COMPLEIÇÃO CORPORAL } & GRANDE & MÉDIA & PEQUENA \\
\hline \multirow{2}{*}{$\mathrm{R}=\frac{\text { ALT. }(\mathrm{cm})}{\mathrm{PP}}$} & HOMENS & $<9,6$ & 9,6 a 10,4 & $>10,4$ \\
& MULHERES & $<10,1$ & $10,1 \mathrm{a} 11,0$ & $>11,0$ \\
\hline
\end{tabular}

2 - Peso Esperado para Estatura

\begin{tabular}{|c|c|c|c|c|c|c|c|}
\hline \multirow[b]{2}{*}{ ALTURA } & \multicolumn{3}{|c|}{ PESO - HOMENS } & \multirow[b]{2}{*}{ ALTURA } & \multicolumn{3}{|c|}{ PESO - MULHERES } \\
\hline & PEQ. & MED. & GR. & & PEQ. & MED. & GR. \\
\hline 155 & 50,0 & 53,6 & 58,2 & 142 & 41,8 & 45,0 & 49,5 \\
\hline 156 & 50,7 & 54,3 & 58,8 & 143 & 42,3 & 45,3 & 49,8 \\
\hline 157 & 51,4 & 55,0 & 59,5 & 144 & 42,8 & 45,6 & 50,1 \\
\hline 158 & 51,8 & 55,5 & 60,0 & 145 & 43,2 & 45,9 & 50,5 \\
\hline 159 & 52,2 & 56,0 & 60,5 & 146 & 43,7 & 46,6 & 51,2 \\
\hline 160 & 52,7 & 56,4 & 60,9 & 147 & 44,1 & 47,3 & 51,8 \\
\hline 161 & 53,2 & 56,8 & 61,5 & 148 & 44,6 & 47,7 & 52,3 \\
\hline 162 & 53,7 & 57,2 & 62,1 & 149 & 45,1 & 48,1 & 52,8 \\
\hline 163 & 54,1 & 57,7 & 62,7 & 150 & 45,5 & 48,6 & 53,2 \\
\hline 164 & 55,0 & 58,5 & 63,4 & 151 & 46,2 & 49,3 & 54,0 \\
\hline 165 & 55,9 & 59,5 & 64,1 & 152 & 46,8 & 50,0 & 54,5 \\
\hline 166 & 56,5 & 60,1 & 64,8 & 153 & 47,3 & 50,5 & 55,0 \\
\hline 167 & 57,1 & 60,7 & 65,6 & 154 & 47,8 & 51,0 & 55,5 \\
\hline 168 & 57,7 & 61,4 & 66,4 & 155 & 48,2 & 51,4 & 55,8 \\
\hline 169 & 58,6 & 62,3 & 67,5 & 156 & 48,9 & 52,3 & 56,8 \\
\hline 170 & 59,5 & 63,2 & 68,6 & 157 & 49,5 & 53,2 & 57,7 \\
\hline 171 & 60,1 & 63,8 & 69,2 & 158 & 50,0 & 53,6 & 58,3 \\
\hline 172 & 60,7 & 64,4 & 69,8 & 159 & 50,5 & 54,0 & 58,9 \\
\hline 173 & 61,4 & 65,0 & 70,5 & 160 & 50,9 & 54,5 & 59,5 \\
\hline 174 & 62,3 & 65,9 & 71,4 & 161 & 51,5 & 55,3 & 60,1 \\
\hline 175 & 63,2 & 66,8 & 72,3 & 162 & 52,1 & 56,1 & 60,7 \\
\hline 176 & 63,8 & 67,5 & 72,9 & 163 & 52,7 & 56,8 & 61,4 \\
\hline 177 & 64,4 & 68,2 & 73,5 & 164 & 53,6 & 57,7 & 62,3 \\
\hline 178 & 65,0 & 69,0 & 74,1 & 165 & 54,5 & 58,6 & 63,2 \\
\hline 179 & 65,9 & 69,9 & 75,3 & 166 & 55,1 & 59,2 & 63,8 \\
\hline 180 & 66,8 & 70,9 & 76,4 & 167 & 55,7 & 59,8 & 64,4 \\
\hline 181 & 67,4 & 71,7 & 77,1 & 168 & 56,4 & 60,5 & 65,0 \\
\hline 182 & 68,0 & 72,5 & 77,8 & 169 & 57,3 & 61,4 & 65,9 \\
\hline 183 & 68,6 & 73,2 & 78,6 & 170 & 58,2 & 62,2 & 66,8 \\
\hline 184 & 69,8 & 74,1 & 79,8 & 171 & 58,8 & 62,8 & 67,4 \\
\hline 185 & 70,9 & 75,0 & 80,9 & 172 & 59,4 & 63,4 & 68,0 \\
\hline 186 & 71,5 & 75,8 & 81,7 & 173 & 60,0 & 64,1 & 68,6 \\
\hline 187 & 72,1 & 76,6 & 82,5 & 174 & 60,9 & 65,0 & 69,8 \\
\hline 188 & 73,3 & 77,3 & 83,2 & 175 & 61,8 & 65,9 & 70,9 \\
\hline 189 & 73,9 & 78,0 & 83,8 & 176 & 62,4 & 66,5 & 71,7 \\
\hline 190 & 74,5 & 78,7 & 84,4 & 177 & 63,0 & 67,1 & 72,5 \\
\hline 191 & 77,7 & 79,5 & 85,0 & 178 & 63,6 & 67,7 & 73,2 \\
\hline
\end{tabular}

Adaptado: Metropolitan Life Ensurance, 1985 


\section{ANEXO 7 \\ Protocolo de avaliação dos pacientes incluídos no estudo \\ FICHA DE AVALIAÇÃO}

$\mathrm{N}^{\mathrm{o}}$ de ordem:

Data da Avaliação:

Horário:

Nome:

Idade:

Sexo:

Cor:

R.G.:

Tel.:

Tel. $\mathrm{p} /$ recado:

Peso estimado:

Peso ideal:

Altura:

IMC:

Indicação da Assist Vent. Mecânica:

Outros HDs que motivaram a internação:

Antecedentes: Tabagismo ( )

Etilismo ( )

DPOC (

HAS ( )

Diabetes ( )

Dislipidemia ( )

Ins Coronariana ( )

Ins Cardíaca ( )

Ins Renal Crônica ( )

Doença Cérebro Vascular ( )

Infecções ( ) local

Outros ( )

Data de admissão na UTI-PS:

Data de alta da UTI-PS:

Período de internação:

Data do Óbito:

horário:

$1+\frac{1}{1}$

_ _ 1_ (total em horas:

Local do óbito:

Data do início da AVM:

Data do fim da AVM

horário:

Local:

Período de ventilação mecânica: horário da extubação:

Data do desmame: Início: / / horário: à

$1 \quad 1 \quad$ (total em horas: )

Fim: $\frac{1}{1}$ horário:

Total em horas:

Necessitou de nova AVM? Sim ( ) Não ( )

Data da nova AVM (invasiva): Início: ___ _ _ _ _ horário:

Fim: _ l l horário:

Total em horas:

Data da nova AVM (não invasiva): Início: ___ _ _ _ _ horário:

Fim $\frac{1}{1}-$ horário:

Total em horas:

Condições após 30 dias do Momento zero de estudo: $\quad$ Vivo ( ) Morto ( )

Na UTI-PS ( ) Em outra UTI do HC ( ) Na enfermaria ( ) Em casa ( ) Indeterminado ( )

OBS: 
IMC = índice de massa corpórea

Assist. Vent. Mecânica = assistência ventilatória mecânica

HDs $=$ hipóteses diagnósticas

DPOC $=$ doença pulmonar obstrutiva crônica

HAS = hipertensão arterial sistêmica

Ins. Coronariana $=$ insuficiência coronariana

Ins. Cardíaca $=$ insuficiência cardíaca

Ins. Renal Crônica = insuficiência renal crônica

UTI-PS = unidade de terapia intensiva do pronto-socorro

$\mathrm{AVM}=$ assistência ventilatória mecânica 


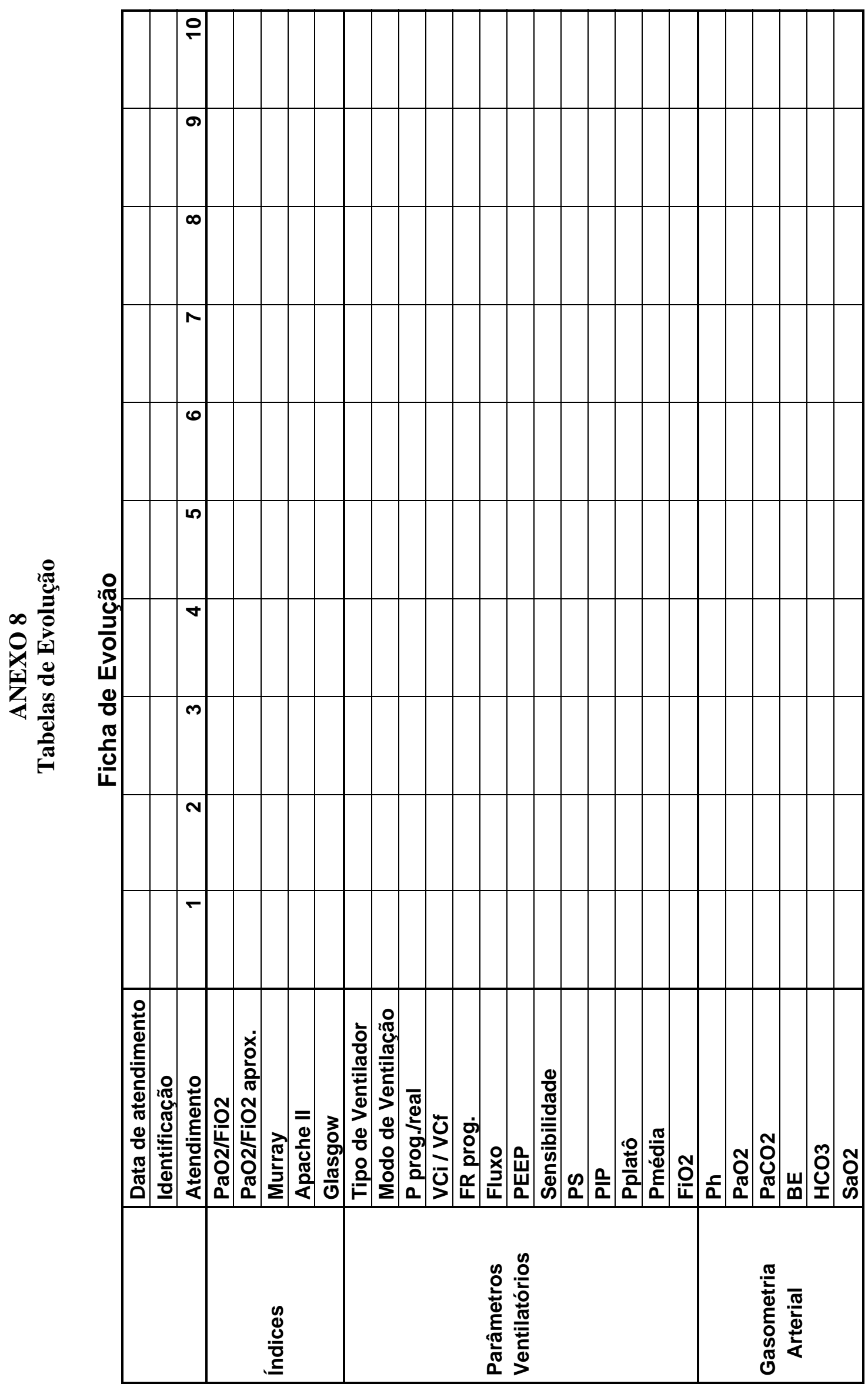




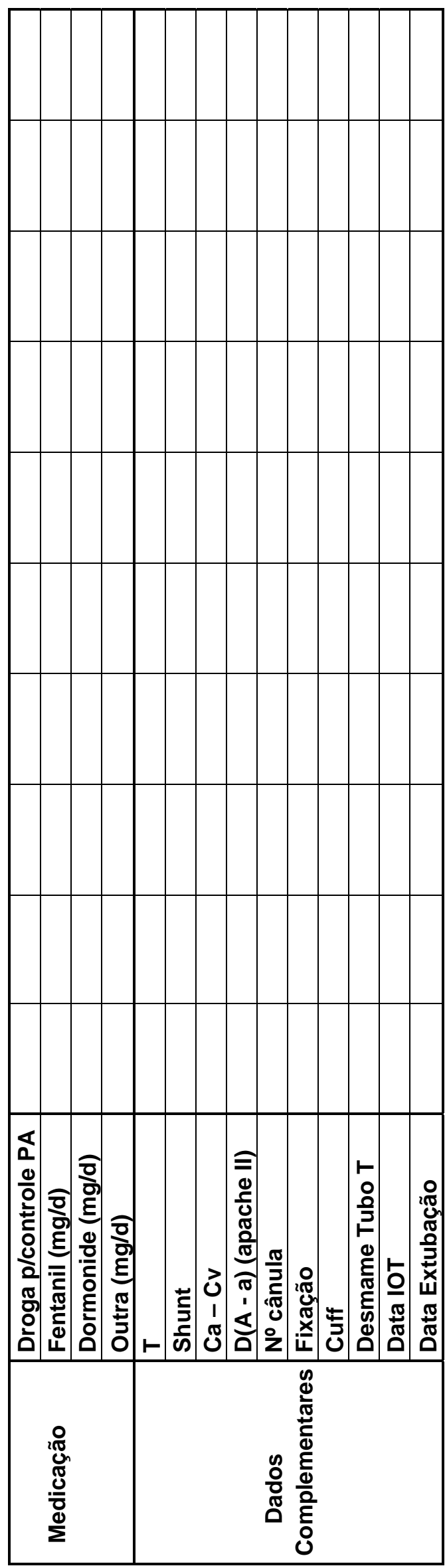




I




10 dia
\begin{tabular}{|l|l|l|l|l|}
\hline \multicolumn{5}{|c|}{ MANHÃ } \\
\hline & Antes & Após & 15' após & 30' após \\
\hline Complacência & & & & \\
\hline FR & & & & \\
\hline FC & & & & \\
\hline PA & & & & \\
\hline SpO2 & & & & \\
\hline
\end{tabular}

\begin{tabular}{|l|l|l|l|}
\hline \multicolumn{5}{|c|}{ TARDE } \\
\hline Antes & Após & $1^{\prime}$ após & 30' após \\
\hline & & & \\
\hline & & & \\
\hline & & & \\
\hline & & & \\
\hline & & & \\
\hline
\end{tabular}

$2^{\circ}$ dia
\begin{tabular}{|l|l|l|l|l|}
\hline \multicolumn{5}{|c|}{ MANHÃ } \\
\hline & Antes & Após & $15^{\prime}$ após & 30 após \\
\hline Complacência & & & & \\
\hline FR & & & & \\
\hline FC & & & & \\
\hline PA & & & & \\
\hline SpO2 & & & & \\
\hline
\end{tabular}

\begin{tabular}{|l|l|l|l|}
\hline \multicolumn{5}{|c|}{ TARDE } \\
\hline Antes & Após & $1^{\prime}$ após & 30' após \\
\hline & & & \\
\hline & & & \\
\hline & & & \\
\hline & & & \\
\hline & & & \\
\hline
\end{tabular}

3 dia
\begin{tabular}{|l|l|l|l|l|}
\hline \multicolumn{5}{|c|}{ MANHÃ } \\
\hline & Antes & Após & $15^{\prime}$ após & $30^{\prime}$ após \\
\hline Complacência & & & & \\
\hline FR & & & & \\
\hline FC & & & & \\
\hline PA & & & & \\
\hline SpO2 & & & & \\
\hline
\end{tabular}

\begin{tabular}{|l|l|l|l|}
\hline \multicolumn{4}{|c|}{ TARDE } \\
\hline Antes & Após & 15' após & 30' após \\
\hline & & & \\
\hline & & & \\
\hline & & & \\
\hline & & & \\
\hline & & & \\
\hline
\end{tabular}

$4{ }^{\circ}$ dia
\begin{tabular}{|l|l|l|l|l|}
\hline \multicolumn{5}{|c|}{ MANHÃ } \\
\hline & Antes & Após & $15^{\prime}$ após & $30^{\prime}$ após \\
\hline Complacência & & & & \\
\hline FR & & & & \\
\hline FC & & & & \\
\hline PA & & & & \\
\hline SpO2 & & & & \\
\hline
\end{tabular}

\begin{tabular}{|l|l|l|l|}
\hline \multicolumn{4}{|c|}{ TARDE } \\
\hline Antes & Após & 15' após & 30' após \\
\hline & & & \\
\hline & & & \\
\hline & & & \\
\hline & & & \\
\hline & & & \\
\hline
\end{tabular}

50 dia
\begin{tabular}{|l|l|l|l|l|}
\hline \multicolumn{5}{|c|}{ MANHÃ } \\
\hline & Antes & Após & $15^{\prime}$ após & $30^{\prime}$ após \\
\hline Complacência & & & & \\
\hline FR & & & & \\
\hline FC & & & & \\
\hline PA & & & & \\
\hline SpO2 & & & & \\
\hline
\end{tabular}

\begin{tabular}{|l|l|l|l|}
\hline \multicolumn{5}{|c|}{ TARDE } \\
\hline Antes & Após & 15' após $^{\prime}$ & 30' após \\
\hline & & & \\
\hline & & & \\
\hline & & & \\
\hline & & & \\
\hline & & & \\
\hline
\end{tabular}


$\mathrm{PaO}_{2} / \mathrm{FiO}_{2}=$ relação da pressão parcial de oxigênio no sangue arterial sobre a fração de oxigênio no ar inspirado

$\mathrm{PaO}_{2} / \mathrm{FiO}_{2}$ aprox. = relação da pressão parcial de oxigênio no sangue arterial sobre a fração de oxigênio no ar inspirado aproximado

$\mathrm{P}$ prog./real = pressão programada do ventilador/pressão real

$\mathrm{VCi} / \mathrm{VCf}=$ volume corrente inicial/volume corrente final

FR prog. $=$ freqüência respiratória programada

PEEP = pressão positiva expiratória final

PS = pressão de suporte (não foi utilizada a modalidade SIMV/PS no estudo)

$\mathrm{PIP}=$ pico de pressão inspiratória

Pplatô $=$ pressão platô

Pmédia $=$ pressão média

$\mathrm{FiO}_{2}=$ fração inspirada de oxigênio

$\mathrm{PaO}_{2}=$ pressão parcial de oxigênio

$\mathrm{PaCO}_{2}=$ pressão parcial de dióxido de carbono

$\mathrm{BE}=$ excesso de base

$\mathrm{HCO}_{2}=$ bicarbonato

$\mathrm{SaO}_{2}=$ saturação arterial de oxigênio

$\mathrm{T}=$ temperatura

$\mathrm{Ca}-\mathrm{Cv}=$ diferença do conteúdo arterial e venoso de oxigênio

$\mathrm{D}(\mathrm{A}-\mathrm{a})=$ diferença alvéolo-arterial

IOT = intubação orotraqueal

$\mathrm{RX}=$ raio- $\mathrm{X}$

$\mathrm{FR}=$ freqüência respiratória

$\mathrm{FC}=$ freqüência cardíaca

$\mathrm{PA}=$ pressão arterial

$\mathrm{SpO}_{2}=$ saturação periférica de oxigênio 


\section{ANEXO 9}

\section{Protocolo de Desmame da Ventilação Mecânica}

Processo de transição da ventilação mecânica para espontânea.

Diariamente desligar sedação e avaliar indicação de desmame.

1) Condições para ser iniciado o desmame:

\begin{tabular}{|l|l|}
\hline Evento agudo que motivou à VM & Revertido ou controlado \\
\hline Estímulo respiratório & Presente \\
\hline Drogas vasoativas ou sedativos & Doses mínimas \\
\hline Glasgow & $\geq 12$ \\
& $\begin{array}{l}\geq \quad \text { em pacientes neurológicos*, se } \\
\text { presentes reflexo de tosse e de náusea. }\end{array}$ \\
\hline Equilíbrio ácido/básico & $\mathrm{pH} \geq 7,3$ \\
\hline Trocas gasosas & $\mathrm{PaO}_{2}>60 ; \mathrm{FiO}_{2} \leq 0,4 ; \mathrm{PEEP} \leq 5-8 ;$ \\
& $\mathrm{PaO}_{2} / \mathrm{FiO}_{2} \geq 150-200$ \\
\hline Eletrólitos séricos $(\mathrm{Na}, \mathrm{K}, \mathrm{Ca}, \mathrm{P}, \mathrm{Mg})$ & $\mathrm{Valores} \mathrm{normais}^{*}$ \\
\hline Hemoglobina & $\geq 7 \mathrm{~g} / \mathrm{dl}(\mathrm{DPOC}$ e $\mathrm{ICO} \geq 10)$ \\
\hline Balanço hídrico & Próximo a zero \\
\hline Intervenção cirúrgica próxima & Sem previsão \\
\hline
\end{tabular}

* Glasgow $<8$ avaliar indicação de traqueostomia

\section{2) Teste de ventilação espontânea (TVE):}

Avaliar condições para extubação. Deverá ser realizado utilizando-se o seguinte método:

- Tubo T: o paciente é retirado da $\mathrm{VM}$ e recebe suplementação com $\mathrm{O}_{2}$ umidificado $5 \mathrm{~L} / \mathrm{min}$.

Durante os 2 primeiros minutos iniciais do desmame, devem ser mantidos os parâmetros abaixo:

- $\mathrm{FR}<35$ ipm

- $\mathrm{VC}$ espontâneo $>5 \mathrm{~mL} / \mathrm{Kg}$

- FR/VT $(\mathrm{L})<105$ (Índice de Tobin)

Caso sejam mantidos os parâmetros, o TVE deverá ser prolongado por 120 minutos.

3) Durante o teste, a ocorrência dos sinais abaixo indica necessidade de avaliação quanto à manutenção do desmame ou retorno à VM:

- FR $>35$ ipm por mais de 5 minutos

$-\mathrm{SaO}_{2}<90 \%$

- FC > 140 ou alteração da FC basal em 20\%, para mais ou para menos

- PAS > $180 \mathrm{mmHg}$

- Agitação e ansiedade

Paciente estável por 120 minutos permite a extubação (julgamento clínico)

4) Cuidados antes da extubação: 
- Informar e orientar o paciente sobre o procedimento

- Aspirar o tubo e a orofaringe

- Avaliar a eficácia da tosse e o volume da secreção

- Teste diagnóstico de edema de glote: se a diferença dos volumes com o balonete desinsuflado for menor que $110 \mathrm{~mL}$, indica presença de edema de glote. Neste caso não indicar extubação e solicitar avaliação otorrinolaringológica.

\section{5) Cuidados pós extubação:}

- $\mathrm{O}_{2}$ suplementar suficiente para manter $\mathrm{SaO}_{2} \geq 90 \%$

- Manter o paciente em observação durante 24h, se estável alta da UTI

- Havendo sinais de falência (item 3) = reintubação

\section{6) Em caso de falência:}

- Reavaliar condições do desmame anterior (Tabela 1)

- Avaliar possíveis complicações da VM não diagnosticadas (infecção)

- Adequar controle da dor e ansiedade

- Avaliar necessidade de broncodilatador inalatório

- Avaliar função cardíaca

7) Desmame gradual: paciente que não tolerou tubo $T$ ou que necessitou ser reintubado:

Repouso por 24 horas. Após iniciar:

\section{1) Tubo T:}

Tubo T diário: por 60 - 120 minutos, com repouso em VM por 24h.

\section{2) Tubo $T$ progressivo:} abaixo:

Intercalar períodos de tubo $\mathrm{T}$ com períodos de $\mathrm{VM}$ (pressão controlada) como na tabela

\begin{tabular}{|l|l|l|l|}
\hline \multicolumn{1}{|c|}{ Tubo T } & \multicolumn{1}{c|}{ PCV } & \multicolumn{1}{c|}{ Tubo T } & \multicolumn{1}{c|}{ PCV } \\
\hline $15 \mathrm{~min}$ & $1 \mathrm{~h} 45 \mathrm{~min}$ & $30 \mathrm{~min}$ & $1 \mathrm{~h} 30 \mathrm{~min}$ \\
\hline $15 \mathrm{~min}$ & $1 \mathrm{~h} 45 \mathrm{~min}$ & $30 \mathrm{~min}$ & $1 \mathrm{~h} 30 \mathrm{~min}$ \\
\hline $15 \mathrm{~min}$ & $1 \mathrm{~h} 45 \mathrm{~min}$ & $30 \mathrm{~min}$ & $1 \mathrm{~h} 30 \mathrm{~min}$ \\
\hline
\end{tabular}

Progredir como modelo acima até o paciente ficar $2 \mathrm{~h}$ em tubo T, sendo então permitido a extubação ou desconecção definitiva do ventilador. 